UNIVERSIDADE DE SÃO PAULO

ESCOLA DE EDUCAÇÃO FÍSICA E ESPORTE

\title{
ESTIMATIVA DOS METABOLISMOS ANAERÓBIOS NO DÉFICIT MÁXIMO ACUMULADO DE OXIGÊNIO
}

Rômulo Cássio de Moraes Bertuzzi

SÃO PAULO

2008 


\title{
ESTIMATIVA DOS METABOLISMOS ANAERÓBIOS NO DÉFICIT MÁXIMO ACUMULADO DE OXIGÊNIO
}

\author{
RÔMULO CÁSSIO DE MORAES BERTUZZI
}

Tese apresentada à Escola de Educação Física e Esporte da Universidade de São Paulo, como requisito parcial para obtenção do grau de Doutor em Educação Física.

ORIENTADORA: Profa. Dra. MARIA AUGUSTA PEDUTI DAL'MOLIN KISS 
Bertuzzi, Rômulo Cássio de Moraes

Estimativa dos metabolismos anaeróbios no Déficit Máximo Acumulado de Oxigênio / Rômulo Cássio de Moraes Bertuzzi - São Paulo : [s.n.], 2008. xvii, $137 \mathrm{p}$.

Tese (Doutorado) - Escola de Educação Física e Esporte da Universidade de São Paulo. Orientadora: Profa. Dra. Maria Augusta Peduti Dal Molin Kiss.

1. Teste anaeróbio. II. Fisiologia do exercício I. Título. 


\section{AGRADECIMENTOS}

À professora doutora Maria Augusta pela credibilidade depositada em mim ao longo desses nove anos de convivência no LADESP.

Aos professores doutores Benedito Pereira, Eduardo Kokubun, Emerson Franchini e Fábio Nakamura pelas relevantes sugestões realizadas durante 0 processo de Qualificação e Defesa.

Ao amigo Márcio Bruno que, involuntariamente e às vezes de forma questionável, me lembra de algumas coisas importantes na vida. Muito obrigado!

Aos amigos Eduardo Rumenig, Fernando R. de Oliveira, Karin Matsushigue, João Fernando Gagliardi e Marcos Merida pela paciência em me ouvir e compartilhar comigo as minhas dúvidas mais recentes.

Aos amigos e companheiros de laboratório Adriano E. L. Silva e Flávio de O. Pires pelo bom humor incondicional, mesmo quando nos encontrávamos perante as situações mais adversas.

Ao Edson Degaki pelo suporte técnico prestado durante o processo de coleta de dados e aos sujeitos que voluntariamente participaram desse estudo.

À amiga Cássia Moreira por ter revisado a maior parte dessa Tese.

Aos funcionários da secretária de Pós-Graduação (Célia, Ilza e Márcio) e do apoio didático que sempre me atenderam atenciosamente. 
Por fim, confesso que gosto muito daquilo que tenho feito atualmente, mas também admito que as vezes sinto falta da época em que à simplicidade estava mais presente nos fatos. Só de pensar nos amigos de infância (Emerson o Pirriu, Alexandre o Esquilo, Anderson o Dissom, Vando o Boca, Edson o Zoinho (em memória), Sandro o Negão, César, Cíntia, Luciana e a Ana), da adolescência (Walmir o Frango, Lilian, Gabriela, Marcelo, Walter a Nilcéia e os seus familiares), da escalada (Estebe o Gringo, Rogério, Roberta Nunes (em memória), Luciana, Léo (em memória), Aleta a prima, Maripaki a Paki, Serafina a Sera e o Daniel) e até do exército (Blasco, José Henrique o Zé, Nascimento, Santos Prado, Sal, Souza Santos, Amorin, Braz e o Preusse) me dá um aperto no peito. Cada um foi para o seu lado, seja pelo destino ou por algum desentendimento. É curioso como algumas pessoas marcam profundamente a nossa vida. Em alguns casos, infelizmente, eu só pude perceber depois que elas partiram para sempre. Hoje, uma das minhas preocupações é fazer com que isso não se repita, embora o tempo não queira. Assim, como se fosse uma forma de tentar imortalizar esse meu desejo, eu dedico a minha Tese de Doutorado ao meu avô Silgiefrido Bertuzzi (em memória), a minha avó Yone Bertuzzi, a minha mãe Nair B. de M. Bertuzzi e a minha eterna namorada Monique Matsuda.

"A felicidade é como a pluma Que o vento vai levando pelo ar Voa tão leve Mas tem a vida breve Precisa que haja vento sem parar" 


\section{SUMÁRIO}

LISTA DE TABELAS.

Página

LISTA DE FIGURAS.

vii

LISTA DE SIGLAS, ABREVIAÇÕES E SÍMBOLOS ………................ $x$

LISTA DE ANEXOS............................................................... xiii

RESUMO.................................................................. xiv

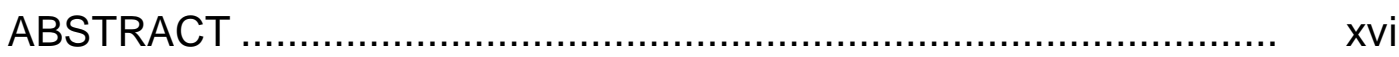

$1 \quad$ INTRODUÇÃO

2 OBJETIVO GERAL............................................................ 3

$2.1 \quad$ Objetivos específicos ............................................................... 4

3 REVISÃO DA LITERATURA …................................................. 4

3.1 Capacidade anaeróbia.................................................................. 4

3.2 Metabolismo do lactato no músculo esquelético ………………........ 7

3.2.1 Lactato e fadiga muscular ........................................................... 14

3.2.2 Lactato e metabolismo energético ………...................................... 19

3.3 Retrospectiva histórica do débito de $\mathrm{O}_{2}$, do déficit de $\mathrm{O}_{2}$, e do déficit

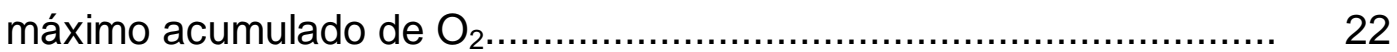

3.4 Evidências de validade do MAOD ............................................. 26

3.5 Divergências sobre a validade do MAOD ............................................ 33

3.6 Variáveis intervenientes no MAOD ................................................. 35

3.7 Reprodutibilidade do MAOD ....................................................... 41

3.8 Ajustes metodológicos aplicados ao MAOD ................................. 42

3.9 Caracterização da resposta cinética off do consumo de oxigênio ....... 53

3.10 Resposta cinética off do consumo de oxigênio e metabolismo anaeróbio alático ........................................................................... 58

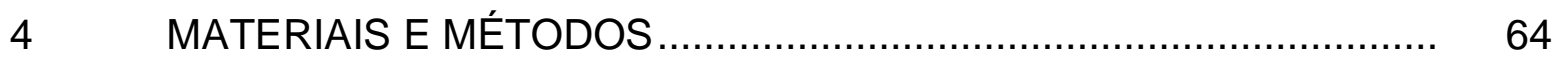

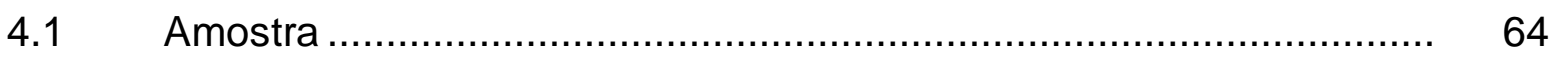

4.2 Desenho experimental...................................................... 64

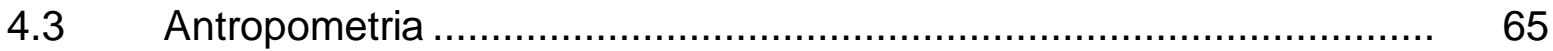


4.4 Determinação do consumo máximo de oxigênio e do limiar anaeróbio 66

$4.5 \quad$ Testes com cargas constantes .................................................... 67

4.6 Teste de Wingate.................................................................. 67

$4.7 \quad$ Coleta dos dados fisiológicos ……………................................ 67

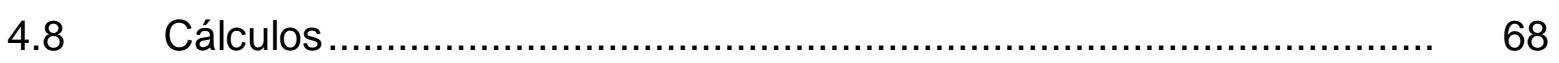

$4.9 \quad$ Análises estatísticas ................................................................. $\quad 70$

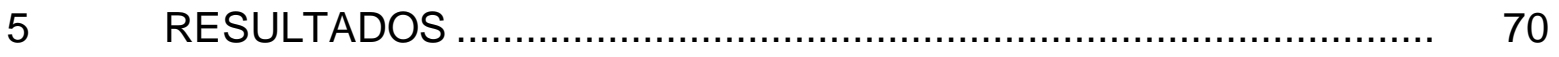

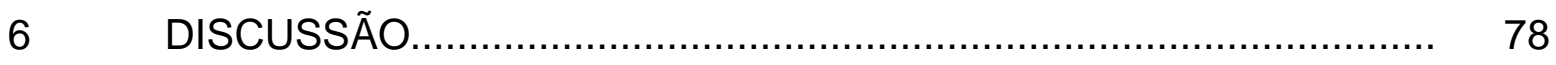

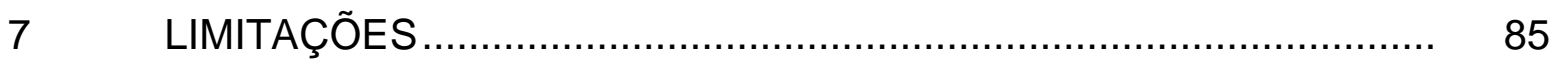

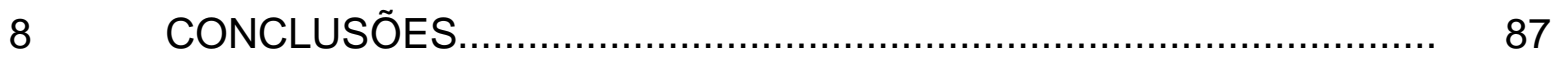

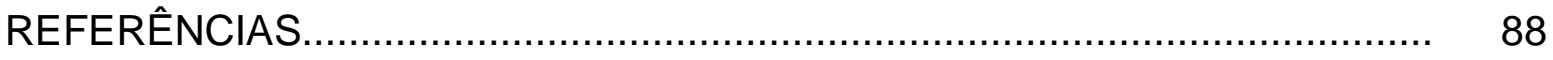

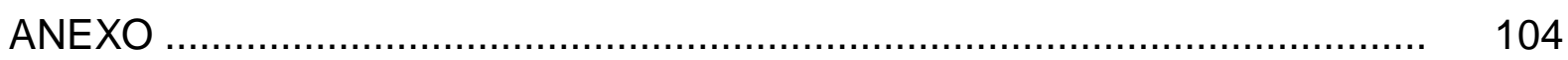




\section{LISTAS DE TABELAS}

Página

TABELA 1 - Resumo das propriedades químicas do ácido lático (Adaptado de ROBERGS et al., 2004)

TABELA 2 - Valores da constante pKa dos demais ácidos intermediários da glicólise anaeróbia (Adaptado de ROBERGS et al., 2004) .

TABELA 3 - Ajustes metodológicos e valores do déficit acumulado de oxigênio.

TABELA 4 - Diferenças absolutas do MAOD ao se comparar com os valores gerados por dez testes submáximos (adaptado de BUCK e NAUGHTON, 1999a)

TABELA 5 - Valores do $\mathrm{t} 1 / 2$ na fase rápida e lenta da resposta off do $\mathrm{\psi}_{2}$ no ciclismo e no teste em banco (adaptado de di PRAMPERO et al., 1989)

TABELA 6 - Constantes de tempo da resposta on e off do $\mathrm{V}_{2}$ em diferentes intensidades. As $\tau_{1}$ e $\tau_{2}$ são referentes as constantes de tempo do primeiro e da segunda exponencial (adaptado de ÖZYENER et al., 2001)

TABELA 7 - Comportamento cinético da resposta off do $\mathrm{V}_{2}$ e da CP mensurados continuamente. $A_{1}$ da CP foi expressa em porcentagem do valor de controle obtido ao início do teste (adaptado de ROSSITER et al., 2002).

TABELA 8 - Idade, antropometria e variáveis analisadas no teste progressivo até a exaustão $(n=10)$.

TABELA 9 - Variáveis mensuradas durante o exercício na intensidade de $110 \%$ do consumo máximo de oxigênio $(n=10)$

TABELA 10 -Resposta cinética off do consumo de oxigênio no exercício executado na intensidade de $110 \%$ da potência externa correspondente ao consumo máximo de oxigênio $(n=10)$ 
TABELA 11 -Respostas do consumo de oxigênio de pico, da freqüência cardíaca de pico, das concentrações sangüíneas de lactato de pico e do tempo de duração do exercício executado nas intensidades abaixo da potência externa correspondente ao consumo máximo de oxigênio $(n=10)$

TABELA 12 -Resposta da cinética off do consumo de oxigênio nas intensidades abaixo da potência externa correspondente ao consumo máximo de oxigênio $(\mathrm{n}=10)$ 


\section{LISTA DE FIGURAS}

FIGURA 1 - Estrutura química do ácido lático e do lactato. Quando o próton se dissocia do seu grupo funcional $\left(\mathrm{COOH}^{-}+\mathrm{H}^{+}\right)$um cátion (nesse caso o sódio, $\mathrm{Na}^{+}$) interage com a negatividade do átomo de oxigênio do grupo carboxílico (adaptado de ROBERGS et al., 2004)

FIGURA 2 - Ilustração das principais etapas do transporte e da degradação do lactato e do piruvato no meio intramuscular (adaptado de GLADDEN, 2004). Hipoteticamente, esses metabólitos poderiam ser transportados para a mitocôndria por meio dos MCT1. Em seguida, o lactato seria convertido em piruvato por meio da LDH. Assim, haveria a redução da NAD e da FAD via LDH e o ciclo do ácido cítrico (CAC), as quais seriam posteriormente oxidadas na cadeia de transporte de elétrons (CTE) para a ressíntese da ATP

FIGURA 3 - Valores médios esperados para o pH mediante a duração do exercício físico, assumindo que a intensidade é sempre máxima (adaptado de CAIRNS, 2006)

FIGURA 4 - Exemplo gráfico do déficit de $\mathrm{O}_{2}$ durante o exercício com a intensidade constante e abaixo do limiar de lactato 
FIGURA 5 - Exemplo gráfico dos princípios metodológicos empregados na determinação do Déficit Máximo Acumulado de $\mathrm{O}_{2}$ (adaptado de MEDBØ et al., 1988). Painel A: a regressão linear é estabelecida entre $\circ \mathrm{W}_{2}$ e as intensidades submáximas do exercício físico. Em seguida, se realiza a extrapolação do $\mathrm{v}_{2}$ para a intensidade supramáxima desejada (quadrado cinza claro). Painel B: O MAOD (cinza escuro) é determinado pela diferença entre a demanda de $\mathrm{O}_{2}$ e o $\mathrm{V}_{2}$ (branco) sob o período de tempo de duração do exercício

FIGURA 6 - Exemplo gráfico da resposta do $\mathrm{V}_{2}$ durante o exercício com a intensidade abaixo (painel A) e acima do limiar anaeróbio (painel B).

FIGURA 7 - Representação gráfica das variáveis cinéticas comumente analisadas na resposta cinética off do $\dot{\mathrm{VO}}_{2} . \mathrm{A}=$ amplitude; $\tau=$ constante de tempo e $\delta=$ tempo de atraso. Os valores subscritos 1 e 2 denotam os termos da fase rápida e lenta do $\mathrm{V}_{2}$ após o exercício, respectivamente

FIGURA 8 - Exemplo do comportamento típico do consumo de oxigênio no teste acima da potência externa correspondente ao consumo máximo de oxigênio (110\%). As linhas pontilhadas marcam o início e o término do exercício

FIGURA 9 - Plotagem de Bland-Altman para o déficit máximo acumulado de $\mathrm{O}_{2}$ (MAOD) e a somatória da fase rápida do excesso do consumo de oxigênio após o exercício com a estimativa do metabolismo anaeróbio lático realizado por meio das

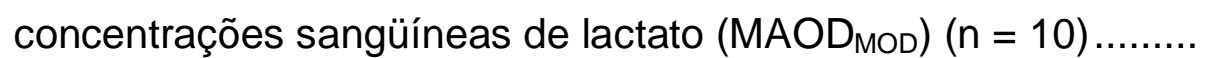


FIGURA 10 -Relação entre a participação alática estimada para o Máximo Déficit Acumulado de $\mathrm{O}_{2}\left(\mathrm{MAOD}_{\mathrm{CP}}\right)$ com a potência de pico do teste de Wingate (painel à esquerda) e da participação lática do Máximo Déficit Acumulado de $\mathrm{O}_{2}\left(\mathrm{MAOD}_{\llcorner\mathrm{A}-1}\right)$ com a potência média no teste de Wingate (painel à direita) $(n=10)$.

FIGURA 11 -Exemplo do comportamento típico do consumo de oxigênio nos testes abaixo da potência externa correspondente ao consumo máximo de oxigênio (\%) em duas sessões experimentais distintas. As linhas pontilhadas marcam o início e o término do exercício

FIGURA 12 -Contribuição percentual dos metabolismos anaeróbios alático e lático durante o exercício realizado nas intensidades abaixo e acima da potência externa correspondente ao consumo máximo de oxigênio $(\mathrm{n}=10)$

FIGURA 13 -Esquema representativo do sistema da lançadeira de creatina (adaptado de GRASSI, 2005). Onde e-CQ = isoforma extramitocondrial da creatina quinase; $\mathrm{m}-\mathrm{CQ}=$ isoforma intramitocondrial da creatina quinase. 


\section{LISTA DE SIGLAS, ABREVIAÇÕES E SÍMBOLOS}

$A=$ amplitude da exponencial.

$\mathrm{ADP}=$ adenosina difosfato.

$\mathrm{AMP}=$ adenosina monofostato.

ATP $=$ adenosina trifosfato.

bpm $=$ batimentos por minuto .

$\mathrm{Ca}^{+}=$íon de cálcio.

CAN = capacidade anaeróbia.

$\mathrm{CP}=$ creatina fosfato.

$E P O C_{\text {RÁPIDO }}$ = fase rápida do excesso de consumo de oxigênio após o exercício.

$\mathrm{FC}=$ freqüência cardíaca.

$\mathrm{H}^{+}=$íon de hidrogênio.

[La'] = concentração sangüínea de lactato.

Lan $=2$ limiar metabólico (definido como sendo o segundo ponto de inflexão da curva da ventilação com concomitante queda da $\mathrm{PCO}_{2}$ ).

$\mathrm{LDH}=$ lactato desidrogenase .

MAA = metabolismo anaeróbio alático.

$\mathrm{MAL}=$ metabolismo anaeróbio lático.

$M A O D$ = déficit máximo acumulado de oxigênio.

$M A O D_{M O D}=$ estimativa do MAOD sem a realização de testes submáximo.

$M A O D_{C P}=$ estimativa do metabolismo anaeróbio alático da CAN mediante o EPOC $_{\text {RÁPIDO. }}$

MAOD $_{\text {LA-1 }}=$ estimativa do metabolismo anaeróbio lático da CAN mediante a subtração do EPOC RáPIDO do MAOD.

$M A O D_{L A-2}=$ estimativa do metabolismo anaeróbio lático da CAN mediante o $\Delta\left[\mathrm{La}^{-}\right]$.

$M C T=$ transportadores monocarboxilatos.

$\mathrm{Na}^{+}=$íon de sódio.

$\mathrm{K}^{+}=$íon de potássio. 
$\mathrm{O}_{2}=$ oxigênio.

$\mathrm{p}=$ nível de significância.

PFK = enzima fosfofrutoquinase.

$\mathrm{pH}=$ logaritmo decimal da concentração de hidrogênio.

PHOS = enzima glicogênio fosforilase.

$\mathrm{Pi}=$ fosfato inorgânico.

$\mathrm{PM}=$ potência média.

$\mathrm{PME}=$ potência metabólica .

$\mathrm{PP}=$ potência de pico.

$\tau=$ constante de tempo do processo exponencial.

$\mathrm{t} 1 / 2$ = reflete a metade do tempo necessário para alcançar o pico de resposta da variável das análises cinéticas.

$\dot{\mathrm{V}} \mathrm{O}_{2}=$ consumo de oxigênio.

$\dot{\mathrm{W}} \mathrm{O}_{2 \mathrm{EXTRAP}}=$ consumo de oxigênio estabelecido mediante a extrapolação da regressão linear entre 0 نंO $\mathrm{v}_{2}$-intensidade dos testes realizados nas intensidades sub-pัنंO

$\dot{\mathrm{V}} \mathrm{O}_{2 \mathrm{DEM}}=$ demanda de oxigênio do teste supra-p $\mathrm{p} \dot{\mathrm{W}} \mathrm{O}_{2 \text { pico }}$ estabelecida pelo $\dot{\mathrm{V}} \mathrm{O}_{2 \mathrm{EXTRAP}}$. $\dot{\mathrm{V}} \mathrm{O}_{2 \mathrm{LB}}=$ consumo de oxigênio em repouso.

$\dot{\mathrm{W}} \mathrm{O}_{2 \max }=$ maior valor do consumo de oxigênio com tendência a estabilização ao final de testes progressivos até a exaustão.

$\dot{\mathrm{V}} \mathrm{O}_{2 \text { off }}=$ resposta cinética do consumo de oxigênio na recuperação.

$\dot{\mathrm{V}}_{2 \mathrm{O}}=$ resposta cinética do consumo de oxigênio na transição do repouso para o exercício físico.

$\dot{\mathrm{V}} \mathrm{O}_{2 \text { pico }}=$ maior valor do consumo de oxigênio observado em uma determinada tarefa.

$\mathrm{p}^{\mathrm{V}} \mathrm{O}_{2 \text { pico }}=$ potência externa correspondente a maior valor do consumo de oxigênio observado em uma determinada tarefa.

sub-p $\mathrm{VO}_{2 \text { pico }}=$ intensidades abaixo da potência aeróbia máxima $(35-90 \%$ da p $\mathrm{v}_{2 \text { pico) }}$. 
supra-p $\dot{V}_{2 p i c o}=$ intensidade acima da potência aeróbia máxima (110\%).

${ }^{31} \mathrm{P}-\mathrm{NMR}=$ Imagem de Ressonância Magnética Nuclear de Fósforo.

$\delta=$ tempo de atraso (time delay).

$\Delta\left[\mathrm{La}^{\mathrm{C}}\right]$ = acúmulo de lactato no sangue acima dos valores de repouso.

$\Delta \dot{\mathrm{V}} \mathrm{O}_{2(\mathrm{ss})}=0$ incremento do consumo de oxigênio sobre os valores inicias de repouso.

$\Delta \dot{V} O_{2(t)}=$ aumento do consumo de oxigênio em dado momento sobre os valores de repouso.

$\theta_{\mathrm{L}}=10$ limiar metabólico (definido como o aumento desproporcional da ventilação em relação ao consumo de oxigênio).

$\beta=$ constante que representa a energia equivalente ao acúmulo de lactato. 


\section{LISTA DE ANEXOS}

Página

ANEXO I - Termo de consentimento informado 104

ANEXO II - Questionário de prontidão para a atividade física.

ANEXO III - Imagem digitalizada do parecer do Comitê de Ética em Pesquisa da Escola de Educação Física e Esporte - USP

ANEXO IV -Resumo das análises estatísticas. 


\title{
RESUMO
}

\section{ESTIMATIVA DOS METABOLISMOS ANAERÓBIOS NO DÉFICIT MÁXIMO ACUMULADO DE OXIGÊNIO}

\author{
Autor: RÔMULO CÁSSIO DE MORAES BERTUZZI \\ Orientadora: PROFa. DRa. MARIA AUGUSTA PEDUTI DAL'MOLIN KISS
}

O objetivo desse estudo foi averiguar a possibilidade de se estimar os componentes anaeróbios do déficit máximo acumulado de oxigênio (MAOD) utilizando apenas o consumo de oxigênio $\left({ }^{\mathrm{V}} \mathrm{V}_{2}\right)$. Adicionalmente, foi proposto um método alternativo que não necessita utilizar a extrapolação do $\mathrm{V}_{2}$ do exercício submáximo para estimar a demanda de $\mathrm{O}_{2}$ para o exercício supramáximo. Para tanto, dez sujeitos fisicamente ativos foram submetidos aos seguintes testes: a) teste progressivo até a exaustão para determinar a carga correspondente ao consumo de oxigênio ( $\left.\mathrm{W}_{\mathrm{V}} \mathrm{O}_{2} \mathrm{max}\right)$; b) seis testes de cargas constantes com intensidades abaixo da $\mathrm{WviO}_{2} \max (40-90 \%$ WvंO ${ }_{2}$ max); c) um teste a $110 \%$ da $\mathbf{W v i O}_{2}$ max; d) teste anaeróbio de Wingate. A fração do metabolismo anaeróbio alático foi estimada pela fase rápida do excesso do

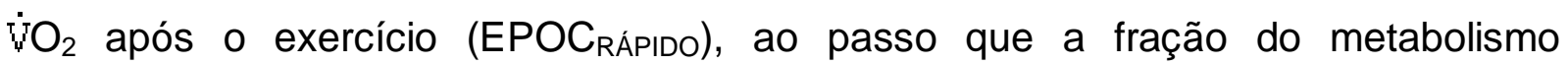
anaeróbio lático foi determinada tanto pela diferença entre MAOD e o EPOC (MAOD $D_{L A-1}$ ) como pelo acúmulo de lactato no sangue $\left(M A O D_{L A-2}\right)$. O MAOD $D_{M O D}$ foi calculado pela somatória do $E P O C_{\text {RÁPIDO }}$ com $M A O D_{L A-2}$. Os principais resultados foram: a) as estimativas das contribuições do metabolismo anaeróbio lático não eram estatisticamente diferentes $\left(\mathrm{MAOD}_{\mathrm{LA}-1}=2,40 \pm 0,66 \mathrm{I} ; \mathrm{MAOD}_{\mathrm{LA}-2}=2,20 \pm 0,4 \mathrm{I} ; \mathrm{p}>\right.$ $0,05)$; b) similarmente, os resultados do MAOD (3,03 $\pm 0,62$ I) MAOD MOD $(2,84 \pm$ $0,41)$ não eram significativamente diferentes $(p>0,05)$; $c)$ foram detectadas

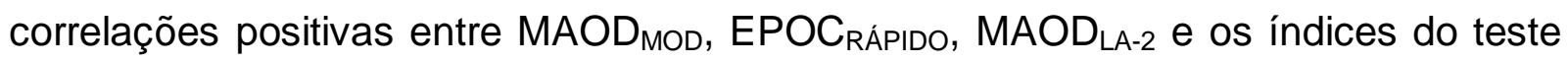
de Wingate; d) os valores percentuais do EPOC $_{\text {RÁPIDO }}$ e do MAOD LA-1 $_{\text {eram }} 22 \pm 9 \%$ e $78 \pm 9 \%$, respectivamente. Esses resultados sugerem que os componentes 
anaeróbios do MAOD podem ser estimados satisfatoriamente utilizando somente 0 $\mathrm{V}_{2}$ e que o MAOD pode ser determinado mediante MAOD ${ }_{M O D}$.

Palavras-chave: metabolismo anaeróbio alático, metabolismo anaeróbio lático, reposta cinética off do consumo de oxigênio, excesso do consumo de oxigênio após o exercício, teste anaeróbio de Wingate. 


\title{
ABSTRACT \\ ESTIMATING OF ANAEROBIC METABOLISMS FOR MAXIMAL ACCUMULATED OXYGEN DEFICIT
}

\author{
Author: RÔMULO CÁSSIO DE MORAES BERTUZZI \\ Adviser: PROFa. DRa. MARIA AUGUSTA PEDUTI DAL'MOLIN KISS
}

The objective of this study was ascertain the possibility of estimate the anaerobic components of the maximal accumulated oxygen deficit (MAOD) used only oxygen uptake $\left(\mathrm{V}_{2}\right)$. In addition, was proposed an alternative method (MAOD $\mathrm{DOD}_{\mathrm{MO}}$ ) to determine the MAOD without using the extrapolation from submaximal $\mathrm{V}_{2}$ to estimate the $\mathrm{O}_{2}$ demand of supramaximal exercise. Thus, ten subjects physically active performed the following tests: a) a maximal incremental exercise test for the measurement of the power output correspondent to maximal oxygen uptake ( $\mathrm{WvO}_{2}$ max); b) six sbumaximal tests with intensities bellow of the $\mathrm{Wv}_{2} \max (40-90 \%$ $\mathrm{Wvi}_{2} \max$ ); c) a supramaximal test at $110 \% \mathrm{Wv}_{2} \max$; d) Wingate anaerobic test. The fraction of the anaerobic alactic metabolism was calculated based on the fast component of excess post-exercise oxygen uptake (EPOC RÁPIDO), although the fraction of the anaerobic lactic metabolism was calculated based on both difference between MAOD and EPOC RÁPIDO $\left(M \mathrm{MOD}_{L A-1}\right)$ and changes in net blood lactate accumulation (MAOD $D_{L A-2}$ ). MAOD ${ }_{M O D}$ was calculated by the sum of the EPOC RÁPIDO with the MAOD $D_{L A-2 .}$. The main results were: a) non significant difference was found between the anaerobic lactic estimates $\left(\mathrm{MAOD}_{\mathrm{LA}-1}=2,40 \pm 0,66 \mathrm{l} ; \mathrm{MAOD}_{\mathrm{LA}-2}=2,20 \pm\right.$ $0,4 \mathrm{I} ; \mathrm{p}>0,05)$; b) similarly, there was no significant difference $(p>0,05)$ between $\operatorname{MAOD}(3,03 \pm 0,62 \mathrm{I})$ and $\operatorname{MAOD}_{\mathrm{MOD}}(2,84 \pm 0,41)$; $\left.\mathrm{c}\right)$ positive and significant correlation were detected between $M_{A O D_{M O D}}, E P O C_{R A ́ P I D O}, M A O D_{L A-2}$ and the indices of the Wingate anaerobic test $(p<0,05)$; $d)$ the mean of the percentage values of the $E P O C_{\text {RÁPIDO }}$ and $M A O D_{L A-1}$ were $22 \pm 9 \%$ e $78 \pm 9 \%$, respectively. 
These data suggest that the anaerobic components of the MAOD can be satisfactorily estimated using only the $\mathrm{\vee}_{2}$ and that the MAOD can be determined using the MAOD $M O D$.

Key words: anaerobic alactic metabolism, anaerobic lactic metabolism, oxygen offtransient response, excess post-exercise oxygen uptake, Wingate anaerobic test. 


\section{INTRODUÇÃO}

A capacidade de ressintetisar as moléculas de ATP pelos processos bioenergéticos tem sido considerada fundamental para o desempenho esportivo (WADLEY \& ROSSIGNOL, 1998; TABATA, IRISAWA, KOUZAKI, NISHIMURA, OGITA \& MIYACHI, 1997; TABATA, NISHIMURA, KOUZAKI, HIRAI, OGITA, MIYACHI \& YAMAMOTO, 1996; MAXWELL \& NIMMO, 1996; MEDB $\varnothing$ \& TABATA, 1993; BANSGBO, MICHALSIK \& PETESEN, 1993; MEDB $\varnothing$ \& TABATA, 1989). Convencionalmente, a taxa máxima de energia transferida pelo metabolismo oxidativo é mensurada pelo consumo máximo de oxigênio ( ${ }^{\mathrm{V}} \mathrm{O}_{2} \max$ ). Entretanto, durante os esforços de curta duração e com alta intensidade, a ATP é ressintetisada predominantemente pelas degradações da fosfocreatina (CP) e do glicogênio muscular, com subseqüente formação de lactato (MEDB $\varnothing$ \& TABATA, 1993; MEDB $\varnothing$ \& TABATA, 1989). A quantidade máxima de ATP ressintetisada por esses sistemas anaeróbios durante uma tarefa específica tem sido denominada de capacidade anaeróbia (CAN) (WEBER \& SCHNEIDER, 2002; WADLEY \& ROSSIGNOL, 1998; MAXWELL \& NIMMO, 1996; MEDB $\varnothing$ \& TABATA, 1993; CAMUS \& THYS, 1991; SCOTT, ROBY, LOHMAN \& BUNT, 1991; TABATA et al., 1996; MEDB $\varnothing$ \& TABATA, 1989; MEDB $\varnothing$, MOHN, TABATA, BAHR, VAAGE \& SEJERSTED, 1988).

Acredita-se que a CAN possa ser estabelecida com mais precisão pela análise direta dos intermediários do metabolismo anaeróbio, os quais são obtidos por meio de biópsia muscular antes e após o exercício físico (SPRIET, 1995). Em virtude da característica invasiva dessa técnica e da dificuldade em se estimar a massa muscular envolvida, alguns estudos têm empregado o Déficit Máximo Acumulado de Oxigênio (MAOD) na determinação da contribuição anaeróbia em diversas tarefas esportivas (OGAWA, HAYASHI, ICHINOSE, WADA \& NISHIYASU, 2007; DUFFIELD, DAWSON \& GOODMAN, 2005; DUFFIELD, DAWSON \& GOODMAN, 2004; SPENCER \& GASTIN, 2001; FAINA, BILLAT, SQUADRONE, ANGELIS, KORALSZTEIN \& DAL MONTE, 1997; PRIPSTEIN, RHODES, MCKENZIE \& COUTTS, 1999). Do ponto de vista metodológico, o cálculo do MAOD é baseado na mensuração do consumo de oxigênio $\left(\dot{V}_{2}\right)$ em múltiplos testes de cargas constantes. Primeiramente, a relação linear entre $\dot{\mathrm{V}}_{2}$-carga dos testes submáximos é determinada para estimar a demanda metabólica do exercício supramáximo. Em 
seguida, o MAOD é calculado pela diferença entre a demanda metabólica estimada e o $\dot{\mathrm{V}}_{2}$ acumulado durante o exercício supramáximo, o qual deve ter a duração entre 2 e 6 minutos (MEDBØ et al., 1988).

Embora algumas limitações acerca do MAOD já tenham sido apontadas (BANGSBO, 1996a; BANGSBO, 1996b; GRAHAM, 1996), a validade desse teste tem sido demonstrada a partir de diferentes perspectivas. Por exemplo, dados obtidos a partir de mudanças metabólicas de amostras do músculo esquelético sugerem que ele fornece uma estimativa satisfatória da energia anaeróbia durante o exercício de alta intensidade (MEDB $\varnothing$ \& TABATA, 1993; BANGSBO, GOLLNICK, GRAHAM, JUEL, KIENS, MIZUNO \& SALTIN, 1990). Além disso, estudos prévios também demonstraram que o MAOD não é afetado pela hipóxia (MEDBØ et al., 1988), que ele se correlaciona positivamente com outros testes anaeróbios (CHATAGNON; POULILLY, THOMAS \& BUSSO, 2005; MAXWELL \& NIMMO, 1996; SCOTT et al., 1991) e que ele é sensível ao treinamento predominantemente anaeróbio (WEBER \& SCHNEIDER, 2002; TABATA et al., 1996).

A determinação das contribuições dos metabolismos anaeróbios lático (MAL) e alático (MAA) pode fornecer informações adicionais para a aplicação adequada da carga de treinamento e para a avaliação do desempenho físico. Dados obtidos a partir de biópsia muscular indicaram que as participações do MAL e do MAA no MAOD são em torno de $75 \%$ e $25 \%$, respectivamente (MEDB $\varnothing$ \& TABATA, 1993). Contudo, alguns trabalhos detectaram um aumento de aproximadamente $10 \%$ do MAOD após a suplementação com creatina monohidratada (JACOBS, BLEUE \& GOODMAN, 1997) ou com cafeína (DOHERTY, 1998). Assumindo que o principal efeito ergogênico dessas substâncias está no acréscimo das concentrações de creatina e da atividade glicolítica intramusculares, é plausível pressupor que os valores do MAOD tenham sido modificados em razão do aumento da contribuição do MAA e do MAL, respectivamente. Nesse sentido, parece ser importante a realização de estudos que proponham métodos alternativos capazes de estimarem os componentes anaeróbios do MAOD.

Como já foi previamente demonstrado, durante a fase inicial do período de recuperação o restabelecimento dos estoques da $\mathrm{CP}$ ocorre por processos metabólicos que dependem do $\mathrm{V}_{2}$ (McMAHON \& JENKINS, 2002; BOGDANIS, 
NEVILL, LAKOMY \& BOOBIS, 1998; di PRAMPERO \& FERRETTI 1999; JANSSON, DUDLEY, NORMAN \& TESCH, 1990; PIIPER \& SPILLER, 1970; MARGARIA, EDWARDS \& DILL, 1933). Por sua vez, di PRAMPERO e FERRETTI (1999) apresentaram um método capaz de expressar em equivalente de $\mathrm{O}_{2}$ a energia oriunda do acúmulo de lactato no sangue $\left(\Delta\left[\mathrm{La}^{-}\right]\right)$. Logo, diversos trabalhos empregaram a fase rápida do excesso do consumo de oxigênio após o exercício $\left(E_{\text {POC }}\right.$ RÁPIDO$)$ e a concentração sangüínea de lactato ([La]) para estimarem as participações do MAA e MAL, respectivamente (GUIDETTI, EMERENZIANI, GALLOTTA \& BALDARI, 2007; SCOTT, 2006a; SCOTT, 2006b; BERTUZZI, FRANCHINI, KOKUBUN \& KISS, 2007; BENEKE, BEYER, JACHNER, ERASMUS \& HÜTLER, 2004; BENEKE, POLLMANN, BLEIF, LEITHÄUSER \& HÜTLER, 2002; FRANCESCATO, TALON, di PRAMPERO, 1995). Portanto, o objetivo desse estudo

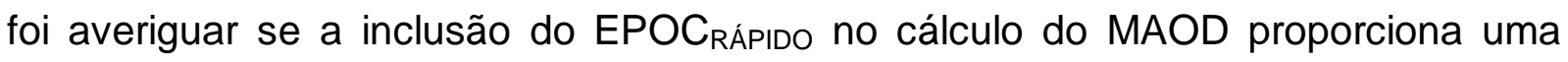
estimativa satisfatória dos componentes lático e alático desse índice fisiológico. Com base nos referenciais teóricos e procedimentais empregados nos estudos supracitados, as hipóteses formuladas foram: a) a porção do MAL no MAOD $\left(M O_{L A-1}\right)$ pode ser determinada pela diferença entre MAOD e o EPOC RÁPIDO $\left(\mathrm{MAOD}_{\mathrm{CP}}\right)$; b) os valores do $\mathrm{MAOD}_{\mathrm{LA}-1}$ são similares aos calculados pelo método proposto por di PRAMPERO e FERRETTI (1999) (MAOD LA-2); c) o MAOD $_{C P}$ e o $M^{M} O D_{L A-1}$ estão positivamente correlacionados, respectivamente, com a potência de pico (PP) e a potência média do teste de Wingate; d) os valores percentuais desses componentes energéticos são de aproximadamente $67 \%$ e $24 \%$ para o MAL e MAA, respectivamente (MEDBØ et al., 1988). Adicionalmente, se a hipótese "b" for aceita, isso significa que o MAOD tradicional pode ser estimado por um método modificado $\left(\mathrm{MAOD}_{\mathrm{MOD}}\right)$ que não necessita determinar a demanda de $\mathrm{O}_{2}$ do exercício de alta intensidade $\left(M^{\prime} A O D_{M O D}=M_{M O D}+M_{C P}+D_{L A-2}\right)$.

\section{OBJETIVO GERAL}

Propor um método capaz de estimar as contribuições dos metabolismos anaeróbios no MAOD mediante a inclusão da resposta cinética off do $\mathrm{v}_{2}$. 


\subsection{Objetivos específicos}

Serão objetivos específicos desse projeto de pesquisa:

a) estimar a contribuição do MAA no MAOD;

b) estimar a contribuição do MAL no MAOD;

c) analisar os valores percentuais das contribuições do MAL e MAA estimados pelo método proposto com os dados citados na literatura científica;

d) comparar os dois métodos empregados na estimativa da porção do MAL que compõe o MAOD;

e) propor um método modificado capaz de estimar o MAOD mediante a somatória do EPOC $_{\text {RÁPIDO }}$ com o MAOD LA-2 $_{\text {(MAOD }}$ MOD);

f) analisar o nível de associação entre os índices proporcionados pelo teste de Wingate e as contribuições do MAL e MAA;

g) estimar as contribuições do MAL e MAA em função da intensidade do exercício físico de carga constante.

\section{REVISÃO DE LITERATURA}

\subsection{Capacidade anaeróbia}

A especificidade do exercício físico é, possivelmente, um dos princípios mais utilizado na planificação do treinamento esportivo. Conseqüentemente, o estabelecimento do perfil bioenergético das modalidades esportivas está entre as principais formas de caracterização da solicitação metabólica imposta por essas tarefas. Acredita-se que, durante o exercício cíclico e de alta intensidade, o metabolismo aeróbio exerce a sua predominância a partir do trigésimo segundo (SPENCER \& GASTIN, 2001). Entre as principais etapas constituintes dessa via metabólica, o oxigênio atua como receptor de íons de hidrogênio $\left(\mathrm{H}^{+}\right)$ao final dos processos da cadeia transportadora de elétrons na mitocôndria. Logo, acredita-se que $\mathrm{O} \mathrm{v}_{2}$ pode ser utilizado como marcador desse sistema bioenergético.

Por outro lado, nos instantes iniciais dos exercícios físicos de alta intensidade e com breve duração, a sustentação dos processos que requerem energia durante a contração muscular ocorre preferencialmente por vias que não necessitam de $\mathrm{O}_{2}$, denominadas de metabolismo anaeróbio. O metabolismo anaeróbio, por sua vez, é 
subdividido em componente alático e lático, os quais se referem respectivamente à hidrólise dos estoques dos fosfatos de alta energia (ATP e CP) e à degradação parcial da glicose, resultando na formação de ácido láctico (GASTIN, 1994; GASTIN, 2001). Esses metabolismos energéticos são capazes de regenerarem uma grande quantidade de ATP por unidade de tempo quando comparados ao metabolismo oxidativo, resultando em uma elevada potência muscular durante o exercício intenso e breve.

Do ponto de vista temporal, acredita-se que a contribuição do metabolismo anaeróbio é de $\cong 80 \%, \cong 45 \%$ e $\cong 30 \%$ da energia total nos exercícios cíclicos e de alta intensidade que têm a duração de até trinta segundos, entre sessenta e noventa segundos e entre cento e vinte e cento e oitenta segundos, respectivamente (SPRIET, 1995). Porém, nessas tarefas os estoques de ATP são os menos afetados pela demanda do exercício físico, ao passo que a quantidade de CP sofre a maior redução (SPRIET, 1995). Além disso, estima-se que entre o 10 e o 30 segundos finais da atividade física intensa a contribuição do MAA seja de apenas $2 \%$ (GREENHAFF \& TIMMONS, 1998). Assim, ao se analisar a relação entre o tempo e a intensidade dos exercícios, supõe-se que esse metabolismo desempenha papel fundamental em algumas tarefas contínuas (DUFFIELD, DAWSON \& GOODMAN, 2004; SPENCER \& GASTIN, 2001; KARVONEN, PELTOLA \& HÄRKÖNEN, 1990) e intermitentes (PLISK, 1991; SPRIET, 1995).

Como descrito na introdução desse trabalho, a CAN pode ser definida como a quantidade total de energia transferida pelos metabolismos anaeróbios durante a execução de um exercício de alta intensidade (GASTIN, 1994). Essa definição está baseada em evidências que sugeriram que a quantidade de ATP ressintetisada anerobiamente é limitada. Além disso, dados experimentais demonstraram que a quantidade de CP depletada durante o exercício intenso não é reduzida substancialmente a partir de 120 s (MEDB $\varnothing$ \& TABATA, 1993). Adicionalmente, resultados prévios obtidos por meio de biópsia muscular demonstram que apesar da glicólise aumentar sua taxa de transferência de energia em aproximadamente 100 vezes em relação ao estado de repouso durante o exercício intenso, esse aumento não pode ser sustentado por muito tempo (GASTIN, 1994).

Porém, diferentemente do metabolismo oxidativo, a estimativa da CAN e das 
vias energéticas alática e lática é de difícil realização por causa da dificuldade de se mensurar os marcadores fisiológicos e/ou mecânicos que melhor as representem. Esse fato decorre diretamente da impossibilidade de se estabelecer um teste padrão ouro e da baixa precisão das técnicas atuais (GASTIN, 2001). Diversos instrumentos têm sido utilizados na tentativa de mensurá-los, entre os principais estão: a) testes de força-velocidade monoarticulares; b) salto vertival; c) teste de subida de degraus; d) teste em cicloergômetros; e) a análise do $\mathrm{V}_{2}$ nos instantes inicial e final do esforço (GASTIN, 1994; VANDEWALLE, PÉRÈS \& MONOD, 1987).

Devido a sua capacidade de medir diretamente as mudanças metabólicas no músculo esquelético, acredita-se que a biópsia muscular realizada antes e após o exercício físico é capaz de proporcionar dados satisfatórios da contribuição anaeróbia durante o exercício físico (SPRIET, 1995). Essa técnica baseia-se na análise direta de metabólitos obtidos a partir de uma pequena amostra do tecido muscular. Todavia, desde que a determinação da massa muscular ativa em uma dada tarefa é de difícil realização e que durante o período entre a obtenção da amostra e a sua respectiva análise ocorrem mudanças na concentração dos metabólitos (por exemplo, ressíntese de CP e efluxo do lactato), tem se indicado que a biópsia muscular também proporciona apenas uma estimativa da CAN (GASTIN, 2004).

A ativação simultânea do MAA e do MAL nos instantes iniciais do exercício de alta intensidade é uma das principais dificuldades encontradas na fragmentação dos componentes anaeróbios da CAN, sobretudo quando se utiliza a potência externa para representá-los (VANDEWALLE et al., 1987). Os resultados dos estudos reunidos por GREENHAFF e TIMMONS (1998) ao final da década de 1990 já indicavam que em músculos eletricamente estimulados (in vivo) por um período de 1,3 segundo havia produção de lactato de aproximadamente $2 \mathrm{mmol} \cdot \mathrm{kg}$ de músculo $\operatorname{seco}^{-1}$. Dessa forma, embora a taxa máxima de ATP ressintetisada pelo MAL atinja o seu máximo em aproximadamente 5 s (GREENHAFF e TIMMONS, 1998), é provável que durante o exercício físico de alta intensidade e de curta duração, a ativação do MAL ocorra quase que imediatamente após o início da contração muscular.

Por outro lado, existe uma tendência de se conceituar o MAOD como o método mais aceitável para avaliação do metabolismo anaeróbio (GREEN \& 
DAWSON, 1993), sobretudo pela fundamentação teórica que o envolve (GASTIN, 1994). O pressuposto dessa técnica está baseado na premissa de que $0 \mathrm{~V}_{2}$ aumenta proporcionalmente com a intensidade do esforço, possibilitando a estimativa da demanda de $\mathrm{O}_{2}$ pela extrapolação linear baseada nas cargas submáximas (GREEN \& DAWSON, 1993). Assim, a diferença entre a demanda acumulada de $\mathrm{O}_{2}$ e $\circ \mathrm{VO}_{2}$ durante o exercício supramáximo representa a CAN. Todavia, assim como os demais métodos de avaliação do metabolismo anaeróbio, o MAOD possui algumas limitações que já foram anteriormente descritas (BEARDEN \& MOFFATT, 2000; GASTIN, 1994; SCOTT, 2000; XU \& RHODES, 1999; WHIPP \& ÖZYENER, 1998) e que serão apresentadas nos tópicos 3.5 e 3.6 .

\subsection{Metabolismo do lactato no músculo esquelético}

Como previamente descrito, uma das porções do sistema de transferência de energia que compõe a CAN é constituída pela degradação parcial da glicose sangüínea e do glicogênio muscular, que por sua vez terá, entre outros produtos, a formação do ácido lático. O químico sueco Carl Wilhelm Schelle foi quem inicialmente descobriu a presença desse ácido em amostras de leite em 1780 (ROBERGS, GHIASVAND \& PARKER, 2004). Em 1922, Otto Meyerhof compartilhou o prêmio Nobel em Fisiologia e Medicina com Archibald V. Hill devido à descoberta da produção de lactato durante a contração muscular.

Assume-se que, durante os esforços de alta intensidade (di PRAMPERO \& FERRETI, 1999) ou quando a energia proporcionada pelo sistema oxidativo não é suficiente para atender a uma determinada demanda metabólica (SPRIET, 1995), a glicólise desempenha um papel importante para a manutenção da potência externa requerida nessas tarefas. Em linhas gerais, supõe-se que o glicogênio muscular é degradado para ressintetizar a ATP que é utilizada nas pontes cruzadas de miosinaactina e no processo ativo das bombas iônicas $\left(\mathrm{Ca}^{2+}-\mathrm{ATPase}\right.$ e $\left.\mathrm{Na}^{+}-\mathrm{K}^{+}-\mathrm{ATPase}\right)$ (CAIRNS, 2006). Assim, o lactato sangüíneo foi considerado por muito tempo um produto final da degradação parcial da glicose em razão da baixa disponibilidade do oxigênio mitocondrial (BROOKS, 1991).

Contudo, essa relação causal tem sido recentemente reformulada. Tem-se proposto que, por causa da interação de múltiplos eventos bioquímicos (GLADDEN, 
2004), a mitocôndria não seria capaz de oxidar todos os piruvatos que são produzidos durante o esforço intenso, o que resultaria na sua conversão em lactado pela enzima lactato desidrogenase (LDH) (ROBERGS et al., 2004). Além disso, acredita-se que as células do tecido epitelial, da parede do intestino e as hemácias, assim como algumas áreas específicas do fígado quando estimuladas pela ação do hormônio glucagon, também são capazes de converterem a glicose em lactato (STAINSBY \& BROOKS, 1990). Nesse sentido, acredita-se que a utilização das [La`] pode ser limitada na mensuração da participação do metabolismo anaeróbio durante o exercício físico extenuante (VANDEWALLE, PÉRÈS \& MONOD, 1987).

Comumente, durante e após o exercício físico, a mensuração do ácido lático é realizada pelas suas concentrações no sangue, que nesses momentos estará na sua forma desprotonada, denominado de lactato. A tabela 1 apresenta um breve resumo das principais propriedades desse ácido.

TABELA 1. Resumo das propriedades químicas do ácido lático (Adaptado de ROBERGS et al., 2004).

\begin{tabular}{ll}
\hline Nome químico & ácido 2-hidroxipropanoico \\
Fórmula química & $\mathrm{CH}_{3}-\mathrm{CHOH}-\mathrm{COOH}$ \\
Peso molecular $\left(\mathrm{g} \cdot \mathrm{mol}^{-1}\right)$ & 90,0 \\
Solubilidade & água, etanol, éter etíl \\
$\mathrm{pKa}\left(37^{\circ} \mathrm{C}\right)$ & 3,87 \\
Calor de combustão $\left(\mathrm{kcal} \cdot \mathrm{mol}^{-1}\right)$ & 321 \\
\hline
\end{tabular}

A sua dissociação no músculo esquelético acontece de forma relativamente rápida, pois a constante pKa dessa substância é de 3,87 em um ambiente com o pH entre 7,08 e 7,10 (FITTS, 1994). Portanto, considerando-se que essa taxa de dissociação é dependente do equilíbrio ácido-base, substâncias que possuem a diferença de até mais ou menos uma unidade de $\mathrm{pH}$ mantêm a sua estrutura constante, ao passo que diferenças superiores ao valor da pKa tendem a facilitar a dissociação e as diferenças inferiores tendem a unir suas bases conjugadas (MARZZOCO \& TORRES, 1990). Essa diferença apresentada entre a pKa do ácido 
lático e do $\mathrm{pH}$ do meio intramuscular resultará em aproximadamente 99\% na degradação dessa substância em prótons $\left(\mathrm{H}^{+}\right)$e ânions $\left(\mathrm{C}_{3} \mathrm{H}_{5} \mathrm{O}_{3}{ }^{-}\right)$(FIGURA 1). Nesse sentido, durante a contração muscular intensa em humanos, as concentrações sarcoplasmáticas e plasmáticas de lactato podem chegar a 40 e 25 $\mathrm{mmol} \cdot \mathrm{I}^{-1}$, respectivamente (CAIRNS, 2006).

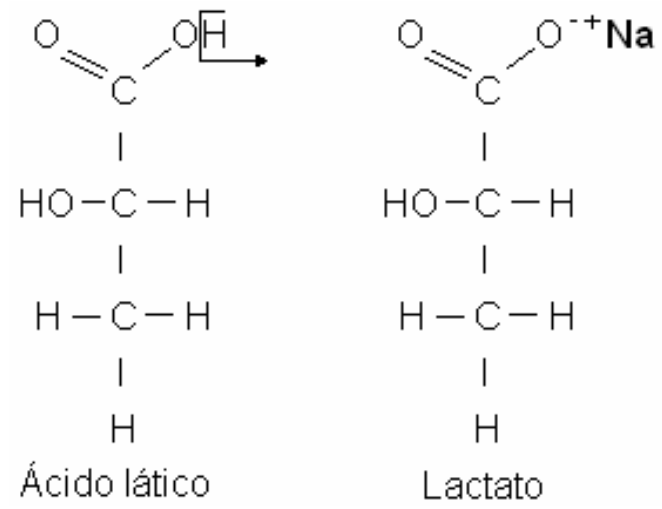

FIGURA 1. Estrutura química do ácido lático e do lactato. Quando o próton se dissocia do seu grupo funcional $\left(\mathrm{COOH}^{-}+\mathrm{H}^{+}\right)$um cátion (nesse caso o sódio, $\mathrm{Na}^{+}$) interage com a negatividade do átomo de oxigênio do grupo carboxílico (adaptado de ROBERGS et al., 2004).

Como descrito inicialmente, em decorrência dessa conexão entre a demanda metabólica requerida pelo exercício físico e a formação do lactato, acreditou-se que essa possível relação causal era decorrente da oferta inadequada de $\mathrm{O}_{2}$ (HILL \& LUPTON, 1923). Todavia, existem evidências mais recentes indicando que ao induzir a redução de aproximadamente $22 \%$ do $\dot{\mathrm{V}}_{2}$ das fibras musculares estimuladas eletricamente, as concentrações de lactato são mantidas semelhantes à situação controle (STAINSBY \& BROOKS, 1990). Adicionalmente, STAINSBY (1986) indicou que, em alguns estudos realizados com animais, foram observados aumentos da produção do ácido lático sem a alteração da pressão parcial de $\mathrm{O}_{2}$ no fluxo sangüíneo muscular.

Isso ocorre em virtude da existência de algumas enzimas-chave participantes desse processo metabólico, entre elas, a glicogênio fosforilase (PHOS) e a 
fosfofrutoquinase (PFK), que têm os seus desempenhos alterados na presença de alguns elementos ou substâncias químicas que atuam como sinalizadores. Por exemplo, a elevação das concentrações de Pi e de cálcio oriundas da contração muscular aumenta a atividade enzimática da PHOS, ao passo que a sua inibição pode ser provocada pelo aumento de $\mathrm{H}^{+}$. Já a PFK aumenta sua atividade enzimática com a diminuição de ATP, bem como a elevação da amônia, epinefrina, AMP, ADP, $\mathrm{Pi}, \mathrm{pH}$ e da frutose 1,6 difosfato (SPRIET, 1995; BROOKS, 1991).

Ao encontrar correlação significativa entre os pontos de inflexão das [La'] e de epinefrina $(r=0,90)$, BROOKS (1986) reforçou a possibilidade da formação do ácido lático independentemente da oferta de $\mathrm{O}_{2}$. Além disso, ele descreveu que essa catecolamina teria também a capacidade de induzir a glicogenólise hepática, mas com uma eficiência menor que a do hormônio glucagon. Posteriormente, STAINSBY, BRECHUE e O'DROBINAK (1991) corroboraram a hipótese da relação causal entre a epinefrina e o aumento da produção de lactato. Eles observaram que ao estimularem eletricamente o músculo gastrocnêmio de cães (4,0 V) em conjunto com a infusão de epinefrina $\left(0,9 \mu \mathrm{g} \cdot \mathrm{kg}^{-1} \cdot \mathrm{min}^{-1}\right)$, a elevação da produção de lactato foi estatisticamente superior à da situação controle $(p<0,05)$. Contraditoriamente, parece que a epinefrina também influencia negativamente na captação do lactato pelo tecido muscular estriado esquelético. Ao estimularem eletricamente os músculos gastrocnêmios de cães $(n=6)$, com e sem a infusão de epinefrina, HAMANN, KELLEY e GLADDEN (2001) observaram que os valores do consumo do lactato eram significativamente inferiores com o acréscimo da epinefrina $(0,527 \pm 0,040$ $\left.\mathrm{mmol} \cdot \mathrm{kg}^{-1} \cdot \mathrm{min}^{-1}\right)$ quando comparados com a situação controle $(0,756 \pm 0,043$ $\left.\mathrm{mmol} \cdot \mathrm{kg}^{-1} \cdot \mathrm{min}^{-1}\right)(\mathrm{p}<0,05)$.

Nesse sentido, acredita-se que por causa dos átomos de hidrogênio e de carbono contidas em sua estrutura, o lactato pode ser utilizado como fonte de energia nos processos biológicos de diversos tecidos (BROOKS, 2000; GLADDEN, 1989). Assim, quando as [La] elevam-se em virtude do esforço físico, há o aumento da sua participação nos processos energéticos, decorrente da elevação do fluxo sangüíneo no miocárdio e da capacidade desse tecido em captá-lo (GLADDEN, 2004; STANLEY, 1991). Em repouso, esse tecido possui o $\mathrm{V}_{2}$ dez a 15 vezes superior ao do músculo estriado esquelético, provavelmente como conseqüência de 
seu maior volume mitocondrial e da atividade superior das enzimas do sistema oxidativo. Todavia, a participação do lactato como fonte de energia para o miocárdio é pequena nessa situação (BROOKS, 2000), pois se estima que os ácidos graxos livres encontrados no plasma sangüíneo nessa situação contribuam entre $60 \%$ e $80 \%$ para o fornecimento da energia total requerida.

Não obstante, tem-se sugerido que o lactato possui uma capacidade superior de participar na gliconeogênese hepática quando comparado à glicose sangüínea (BROOKS, 1986), pois uma parte da dieta de carboidratos catabolisada em ácido lático serviria como precursor da síntese do glicogênio no fígado (STAINSBY \& BROOKS, 1990). Esse fenômeno foi denominado de "paradoxo da glicose" (BROOKS, 2000). Entretanto, MAGNUSSON e SHULMAN (1991) apresentam dados que indicaram que a participação dos substratos na gliconêogenese hepática é dependente da hora da refeição, haja vista que no café da manhã a glicose aumenta a sua contribuição nesse processo para $69 \pm 7 \%$, ao passo que no jantar ela contribui entre 35 e $50 \%$.

Outros fatores, além dos supracitados, podem intervir na produção do metabólito em questão, tais como o aumento da produção de insulina (JUEL, HOLTEN \& DELA, 2004), o conteúdo de glicogênio muscular e o consumo agudo de glicose (JACOBS, 1986). JACOBS (1981) observou que os níveis musculares de lactato são estatisticamente menores em relação à situação controle quando a depleção de glicogênio é induzida pela manipulação de dieta ou pelo exercício físico vigoroso, sendo esse comportamento semelhante nas concentrações sanguíneas.

GAESSER e BROOKS (1984) afirmaram que tanto em animais como em humanos a maior parte do lactato produzido durante e após o exercício é removido pela sua oxidação. BROOKS (1986) acredita ainda que em humanos esse comportamento parece ser linear em intensidades moderadas de esforço (entre 50\% e $75 \%$ do $\mathrm{V}_{2 m a x}$ ). Supostamente, o tipo de fibra que constitui um determinado grupo muscular poderia influenciar na remoção do lactato, pois as fibras de contração lenta teriam maior capacidade de oxidá-lo que as de contração rápida (GLADDEN, 2004; BROOKS, 1986). De fato, o estudo de GRANIER, DUBOUCHAUD, MERCIER, MERCIER, AHMAIDI e PRÉFAUT (1996) confirmou mediante a diferença artériovenosa das [La] que grupos musculares com grande percentual de fibras lentas 
(antebraço com $\cong 50 \%$ ) tinham grande participação na remoção do lactato. Utilizando uma atividade intermitente supráxima realizada com membros inferiores (cinco períodos de seis segundos de estímulo por cinco minutos de recuperação), esses pesquisadores verificaram que o lactato na amostra de sangue arterial do antebraço era significantemente maior após cada estímulo quando comparado ao venoso ( $p<$ 0,001). Adicionalmente, foi encontrada correlação significativa do pico das concentrações de lactato arterial com o aumento da potência gerada pelo protocolo adotado ( $r=0,66 ; p<0,001 ; n=7)$.

Por sua vez, a utilização do lactato como substrato energético pelo músculo esquelético ou por outros órgãos é possível graças ao seu transporte no meio intra e extracelular. Dessa forma, a hipótese das "lançadeiras" (shuttle) de lactato foi introduzida por George A. Brooks em 1984, no primeiro congresso internacional de fisiologia comparada e bioquímica, na Bélgica. Em linhas gerais, acredita-se que durante o exercício físico, sobretudo de intensidade elevada, o lactato produzido se desloca do meio intramuscular por meio dos transportadores monocarboxilatos (MCT1 e MCT4) (THOMAS, PERRY, LAMBERT, HUGON, MORNET \& MERCIER, 2005; BROOKS, 2000). Sugeriu-se que a isoforma MCT1 está presente em maior quantidade nas fibras de contração lenta, ao passo que a isoforma MCT4 está em maior quantidade nas fibras de contração rápida (JUEL et al., 2004). Em relação às suas respectivas localizações, é provável que o MCT1 e o MCT4 estejam preferencialmente no sarcolema e na membrana da mitocôndria (DUBOUCHAUD, BUTTERFIELD, WOLFEL, BERGMAN \& BROOKS, 2000). Nesse sentido, THOMAS et al. (2005) detectaram transversalmente que a concentração de MCT1 era estatisticamente diferente entre grupos com diferentes níveis de aptidão aeróbia ( $p<$ $0,05)$ e que ela também estava positivamente correlacionada com a taxa de remoção das [La] $(r=70 ; p<0,01)$. Além disso, já se demonstrou o aumento de aproximadamente $32 \%$ do MCT4 em sujeitos saudáveis após serem submetidos a um regime de seis semanas de treinamento resistido (JUEL et al., 2004), ao passo que nove semanas de treinamento aeróbio resultou no acréscimo de aproximadamente $78 \%$ do MCT1 de indivíduos sedentários (DUBOUCHAUD et al., 2000).

BROOKS (2000) afirmou que existem muitas evidências que demonstraram a 
presença da LDH e da MCT1 na mitocôndria, fato que levaria a uma nova interpretação da relação entre os metabolismos anaeróbio lático e aeróbio, haja vista a existência da possibilidade do transporte e da conversão do lactato em piruvato nessa organela. De forma similar, o fato do piruvato também poder ser transportado para a mitocôndria por meio dos MCT (GLADDEN, 2004; DUBOUCHAUD et al., 2000), reforça a necessidade de uma reformulação de parte dos conceitos aplicados à explicação da degradação parcial dos carboidratos (FIGURA 2). Adicionalmente, a presença das isoformas MCT1 e MCT2 na fenda sináptica fortalece a proposição que o lactato também pode ser transportado entre os neurônios para ser utilizado como substrato energético (GLADDEN, 2004).

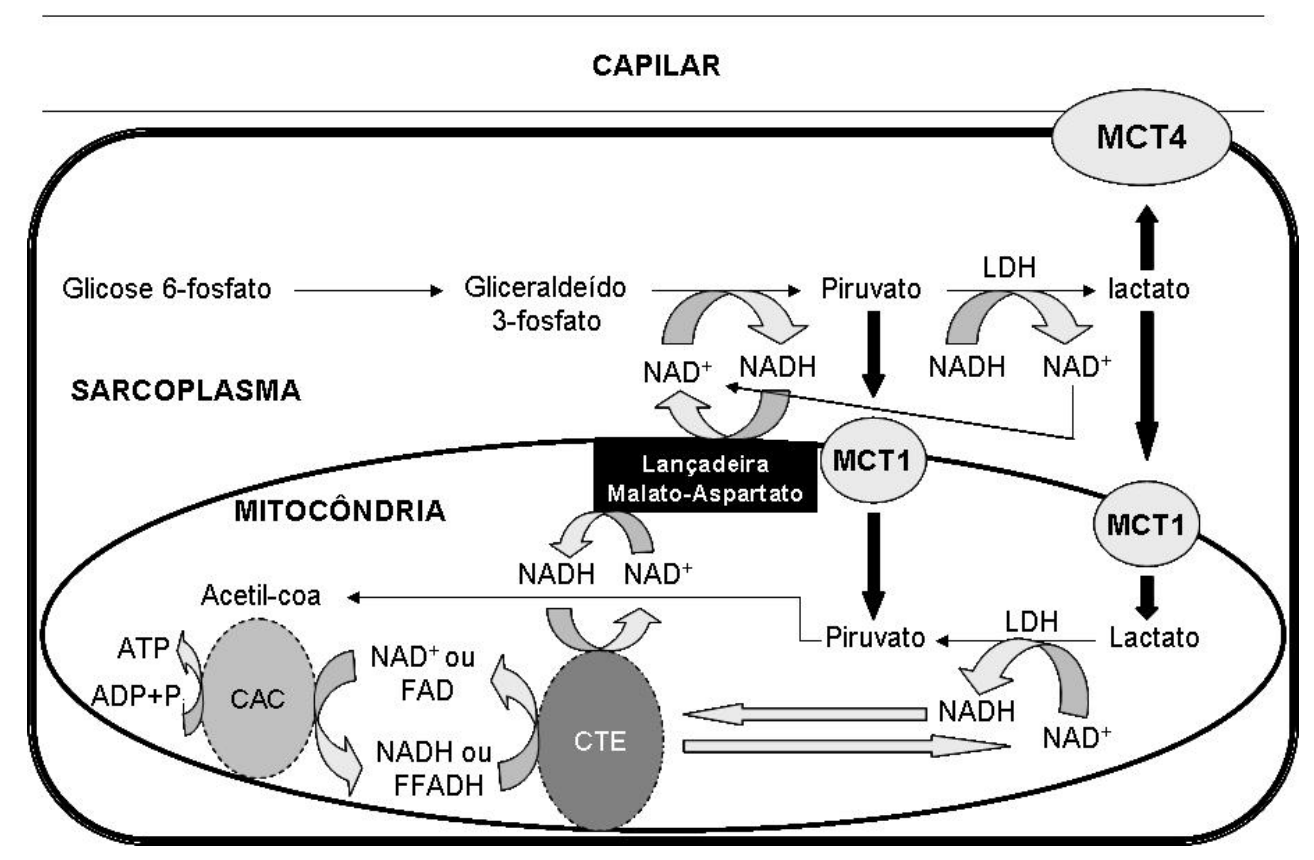

FIGURA 2. llustração das principais etapas do transporte e da degradação do lactato e do piruvato no meio intramuscular (adaptado de GLADDEN, 2004). Hipoteticamente, esses metabólitos poderiam ser transportados para a mitocôndria por meio dos MCT1. Em seguida, o lactato seria convertido em piruvato por meio da LDH. Assim, haveria a redução da NAD e da FAD via $\mathrm{LDH}$ e do ciclo do ácido cítrico (CAC), as quais seriam posteriormente oxidadas na cadeia de transporte de elétrons (CTE) para a ressíntese da ATP. 


\subsubsection{Lactato e fadiga muscular}

Tradicionalmente, a produção do lactato também esteve relacionada à liberação dos íons $\mathrm{H}^{+}$e à diminuição do $\mathrm{pH}$ intramuscular (BROOKS, 1991), os quais seriam agentes depressores da contração muscular (BASSET \& HOWLEY, 2000; BERGH, EKBLOM \& ASTRAND, 2000). As alterações no pH resultantes do acúmulo de $\mathrm{H}^{+}$teriam participação na inibição da liberação de $\mathrm{Ca}^{+}$, no aumento do $\mathrm{Ca}^{+}$livre, na inibição do motoneurônio, no tempo de transição do estado de ligação das pontes cruzadas de forte para fraca e na inibição das enzimas associadas à glicogenólise e à glicólise (FITTS, 1994; GASTIN, 1994). Portanto, o pH intracelular diminui de forma progressiva com o aumento da duração do exercício intenso (FIGURA 3) seguido, supostamente, pela redução da capacidade de gerar tensão a partir do valor de 6,8 (CAIRNS, 2006). Esse processo metabólico é denominado de acidose lática (ROBERGS et al., 2004).

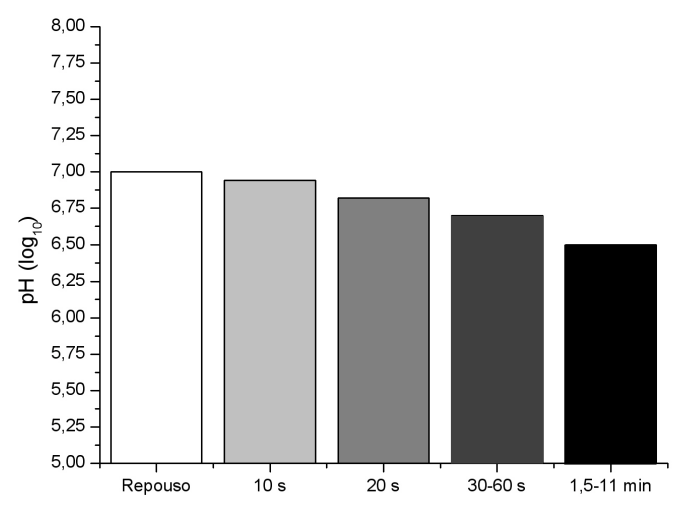

FIGURA 3. Valores médios esperados para o $\mathrm{pH}$ mediante a duração do exercício físico, assumindo que a intensidade é sempre máxima (adaptado de CAIRNS, 2006).

Todavia, a associação entre o ácido lático, os íons $\mathrm{H}^{+}$e o desempenho físico tem sido questionada (BROOKS, 2001). Mais recentemente, ROBERGS et al. (2004) retomaram a discussão sobre as principais etapas do metabolismo energético que produzem os íons $\mathrm{H}^{+}$e, conseqüentemente, as causas da acidose celular e as limitações dos métodos que estimam o pH intracelular por meio da produção do lactato. Esses pesquisadores sugeriram que a glicólise isoladamente não seria capaz 
de produzir os prótons, haja vista que na reação intermediada pela fosfoglicerato quinase, a qual envolve a retirada de um fosfato inorgânico do 1,3-difosfoglicerato, formaria um dos ácidos carboxílicos (TABELA 2), os quais não possuem a capacidade de liberar prótons (ROBERGS et al., 2004). As reações 1, 2 e 3 apresentam as principais etapas da liberação dos íons $\mathrm{H}^{+}$durante a contração muscular segundo ROBERGS et al. (2004).

TABELA 2. Valores da constante pKa dos demais ácidos intermediários da glicólise anaeróbia (Adaptado de ROBERGS et al., 2004).

\begin{tabular}{ll}
\hline 3-fosfoglicerato & 3,42 \\
2-fosfoglicerato & 3,42 \\
Fosfoenolpiruvato & 3,50 \\
Piruvato & 2,50 \\
\hline
\end{tabular}

ATP $+\mathrm{H}_{2} \mathrm{O} \stackrel{\text { ATPase }}{\longrightarrow} \mathrm{ADP}+\mathrm{Pi}+\mathbf{H}^{+}$ REAÇÃO 1

Glicose $+2 \mathrm{ADP}+2 \mathrm{Pi}+2 \mathrm{NAD}^{+} \rightarrow 2$ piruvatos $+2 \mathrm{ATP}+2 \mathrm{NADH}$

$$
+2 \mathrm{H}_{2} \mathrm{O}+2 \mathbf{H}^{+}
$$

REAÇÃO 2

Glicogênio + $3 \mathrm{ADP}+3 \mathrm{Pi}+2 \mathrm{NAD}^{+} \rightarrow 2$ piruvatos + $3 \mathrm{ATP}+2 \mathrm{NADH}$

$$
+2 \mathrm{H}_{2} \mathrm{O}+1 \mathbf{H}^{+}
$$

REAÇÃO 3

Além disso, ROBERGS et al. (2004) indicaram que a reação da LDH oxidaria a NAD para a formação do lactato, o que permitiria o fluxo do substrato para a segunda fase da glicólise ou da glicogenólise. Assim, foi sugerido que a LDH atua como uma substância tampão e não acidificante do citoplasma, pois durante a formação do lactato via LDH há o consumo de $\mathrm{H}^{+}$(reação 4). Em outras palavras, tem-se proposto que, durante a degradação anaeróbia da glicose, não há formação de ácido lático (ROBERGS \& PARKER, 2005) e que a formação do lactato retardaria o 
desenvolvimento da acidose celular (ROBERGS et al., 2004). Portanto, esses pesquisadores indicaram que a liberação dos íons $\mathrm{H}^{+}$durante a glicólise ou a glicogenólise ocorre de forma secundária, ou seja, somente pela hidrólise da ATP nas reações que envolvem a hexoquinase e a fosfofrutoquinase.

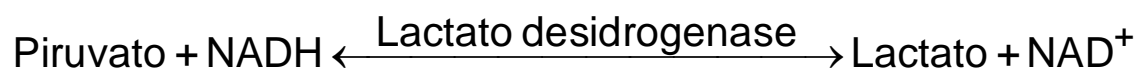
REAÇÃO 4

Não obstante, ROBERGS et al. (2004) também sugeriram que a acidose metabólica não ocorre somente pela liberação de próton, mas que ela é resultante do desequilíbrio entre a produção e o consumo dos íons $\mathrm{H}^{+}$. Esse contraponto foi fundamentado mediante os resultados de outros estudos experimentais que demonstraram que a quantidade de $\mathrm{H}^{+}$excede a produção de lactato durante a contração muscular. Assim, ROBERGS et al. (2004) dividiram o consumo total de prótons em três compartimentos, sendo estes: $1^{\circ}$ ) a idéia tradicional dos componentes que compõem o sistema de tamponamento intracelular estático $(\mathrm{Pi}$, $\mathrm{HCO}_{3}{ }^{-}$, IMP e aminoácidos); 2º) o consumo durante a degradação da $\mathrm{CP}$ (reação 5); $3^{\circ}$ ) consumo de prótons durante a glicólise ou glicogenólise via LDH (reação 6). Por fim, ROBERGS et al. (2004) e CAIRNS (2006) indicaram que as evidências científicas que estabeleceram a relação causal entre a produção de lactato e a acidose celular foram baseadas apenas em observações correlacionais, as quais resultariam apenas na formulação de um constructo não factual.

$$
\begin{aligned}
\mathrm{ADP}+\mathrm{CP}+\mathbf{H}^{\mathbf{+}} \stackrel{\text { creatina quinase }}{\longrightarrow} \mathrm{ATP}+\mathrm{C} \\
2 \text { fosfoenolpiruvato } \\
{ }^{3-}+2 \mathrm{MgADP}^{-}+2 \mathbf{H}^{+} \underset{2 \text { piruvatos }+2 \mathrm{MgATP}^{2-}}{\text { piruvato quinase }}
\end{aligned}
$$$$
\text { REAÇÃO } 5
$$

LINDINGER et al. (2005) contra-argumentaram afirmando que os conceitos apresentados por ROBERGS et al. (2004) e por ROBERGS e PARKER (2005) foram baseados em outros constructos que também não representam a realidade dos fatos. Mais especificamente, LINDINGER et al. (2005) criticaram as idéias propostas por 
ROBERGS et al. (2004) por eles não levarem em consideração duas leis físicas que regem as reações químicas em meios aquosos: a conservação de massa e a manutenção da eletroneutralidade. Em linhas gerais, a eletroneutralidade é alcançada quando a diferença iônica no meio intracelular é igual à zero (reação 7). Segundo esses pesquisadores, o comportamento das moléculas é dependente das suas respectivas interações com a água, pois eles acreditam que por causa da concentração desse líquido ser muito maior que a quantidade de $\mathrm{H}^{+}$no músculo esquelético, ela providencia um infinito suplemento de prótons (reação 8) e que, de forma similar, os $\mathrm{H}^{+}$também podem se reagrupar ao $\mathrm{HO}^{-}$. Nesse sentido, foi proposto que o aumento das concentrações dos ânions de lactato oriundos da glicólise induziria a dissociação dos íons $\mathrm{H}^{+}$contidos na água, no intuito de manter a eletroneutralidade. Em suma, LINDINGER et al. (2005) alegaram que o lactato contribui diretamente para a acidose celular, haja vista que ele é um ânion que pode alterar o comportamento do citoplasma.

$$
\begin{aligned}
& \left(\left[\mathrm{Na}^{+}\right]+\left[\mathrm{H}^{+}\right]+\left[\mathrm{Ca}^{+}\right]+\left[\mathrm{K}^{+}\right]\right)-\left(\left[\mathrm{Cl}^{-}\right]+\left[\mathrm{La}^{-}\right]\right)=0 \\
& \mathrm{~K}_{\mathrm{W}}\left[\mathrm{H}_{2} \mathrm{O}\right]=\left[\mathrm{H}^{+}\right]\left[\mathrm{HO}^{-}\right]
\end{aligned}
$$

Onde a constante de dissociação da água $\left(K_{W}\right)$ é muito pequena $\left(\cong 4,4 \times 10^{-14}(E q / /)^{2}\right)$ e as $\left[\mathrm{H}^{+}\right]$e $[\mathrm{HO}]$ são muito baixas $\left(\cong 10^{-7} \mathrm{Eq} / \mathrm{l}\right)$.

KEMP (2005) e KEMP, BÖNING, BENEKE e MAASSEN (2006) também refutaram parcialmente as proposições de ROBERGS et al. (2004) e ROBERGS e PARKER (2005). KEMP (2005) indicou que, de fato, em repouso ( $\mathrm{pH} \cong 7,0$ ) os prótons seriam liberados principalmente pela hidrólise da ATP, mas à medida que o $\mathrm{pH}$ é reduzido durante a contração muscular $(\cong 6,4)$, a produção do lactato pela degradação do glicogênio assumiria o papel fundamental na liberação do $\mathrm{H}^{+}$. Além disso, ainda contrapondo ROBERGS et al. (2004), KEMP (2005) e KEMP et al. (2006) afirmaram que para todos os valores de $\mathrm{pH}$, sempre há a liberação de um próton por lactato, independentemente do substrato utilizado. Adicionalmente, KEMP (2005) chamou atenção para o fato de que o consumo de prótons pela reação da 
creatina quinase é dependente da regulação metabólica, uma vez que a ativação da enzima glicogênio fosforilase interfere na disponibilidade de um dos seus substratos, o Pi.

Contudo, cabe ressaltar que a maioria dos estudos supracitados que deram origem a essas hipóteses não foram conduzidos em temperaturas fisiológicas (WESTERBLAD et al., 2002; NIELSEN, de PAOLE e OVERGAARD, 2001). Logo, WESTERBLAD et al. (2002) acreditam que se a redução do pH está envolvida na fadiga aguda, o efeito poderia ser indireto pela acidose extracelular, que ativaria os quimiorreceptores dos grupos III e IV das vias aferentes, os quais estariam relacionados à sensação de desconforto presente na fadiga aguda. Assim, alguma outra conseqüência do metabolismo anaeróbio pode ser a causa verdadeira da queda da função muscular, como por exemplo, o aumento das concentrações do $\mathrm{P}_{\mathrm{i}}$ (WESTERBLAD et al., 2002). Essa elevação do $P_{\mathrm{i}}$ resultante da hidrólise da ATP e da CP parece ter a capacidade de inibir a reabsorção do $\mathrm{Ca}^{+}$, que conseqüentemente influenciará no ambiente intracelular (FAVERO, 1999).

Alguns estudos mais recentes demonstraram que, além de não levar à fadiga, a acidose celular poderia ter um possível efeito protetor na manutenção da contração muscular. Por exemplo, após acidificarem os músculos gastrocnêmios de ratos Wistar mediante $\mathrm{O}$ aumento de $\mathrm{CO}_{2}$ (de $5 \%$ para $24 \%$ ), PEDERSEN, de PAOLI e NIELSEN (2005) constataram que a força muscular, previamente reduzida em $85 \%$ pelo aumento de $11 \mathrm{mM}$ da concentração de $\mathrm{K}^{+}$extracelular, retornou $\mathrm{em} \cong 80 \%$ dos valores controle quando o $\mathrm{pH}$ foi reduzido de 7,4 para 6,8 . Além disso, verificou-se também uma diminuição no trânsito de $\mathrm{Cl}^{-}$extracelular ( $\cong 54 \%$ ) após a acidificação. Nesse sentido, esses pesquisadores concluíram que a acidose celular é capaz de recuperar a produção da força de músculos esqueléticos privados dessa função, possivelmente pelo aumento da capacidade das fibras em iniciarem e propagarem os potenciais de ação, pela redução do $\mathrm{Cl}^{-}$extracelular ou pelo bloqueio do seu canal na membrana.

De forma similar, NIELSEN et al. (2001) verificaram que a capacidade de gerar tensão foi completamente restabelecida após a acidose intramuscular (de 7,44 $\pm 0,02$ para 6,80 $\pm 0,02$ ) mediante a infusão de $20 \mathrm{mM}$ de ácido lático em músculos gastrocnêmios de ratos fatigados ( $11 \mathrm{mM}$ de $\mathrm{K}^{+}$extracelular). Entretanto, naquela 
ocasião, NIELSEN et al. (2001) não detectaram mudanças significativas no potencial de repouso da membrana (de - $62 \pm 3$ para $-64 \pm 4 \mathrm{mV}$ em $40 \mathrm{~min}$ ) após a intervenção com o ácido lático. Adicionalmente, parte dos resultados do estudo de de PAOLI, OVERGAARD, PEDERSEN e NIELSEN (2007) demonstram que $75 \%$ da força é recuperada após o acréscimo de $10^{-5} \mathrm{M}$ de adrenalina em músculos que já haviam sido induzidos à fadiga pelo aumento de $15 \mathrm{mM}$ da concentração de $\mathrm{K}^{+}$extracelular e expostos à acidose pela infusão de $20 \mathrm{mM}$ de ácido lático $(\mathrm{pH}=6,8)$. Além disso, constatou-se que a infusão de epinefrina também resultou na hiperpolarização da membrana (de $-63,8 \pm 0,7$ para $-67,6 \pm 0,6 ; p<0,001$ ) em razão da diminuição de $49 \%$ da concentração de $\mathrm{Na}^{+}$intracelular mediante o aumento de $147 \%$ no funcionamento da bomba de $\mathrm{Na}^{+}-\mathrm{K}^{+}$. Com base nesses achados, de PAOLI et al. (2007), concluíram que: a) a acidose celular pode alterar a excitabilidade dos túbulos T no intuito de favorecer a despolarização das fibras; b) a epinefrina tem um efeito aditivo ao da acidose no restabelecimento da contração muscular, contudo a sua principal atuação está no restabelecimento do potencial de repouso da membrana.

\subsubsection{Lactato e metabolismo energético}

Em virtude das suas associações com os sistemas bioenergéticos, as [La'] têm sido comumente utilizadas para se estimar o metabolismo aeróbio em testes ergométricos (BILLAT, 1996; HECK, MADER, HESS, MUCKE, MULLER \& HOLLMANN, 1985) e a contribuição do sistema glicolítico no exercício físico (JACOBS, 1986). Por exemplo, existem evidências que apontam para a diminuição das [La], bem como a sua correlação significativa com mudanças bioenergéticas detectas no músculo esquelético em testes progressivos realizados em cicloergômetro (JACOBS, 1986).

REHUNEN, NÄVERI, KUOPPASALMI e HÄRKÖNEN (1982) observaram que corredores velocistas possuíam valores superiores das [La] imediatamente após $(17,1 \pm 1,0 \mathrm{mM})$ e no quinto minuto de recuperação $(18,1 \pm 0,7 \mathrm{mM})$ subseqüentemente a uma tarefa intermitente máxima, quando comparado com corredores de longa distância $(15,5 \pm 1,0 \mathrm{mM}$ e 16,4 0,9 mM, respectivamente) $(\mathrm{p}<$ 0,05). O estudo de CRAIG, PYKE e NORTON (1989) demonstrou haver correlações significativas entre o pico da potência gerada em 30 e 40 segundos em 
cicloergômetro e o pico de acúmulo das [La`] nessas tarefas ( $r=0,67$ e 0,79, respectivamente) $(n=9)$. Contudo, os próprios autores descreveram que um dos sujeitos alcançou $\cong 90 \%$ do $\dot{\mathrm{V}}_{2 \max }$ no estímulo de 30 segundos, o que poderia indicar que esses indivíduos possuíam uma condição aeróbia elevada, que por sua vez poderia implicar as repostas das [La'] (BILLAT, 1996).

di PRAMPERO (1981) e di PRAMPERO e FERRETTI (1999) afirmaram que é plausível estimar o total de lactato produzido por quilograma de massa corporal e que, mediante esse cálculo, haveria possibilidade de se adquirir informações sobre a energia transferida pelo metabolismo glicolítico. Para isso, é necessário assumir que: as elevações das [La`] sobre os valores de repouso induzidos pelo exercício físico são acumuladas proporcionalmente no organismo, o pico de concentração sangüínea de lactato após o exercício é resultante de uma condição de equilíbrio entre o meio intracelular e extracelular, e que as taxas de remoção do lactato nos vários compartimentos de fluídos corporais têm a mesma constante de tempo.

Em relação ao momento do pico de concentração das [La'], supõe-se que o maior valor deve ser atingido entre o $5^{\circ}$ e o $9^{\circ}$ minuto após os exercícios de curta duração e de alta intensidade (BILLAT, 1996). Contudo, SPRIET (1995) descreveu que cerca de $67 \%$ do lactato produzido permanece nos grupos musculares e que apenas os 33\% remanescentes são removidos para a circulação. Dessa forma, pressupõe-se que em exercício supramáximo com duração superior a 30 segundos, a energia transferida por unidade de tempo (potência metabólica ou PME) é representada pela somatória de dois termos: o primeiro refere-se ao metabolismo aeróbio e o segundo ao anaeróbio, podendo ser expresso pela equação 1 (di PRAMPERO \& FERRETTI, 1999):

$$
\mathrm{PME}=\mathrm{PAM}+\beta\{\Delta(\mathrm{La})\}
$$

Onde $\mathrm{PME}=$ potência metabólica; $\mathrm{PAM}=$ potência aeróbia máxima (normalmente representada pelo $\dot{\mathrm{V}}_{2 \text { max }}$ ); $\beta=$ a constante gerada para representar a energia equivalente ao acúmulo de lactato; $\Delta[\mathrm{La}]=$ a taxa de acúmulo de lactato de pico no sangue sobre os valores de repouso. 
Os valores provenientes do sistema glicolítico ou a constante $\beta$ podem ser estimados pelo cálculo da inclinação de uma reta gerada com base na mensuração das [La'] de pico para uma potência requerida em uma determinada tarefa. Como a PME e a PAM (representada pelo $\dot{V}_{2 \max }$ ) geralmente são expressas em $\mathrm{ml} \mathrm{O} \cdot \mathrm{min}^{-1} \cdot \mathrm{kg}^{-1}$ e o $\Delta$ La é apresentado em $\mathrm{mM}$, a constante $\beta$ pode ser expressa em $\mathrm{ml}$ de $\mathrm{O}_{2} \cdot \Delta \mathrm{La}^{-1}$. Para comparar sujeitos com diferentes PAM e. possivelmente com diferentes intensidades no exercício supramáximo, os autores sugerem expressar a PME de forma relativa a PAM (di PRAMPERO \& FERRETTI, 1999). Quando os resultados são apresentados de forma relativa a PAM na corrida, natação ou ciclismo, as retas geradas têm inclinações semelhantes, indicando que a energia proveniente do sistema glicolítico para os três exercícios são aproximadamente as mesmas $\left(\beta=3,0 \mathrm{ml} \mathrm{de} \mathrm{O}_{2} \cdot \mathrm{kg}^{-1} \cdot \mathrm{mM}^{-1} ; 2,7 \mathrm{ml}\right.$ de $\mathrm{O}_{2} \cdot \mathrm{kg}^{-1} \cdot \mathrm{mM}^{-1}$ e $2,8 \mathrm{ml} \mathrm{de} \mathrm{O}_{2} \cdot \mathrm{kg}^{-1} \cdot \mathrm{mM}^{-1}$ para corrida, natação e ciclismo, respectivamente). Esses resultados levaram di PRAMPERO e FERRETTI (1999) a sugerir a compatibilidade do valor fixo da constante $\beta$ de $3 \mathrm{ml} \mathrm{de} \mathrm{O}_{2} \cdot \mathrm{kg}^{-1} \cdot \mathrm{mM}^{-1}$ de lactato de pico acima dos valores de repouso, viabilizando assim o cálculo da energia oriunda do sistema glicolítico por meio das [La'] de pico e dos valores de repouso. Por outro lado, cabe destacar que essas estimativas não levam em consideração a contribuição do MAA, o que poderia estar subestimando o valor real da PME.

Em resumo, tem se demonstrado que a redução do oxigênio mitocondrial não é o único fator que induz ao aumento da produção do lactato. Por outro lado, a sua produção ainda se mantém relacionada à ATP ressintetisada anaerobiamente. Logo, muitos estudos têm utilizado as [La'] para estimar a contribuição do metabolismo glicolítico durante o exercício físico (GUIDETTI et al., 2007; SCOTT, 2006a; SCOTT, 2006b; BENEKE et al. 2004, BENEKE et al., 2002; FRANCESCATO et al., 1995). Entretanto, os resultados desses estudos devem ser analisados com cautela, pois se acredita que as [ $\left.\mathrm{La}^{-}\right]$são comumente menores que as observadas nos grupos musculares devido à sua degradação em outros tecidos (BANGSBO, 1998). Além disso, estudos recentes têm questionado veementemente o paradigma que propõe a relação entre o aumento das [La] e a fadiga muscular aguda. Porém, BANGSBO e JUEL (2006) apontaram que os resultados dessas investigações são de difícil extrapolação para o exercício em humanos, pois: a) nesses trabalhos a estimulação 
elétrica não foi realizada de forma repetitiva e ela também não levou o músculo à exaustão; b) in vivo, a atividade da bomba de $\mathrm{N}^{+}-\mathrm{K}^{+}$é elevada tanto pelo aumento do $\mathrm{K}^{+}$extracelular como pela ação de hormônios, o que levaria ao restabelecimento do potencial de repouso da membrana e a manutenção da excitabilidade independentemente do $\mathrm{pH} ; \mathrm{c}$ ) a incubação dos músculos em ácido lático diminuiria o $\mathrm{pH}$ intracelular menos que o $\mathrm{pH}$ extracelular, criando assim a redução do gradiente do $\mathrm{pH}$ transmembranar, o qual é diferente do observado durante a contração muscular voluntária; d) quando os músculos são eletricamente estimulados é comum se observar falhas na contração, a qual é raramente detectada durante o exercício físico. Dessa forma, parece que é precoce afirmar que a acidose lática não está envolvida direta ou indiretamente com a fadiga muscular durante o exercício intenso.

\subsection{Retrospectiva histórica do débito de $\mathrm{O}_{2}$, do déficit de $\mathrm{O}_{2}$ e do déficit máximo acumulado de $\mathrm{O}_{2}$}

Os conceitos do débito e do déficit de oxigênio foram inicialmente introduzidos por um dos estudos realizados pelo notável cientista escandinavo Schack August Steenberg Krogh (1874-1949). August Krogh iniciou a sua carreira científica aos 23 anos de idade no laboratório que era coordenado por Christian Bohr, na universidade de Copenhague na Dinamarca. Christian Bohr, já era um renomado pesquisador naquela ocasião, pois havia demonstrado alguns princípios da dinâmica da contração muscular e a solubilidade do oxigênio em alguns fluídos, inclusive no sangue. Em 1904, Christian Bohr descreveu o fenômeno, que hoje conhecemos como "efeito Bohr", demonstrando o comportamento da oxihemoglobina mediante a mudança da concentração de $\mathrm{CO}_{2}$ (ZIMMER, 2006).

Embora Krogh tenha sido considerado um cientista muito versátil, a grande maioria dos 300 artigos científicos que ele publicou foram relacionados às trocas gasosas, provavelmente, em virtude da influência exercida por Christian Bohr. Aos 32 anos de idade, ele ganhou o prêmio da Academia Austríaca de Ciências por causa do estudo que comprovou que a concentração de nitrogênio permanecia constante durante a respiração

pulmonar (http://nobelprize.org/nobel_prizes/medicine/laureates/1920/index.html).

Em 1920, Krogh foi laureado com o prêmio Nobel em Fisiologia ou Medicina 
devido à descoberta do mecanismo que controla o fluxo sangüíneo nos capilares (ZIMMER, 2006). O trabalho vencedor desse prêmio foi constituído por uma série de experimentos realizados com modelo animal, os quais resultaram no desenvolvimento do método de óxido nítrico para o estabelecimento do fluxo sangüíneo geral e a demonstração do aumento da utilização do $\mathrm{O}_{2}$ pelo músculo esquelético.

Especificamente em relação à Fisiologia do Exercício, é provável que o trabalho de Krogh que mais influenciou os estudos clássicos dessa área, tenha sido conduzido em colaboração com o seu colega escandinavo Johannes Lindhard. Naquela ocasião, KROGH e LINDHARD (1920) fizeram uma série de apontamentos acerca dos ajustes agudos que eram promovidos no $\mathrm{v}_{2}$ de seres humanos durante os períodos de transição do repouso-exercício e do exercício-recuperação. Entre os principais resultados apresentados nesse estudo, foi demonstrado que durante a recuperação passiva, a resposta do $\dot{\mathrm{V}}_{2}$ era constituída por uma fase rápida $(\cong 3$ minutos) e uma outra fase lenta ( $>5$ horas), as quais eram dependentes da intensidade do esforço físico realizado previamente. Esse achado proporcionou a base teórica para construção da hipótese do débito de $\mathrm{O}_{2}$ que foi primeiramente apresentada por Archibald Vivian Hill em 1923 e, subseqüentemente, reformulada por Rudolf Margaria em 1933 (BALDWIN, 2005).

HILL e LUPTON (1923) descreveram que o débito de oxigênio era constituído por duas fases, com a primeira possuindo a duração entre seis e oito minutos, devido à remoção oxidativa do lactato nos músculos que o produziram, ao passo que a segunda fase tinha duração mais prolongada e estava relacionada à remoção oxidativa do lactato que havia se difundido da musculatura. Cerca de dez anos mais tarde, MARGARIA, EDWARDS e DILL (1933) revisaram o comportamento e os conceitos relacionados ao débito de $\mathrm{O}_{2}$. Eles verificaram que o decréscimo inicial era mais rápido que o descrito por HILL e LUPTON (1923), o qual teve a duração aproximada de três a quatro minutos. Além disso, durante a fase rápida de recuperação, $\mathrm{o} \dot{\mathrm{V}}_{2}$ após os exercícios de intensidades moderadas não havia, aparentemente, a formação extra de lactato, o que os levou a denominar esse fenômeno de débito alático de $\mathrm{O}_{2}$. Em razão dessa ausência de formação extra de lactato, os autores deduziram que o débito alático de $\mathrm{O}_{2}$ estava associado ao 
processo de ressíntese da CP pela via oxidativa. Além disso, MARGARIA et al. (1933) mantiveram a relação originalmente apresentada entre o processo oxidativo da combustão do lactato com a fase lenta do $\mathrm{V}_{2}$, sendo naquele momento renomeada de débito lático de $\mathrm{O}_{2}$.

Não obstante, KROGH e LINDHARD (1920) também demonstraram que, durante a transição do repouso-exercício, o $\mathrm{V}_{2}$ não aumentava instantaneamente até atingir o seu estado estável. Em outras palavras, constatou-se que o déficit de $\mathrm{O}_{2}$ era gerado durante a fase inicial do esforço físico, o qual poderia ser determinado pela diferença entre a projeção do valor assintótico do estado estável do $\mathrm{V}_{2}$ e o ฟेO $_{2}$ mensurado durante a tarefa executada (GASTIN, 1994) (FIGURA 4). Assim, sugeriuse ao longo dos anos que, no início do exercício submáximo e com a intensidade constante, a energia química utilizada para a ressíntese da ATP é transferida principalmente por processos metabólicos que não necessitam de $\mathrm{O}_{2}$. Desde então, o déficit de $\mathrm{O}_{2}$ tem sido utilizado para estimar a contribuição do metabolismo anaeróbio em diversas tarefas (CARTER, PRINGLE, BARSTOW \& DOUST, 2005; GASTIN, 1994).

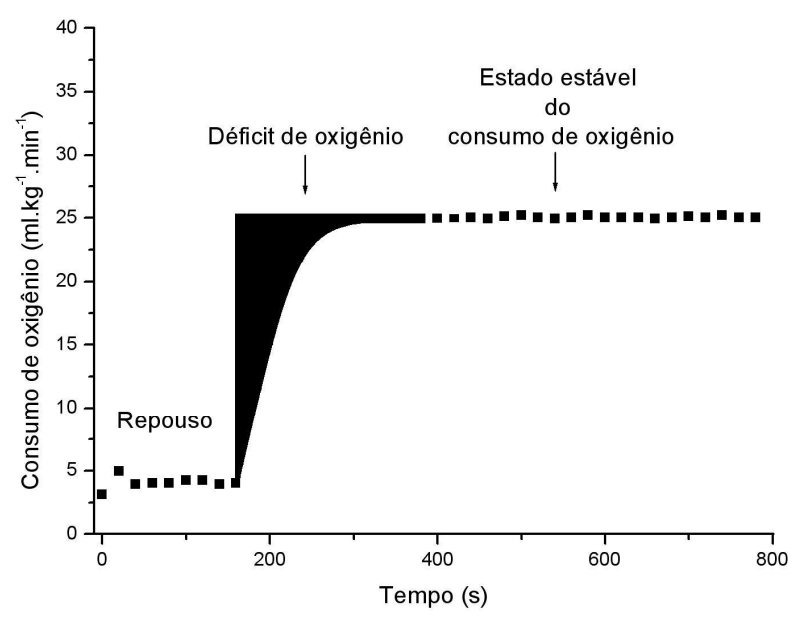

FIGURA 4 - Exemplo gráfico do déficit de $\mathrm{O}_{2}$ durante o exercício com a intensidade constante e abaixo do limiar de lactato.

Ao final da década de 1980, MEDB $\varnothing$ et al. (1988) reformularam o conceito do déficit de $\mathrm{O}_{2}$, no intuito de empregá-lo como uma medida indireta da CAN. Em linhas 
gerais, assumiu-se que a CAN poderia ser determinada pela diferença entre a demanda de $\mathrm{O}_{2}$ e o $\mathrm{V}_{2}$ mensurado durante o exercício físico supramáximo contínuo e de breve duração (entre 120-180 s). Do ponto de vista metodológico, supõe-se que a demanda de $\mathrm{O}_{2}$ no exercício supramáximo pode ser estabelecida por meio da projeção dos valores do $\mathrm{V}_{2}$ medido durante os testes retangulares submáximos. A relação $\mathrm{V}_{2}$-intensidade é determinada por meio de uma equação de regressão linear (equação 2), a qual posteriormente é utilizada na extrapolação do $\mathrm{W}_{2}$ para a intensidade do exercício desejado (equação 3). As áreas correspondentes à demanda de $\mathrm{O}_{2}$ e ao $\dot{\mathrm{V}}_{2}$ mensurado são estabelecidas pelas suas respectivas integrações sobre o período de tempo de duração da tarefa (equação 4). A figura 5 apresenta um exemplo desses princípios metodológicos.

$\dot{\mathrm{W}} \mathrm{O}_{2}=\mathrm{a}+\mathrm{b} \cdot \mathrm{x}$

EQUAÇÃO 2

$\dot{\mathrm{W}} \mathrm{O}_{2}$ supramáximo $=\mathrm{b} \cdot \mathrm{x}$

EQUAÇÃO 3

$\mathrm{MAOD}=\left[\left(\int_{0}^{z} \mathrm{VO}_{2}\right.\right.$ supramáximo $\left.\left./ 60\right)-\left(\int_{0}^{z} \mathrm{VO}_{2} / 60\right)\right]$

EQUAÇÃO 4

Onde $\dot{\mathrm{V}}_{2}=$ consumo de oxigênio em $\mathrm{ml} \cdot \mathrm{min}^{-1} ; \mathrm{a}=$ intercepto no eixo $\mathrm{y} ; \mathrm{b}=$ coeficiente angular da reta; $\mathrm{x}=$ intensidade percentual ao $\dot{\mathrm{V}} \mathrm{O}_{2} \mathrm{max} ; \dot{\mathrm{V}} \mathrm{O}_{2}$ supramáximo $=\dot{\mathrm{V}} \mathrm{O}_{2}$ projetado para a intensidade do exercício supramáximo desejado; $\int=$ integração da demanda de $\mathrm{O}_{2} ; 0$ e $\mathrm{Z}=$ início e término do exercício supramáximo expresso em segundos, respectivamente. 


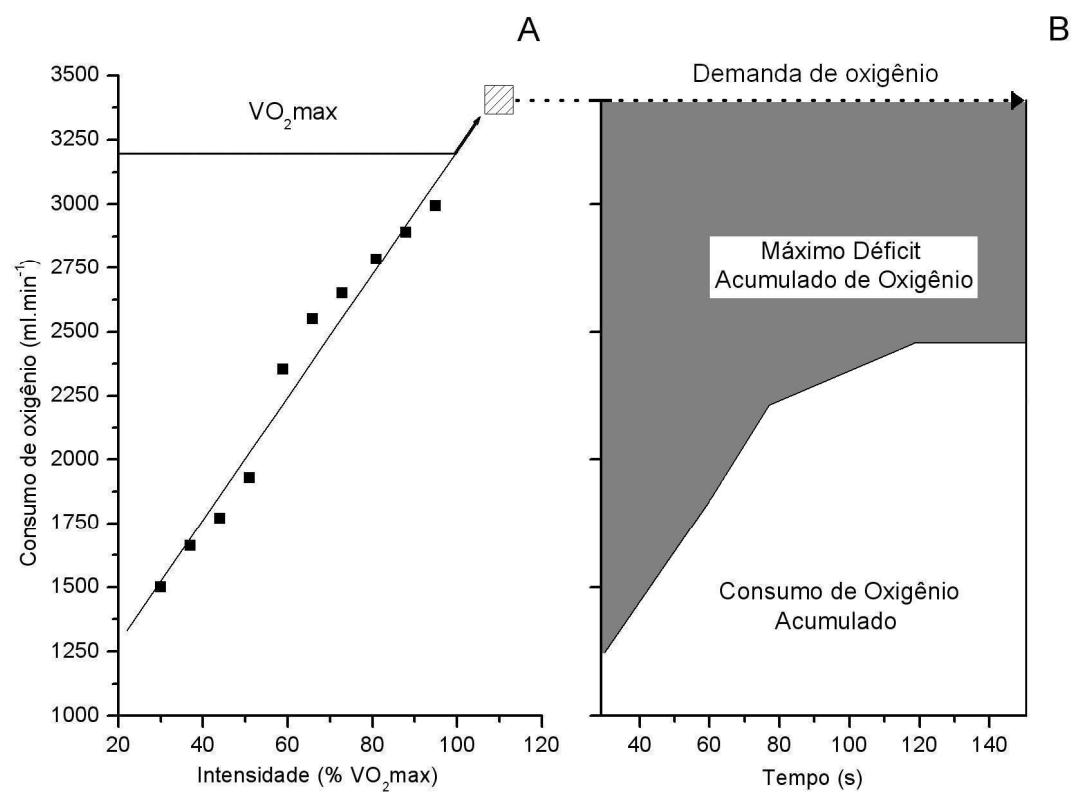

FIGURA 5 - Exemplo gráfico da metodologia empregada na determinação do Déficit Máximo Acumulado de $\mathrm{O}_{2}$ (adaptado de MEDBØ et al., 1988). Painel A:

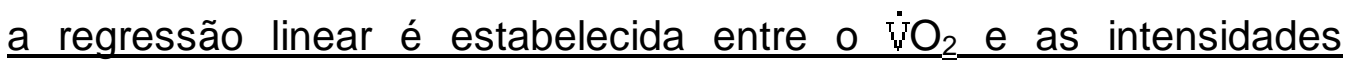
submáximas. Em seguida, realiza-se a extrapolação do ${ }^{\dot{V}} \underline{O}_{2}$ para a intensidade supramáxima desejada (quadrado cinza claro). Painel B: o MAOD (cinza escuro) é determinado pela diferença entre a demanda de $\underline{\mathrm{O}}_{2} \underline{\text { e o } \underline{\mathrm{V}}_{2}} \underline{\text { acumulado (branco) sob o período de tempo de duração do }}$ exercício.

\subsection{Evidências de validade do MAOD}

Em razão da inexistência de um método universalmente aceito como padrão ouro (gold standard) para a avaliação do metabolismo anaeróbio (GASTIN, 1994), as principais evidências acerca da validade do MAOD basearam-se na sua sensibilidade ao treinamento predominantemente anaeróbio (WEBER \& SCHNEIDER, 2002; TABATA et al., 1996) e nas correlações significativas constatadas com outros testes anaeróbios (SCOTT, 2006b; CHATAGNON; POULILLY, THOMAS \& BUSSO, 2005; MAXWELL \& NIMMO, 1996; SCOTT et al., 1991). O MAOD também se mantém inalterado mediante a situação de hipóxia (MEDB $\varnothing$ et al., 1988), é sensível ao consumo de substâncias estimuladoras da glicólise anaeróbia (BELL, JACOBS \& ELLERINGTON, 2001; DOHERTY, 1998) e tem a capacidade de distinguir 
transversalmente sujeitos com diferentes estados de treinamento (SCOTT et al., 1991; OLESEN, 1992; MEDB $\varnothing$ \& BURGERS, 1990).

MEDB $\varnothing$ e BURGERS (1990) conduziram um estudo com dois experimentos que analisou transversalmente e longitudinalmente os efeitos de diferentes regimes de treinamento na capacidade anaeróbia. No primeiro, o MAOD foi medido em indivíduos com diferentes níveis de aptidão física, ao passo que no segundo o MAOD foi mensurado em homens e mulheres fisicamente ativos, antes e após seis semanas de treinamento predominantemente anaeróbio. Os principais resultados obtidos foram: a) não havia diferença significativa entre o MAOD dos atletas treinados aerobiamente e o grupo controle $(p=0,50)$, mas os atletas treinados anaerobiamente possuíam o MAOD cerca de $30 \%$ maior que o apresentado por esses dois grupos ( $p$ $<0,001)$; b) mesmo possuindo o MAOD estatisticamente maior no início do estudo $(17 \% ; p=0,03)$, somente os homens aumentaram o MAOD significativamente após o período de treinamento $(16 \% ; p=0,02)$. Nesse sentido, além de proporcionarem informações sobre a sensibilidade ao treinamento anaeróbio e a capacidade de distinguir grupos com diferentes graus de condicionamento físico, esses autores sugeriram que o gênero da amostra estudada parece ser um fator importante na análise da CAN.

Dois outros estudos utilizaram um desenho experimental transversal para verificar a eficácia do MAOD em distinguir indivíduos com diferentes níveis de aptidão anaeróbia. GASTIN e LAWSON (1994) observaram que os ciclistas velocistas possuíam o MAOD estatisticamente superior ao do grupo controle e ao dos ciclistas fundistas $(37 \%$ e $26 \%$, respectivamente; $p<0,05)$, ao passo que SCOTT et al. (1991) constataram que os corredores fundistas (> $3000 \mathrm{~m}$ ) tinham 0 MAOD estatisticamente menor $(p<0,05)$ que os corredores de meia distância (800$1500 \mathrm{~m})$ e corredores velocistas (200-400 m). Assim, com base nesses resultados, GASTIN e LAWSON (1994) sugeriram que o MAOD é um teste válido para mensurar indiretamente a CAN.

Embora WEBER e SCHNEIDER (2002) também tenham confirmado que o MAOD é sensível ao treinamento anaeróbio mediante um estudo longitudinal, os resultados desse trabalho demonstraram que essa característica não é sexo dependente. Para tanto, a amostra foi composta por dois grupos de indivíduos do 
sexo masculino ou feminino, os quais foram submetidos a oito semanas de treinamento intervalado de alta intensidade. Esse programa de condicionamento físico foi estruturado da seguinte forma: a) três sessões semanais de treinamento; b) cada sessão possuía três exercícios de cargas constantes, os quais duraram em média dois minutos e eram intermediados por seis minutos de recuperação; c) as intensidades variaram entre $82,5-100 \%$ da carga utilizada no teste supramáximo para o estabelecimento do MAOD (120\% $\mathrm{v}_{2}$ max). Adicionalmente, os testes realizados com as mulheres foram conduzidos na fase folicular do ciclo menstrual. Entre os principais achados, constatou-se que O MAOD dos homens era significativamente maior que o das mulheres no início da investigação $(p<0,01)$, mas que os dois grupos aumentaram significativamente esse índice após a intervenção supracitada (homens $=21,9 \pm 6,3 \%$; mulheres $=19,6 \pm 3,1 \% ; p<0,05$ ). Quando o MAOD foi corrigido pela massa muscular envolvida no ergômetro utilizado no estudo, verificouse que tanto antes como após o treinamento o MAOD dos homens era estatisticamente maior $(p<0,05)$. Em síntese, sugeriu-se que as diferenças entre os grupos podem ser em decorrência das características estruturais e/ou bioquímicas do músculo esquelético desses indivíduos (por exemplo, o percentual das fibras de contração rápida e a atividade da enzima fosfofrutoquinase), porém os grupos respondem de forma similar ao estímulo proporcionado pelo exercício intenso. Segundo WEBER e SCHNEIDER (2002), a comparação desses achados com os do estudo de MEDBØ e BURGERS (1990) é de difícil realização, pois no trabalho de MEDBØ e BURGERS (1990) o volume de treinamento não foi equivalente entre os grupos e que o ciclo menstrual das mulheres não foi levado em consideração.

TABATA et al. (1996) conduziram um trabalho longitudinal que teve por objetivo analisar os efeitos do treinamento físico na capacidade anaeróbia e no $\dot{\mathrm{V}} \mathrm{O}_{2} \max$. Durante um período de seis semanas, dois grupos foram submetidos a cinco sessões semanais de treinamento, as quais foram compostas por 60 minutos de exercício contínuo a $70 \% \mathrm{~V}_{2}$ max ou intermitente a $170 \% \mathrm{v}_{2}$ max. O grupo que treinou intermitentemente teve um aumento significativo tanto do $\mathrm{v}_{2}$ max como do MAOD, ao passo que o outro grupo teve apenas um ganho no $\mathrm{v}_{2} \max (p<0,05)$. Dessa forma, além de apresentarem dados que corroboram o princípio da especificidade do treinamento, esses autores afirmaram que o MAOD é uma medida 
específica da CAN, em virtude de sua sensibilidade ao treinamento intermitente de alta intensidade, o qual se acreditou ser predominantemente anaeróbio.

Tem-se sugerido que a capacidade de ressintetisar ATP anaerobiamente durante o exercício de alta intensidade e de breve duração é limitada (GASTIN, 1994). Logo, acredita-se que o MAOD é um método válido para se estimar a CAN, porque ele não é afetado pelo da duração do exercício supramáximo (PRIPSTEIN et al., 1999; MEDB $\varnothing$ \& TABATA, 1989). Por exemplo, ao utilizarem testes supramáximos que duraram $15 \mathrm{~s}, 30 \mathrm{~s}, 1 \mathrm{~min}, 2 \mathrm{~min}$ e 4 min na medida do MAOD, MEDB $\varnothing$ et al. (1988) constataram que para as intensidades que possuíam o período de duração entre 2 min e 4 min as diferenças não eram significativas ( $p>0,2$ ), ao passo que nas demais situações o MAOD aumentou proporcionalmente ao tempo de duração $(p<0,001)$. Além disso, também foi constatado, por meio da somatória da variância dos valores do MAOD de onze sujeitos, que havia um menor erro do MAOD (em torno de 4\%) quando ele foi determinado com teste supramáximo que durou 2 min. Supostamente, isso se deve à falta de motivação para se exercitar por mais tempo nas intensidades elevadas. Dessa forma, concluiu-se que o MAOD pode ser mensurado mediante o exercício exaustivo com duração entre 2-3 min e que o aumento do tempo do teste supramáximo diminui a sua precisão. Todavia, naquela ocasião, MEDB $\varnothing$ et al. (1988) não providenciaram medidas diretas que analisassem a relação entre o platô do MAOD em exercícios supramáximos com duração $\geq 2$ min e a quantidade total de ATP ressintetisada anerobiamente.

Em um estudo posterior, MEDB $\varnothing$ e TABATA (1993) mensuraram o MAOD e as respostas bioquímicas do músculo esquelético nos períodos de $30 \mathrm{~s}, 60 \mathrm{~s}$ e 120$180 \mathrm{~s}$ durante o ciclismo estacionário supramáximo e demonstraram que havia diferenças significativas entre o MAOD $(1,87 \pm 0,07 ; 2,16 \pm 0,07$ e 2,35 $\pm 0,09$ $\mathrm{mmol} \cdot \mathrm{kg}^{-1}$, respectivamente) e as concentrações musculares de lactato $(20,6 \pm 1,7$; $29,9 \pm 1,1$ e $31,1 \pm 1,2 \mathrm{mmol} \cdot \mathrm{kg}^{-1}$ de músculo seco, respectivamente) e de CP $(9,9 \pm$ 0,$6 ; 7,6 \pm 1,0$ e 6,0 $\pm 0,7 \mathrm{mmol} \cdot \mathrm{kg}^{-1}$ de músculo seco, respectivamente) somente na situação de $30 \mathrm{~s}$ quando comparada às demais $(p<0,05)$. Adicionalmente, foi detectado um elevado coeficiente de correlação entre a taxa de ATP ressintetisada anaerobioamente e o MAOD $(r=0,94 ; p<0,05)$. Nesse sentido, corroboraram-se os achados prévios que para a mensuração da CAN é necessário o esforço intenso com 
duração entre 2 e 3 minutos e que o MAOD está associado às mudanças bioenergéticas do músculo esquelético.

Ao comparar as estimativas do metabolismo anaeróbio feitas pelo déficit de $\mathrm{O}_{2}$, débito de $\mathrm{O}_{2}$, produção de $\mathrm{CO}_{2}$ e as [La'] no exercício realizado em diferentes intensidades $\left(50,100\right.$ e $200 \%$ VัO $\left._{2} \max \right)$ e períodos de duração $(2,4,10,15,30$ e 75 s), SCOTT (2006) constatou que nas cargas mais elevadas e breves, essas técnicas apresentaram elevada variabilidade, mas sem diferença significativa entre elas $(p>$ 0,05). Além disso, à medida que se aumentava o tempo de exercício, apenas o débito de $\mathrm{O}_{2}$ era significativamente menor que as demais estimativas $(\mathrm{p}<0,05)$. Contudo, cabe ressaltar que nesse estudo, o débito de $\mathrm{O}_{2}$ foi representado pelo

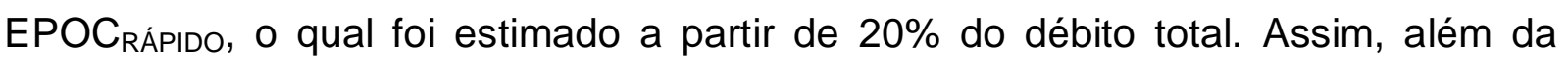
imprecisão na forma utilizada para se estabelecer o débito de $\mathrm{O}_{2}$, esses resultados também podem ter sido influenciados pelo fato do EPOC $_{\text {RÁPIDO representar apenas } 0}$ MAA.

De forma similar, BANGSBO et al. (1990) propuseram que o débito total de $\mathrm{O}_{2}$ é um método impreciso para estimar a contribuição do metabolismo anaeróbio, ao passo que o déficit de $\mathrm{O}_{2}$ providencia estimativas adequadas da produção de lactato muscular e da degradação de ATP e CP durante o exercício intenso e breve. Para tanto, esses pesquisadores submeteram oito sujeitos a um teste constituído pela flexão e extensão de apenas uma perna, com a intensidade que levou à exaustão entre 2-3 minutos ( $\cong 64 \mathrm{~W}$ ). Além da mensuração do $\mathrm{V}_{2}$ e da diferença artériovenosa de $\mathrm{O}_{2}$ durante todo o experimento, as biópsias musculares foram obtidas em repouso, imediatamente após o exercício e três, dez e sessenta minutos de recuperação. Adicionalmente, o débito de $\mathrm{O}_{2}$ foi determinado por meio da medida do $\dot{\mathrm{V}} \mathrm{O}_{2}$ durante todo o período de recuperação (60 min). Contudo, como já era sabido naquela ocasião, o valor total do excesso do consumo de oxigênio após o exercício físico não representa apenas a ressíntese de CP e a oxidação de lactato sangüíneo, pois ele é influenciado por múltiplos eventos fisiológicos que estimulam a respiração mitocondrial (GAESSER \& BROOKS, 1984).

MEDB $\varnothing$ et al. (1988) obtiveram uma outra importante evidência de validade do índice fisiológico em questão. Nesse estudo, o MAOD foi mensurado durante a corrida nas situações de normóxia e hipóxia $\left(13,5 \pm 0,2 \%\right.$ de $\left.\mathrm{O}_{2}\right)$, e constatou-se que 
esse índice fisiológico não foi estatisticamente alterado nessas situações $(p=0,60)$. Isso indica que MAOD é pouco influenciado pelos estoques corporais de $\mathrm{O}_{2}$ e que a CAN é determinada principalmente pela capacidade limitada dos MAA e MAL de ressintetisar ATP. Contudo, cabe ressaltar que o pequeno número de sujeitos que compuseram a amostra $(n=3)$ pode ter influenciado esses resultados.

Com base na hipótese apresentada por estudos prévios que a exposição crônica à hipóxia também poderia aprimorar o desempenho anaeróbio, ROBERTS, CLARK, TOWNSEND, ANDERSON, GORE e HAHN (2003) mediram o MAOD em dezenove ciclistas antes e durante um programa de treinamento denominado "vivendo alto - treinando baixo" (living high-training low). Durante esse período, os atletas dormiam em média 8-10 h em uma casa que tinha a capacidade de induzir a hipóxia equivalente à altitude de $2.650 \mathrm{~m}$ acima do nível do mar, ao passo que o treinamento aeróbio era realizado na situação de normóxia (600 m acima do nível do mar). Naquela ocasião, foram constatadas diferenças significativas no MAOD a partir do quinto dia de treinamento $(p<0,05)$. Logo, esses pesquisadores sugeriram que a exposição à hipóxia pode induzir as alterações no músculo esquelético, tais como o aumento da capacidade de tamponamento celular.

Em contrapartida, LEVINE e STRAY-GUNDERSEN (1997) não detectaram quaisquer mudanças no MAOD em três grupos de atletas de várias modalidades esportivas após quatro semanas de participação dos programas de treinamento denominados de "vivendo alto - treinando baixo" (2.500 - $1.200 \mathrm{~m}$ acima do nível do mar), "vivendo alto - treinando alto" (2.500 - $2.500 \mathrm{~m}$ acima do nível do mar) ou "vivendo baixo - treinando baixo" (150 m acima do nível do mar) ( $p>0,05)$. Em linhas gerais, as diferenças estatísticas foram observadas principalmente nas variáveis relacionadas à aptidão aeróbia $\left({ }^{\mathrm{V}} \mathrm{O}_{2} \mathrm{max}\right.$, velocidade do $\mathrm{V}_{2} \mathrm{max}$, primeiro e segundo limiares ventilatórios e o tempo de prova de $5 \mathrm{~km}$ ) dos grupos que foram expostos à altitude, sobretudo o do programa "vivendo alto - treinando baixo". Além disso, nesses grupos foi detectado o aumento de aproximadamente $9 \%$ do volume de células vermelhas $(p<0,01$ ), o qual se correlacionou significativamente com 0 $\mathrm{V}_{2} \max (r=0,37 ; p=0,02)$. Nesse sentido, LEVINE e STRAY-GUNDERSEN (1997) propuseram que a exposição à altitude promove o aumento do desempenho aeróbio devido ao aprimoramento do sistema de transporte do oxigênio. Logo, esses achados 
não sustentam a hipótese supracitada do estudo de ROBERTS et al. (2003), a qual sugere que a capacidade de tamponamento muscular $\mathrm{e}$, conseqüentemente 0 MAOD, são aumentados nessas condições. Contudo, cabe ressaltar que no trabalho de LEVINE e STRAY-GUNDERSEN (1997) a demanda de $\mathrm{O}_{2}$ do exercício supramáximo foi estimada utilizando apenas dois testes submáximos com intensidades estabelecidas de forma absoluta (5-7 $\mathrm{mph}$ ), ao passo que são necessários uma quantidade superior de testes e com as intensidades relativas ao $\dot{\mathrm{W}}{ }_{2} \max (\mathrm{MEDB} \varnothing$ et al., 1988).

Por sua vez, MEZZANI et al. (2006) constataram que o MAOD de indivíduos com idade aproximada de 66 anos e portadores de insuficiência cardíaca crônica era estatisticamente menor que dos sujeitos assintomáticos com disfunção do ventrículo esquerdo e do grupo controle $(p<0,05)$. Além disso, esses autores mencionaram que os valores do MAOD dos portadores de insuficiência cardíaca crônica eram menores que os reportados na literatura científica para sujeitos adultos saudáveis. Embora ainda não seja muito bem compreendida a influência do processo de envelhecimento sobre o MAOD, MEZZANI et al. (2006) indicaram que os portadores de insuficiência cardíaca crônica também possuem atrofia muscular e, conseqüentemente, uma baixa capacidade de gerar tensão. Assim, as diferenças supracitadas foram atribuídas às possíveis modificações que ocorrem no músculo esquelético mediante a idade cronológica e a essa patologia do miocárdio. Adicionalmente, GASTIN (1994) indicou que o desempenho anaeróbio de indivíduos dos gêneros masculino e feminino atinge o seu ápice aos vinte anos de idade e que há uma redução de $6 \%$ por década a partir desse período.

Com o intuito de analisar indiretamente a validade do MAOD, alguns pesquisadores verificaram o seu nível de associação com outros testes anaeróbios. Por exemplo, SCOTT et al. (1991) constataram que o MAOD se correlacionava significativamente com os índices do teste de Wingate (potência de pico $r=0,69$; potência média $r=0,64 ; p<0,05)$, com o trabalho realizado na esteira com a intensidade que levou a exaustão entre 120 e 130 segundos $(r=0,62 ; p<0,05)$ e com o tempo na corrida de $300 \mathrm{~m}(r=-0,76 ; p<0,01)$. Dessa forma, esses pesquisadores sugeriram que esses testes são análogos na mensuração do desempenho anaeróbio e, conseqüentemente, que o MAOD é um método propício 
para avaliação da CAN. Contudo, SCOTT et al. (1991) sugeriram que, assim como em outros estudos, as correlações detectadas em seu trabalho não foram elevadas porque esses testes podem ser influenciados pela habilidade motora específica de cada tarefa empregada na avaliação anaeróbia. Adicionalmente, CALBET et al. (1997) também detectaram coeficientes de correlação de 0,64 e 0,62 entre o MAOD e a potencia média no teste de Wingate $(p<0,01)$, o qual teve a duração de trinta e 45 segundos, respectivamente.

MAXWELL e NIMMO (1996) analisaram o nível de associação do MAOD com um outro teste anaeróbio, o Teste Máximo de Corrida Anaeróbia (Maximal Anaerobic Running Test - MART). Curiosamente, MAXWELL e NIMMO (1996) adotaram o MAOD como o método de referência para analisar a validade do MART. Assim como os resultados supracitados, esses testes também se correlacionaram significativamente $(r=0,83 ; p<0,001)$. Com base nesse achado, esses autores sugeriram que o MART e o MAOD demonstraram ter uma associação muito próxima na estimativa da CAN. Adicionalmente, CHATAGNON et al. (2005) encontraram correlação significativa com a capacidade de trabalho anaeróbio do modelo de potência crítica, o qual foi estabelecido por um modelo hiperbólico com dois $(r=0,76$; $p<0,01)$ ou três parâmetros $(r=0,72 ; p<0,01)$.

Em suma, a validade do MAOD tem sido estabelecida a partir de diversas perspectivas. Evidentemente, a sua aceitação depende da capacidade desses estudos terem efetivamente analisado a CAN. Desconsiderando-se a dificuldade de se medir os marcadores fisiológicos que melhor representem o MAL e o MAA, bem como a inexistência de um método padrão ouro para a avaliação da CAN, parece que a maioria das evidências aponta que o MAOD é um método aceitável para a mensuração da CAN.

\subsection{Divergências sobre a validade do MAOD}

Diferentemente das evidências de validade supracitadas, os resultados de outros estudos que realizaram medidas da estrutura do músculo esquelético, das respostas fisiológicas e bioquímicas desse tecido, põem em dúvida a capacidade do MAOD em representar a demanda anaeróbia durante o exercício intenso. Por exemplo, ao mensurarem por meio de biópsia muscular o percentual do tipo de 
fibras, a capacidade de tamponamento muscular e a atividade das enzimas lactato desidrogenase, citrato sintase e 3-hidroxiacil-CoA desidrogenase dos membros inferiores de atletas de alto nível, BANSGBO et al. (1993) constataram que essas variáveis musculares não estavam inversamente associadas ao MAOD ( $p>0,05)$. Nesse sentido, esses pesquisadores sugeriram que o MAOD não é um método capaz de avaliar com precisão a energia transferida pelo metabolismo anaeróbio durante o esforço. Adicionalmente, assim como no estudo BANSGBO et al. (1993), a correlação entre o percentual das fibras de contração rápida e o MAOD obtida no estudo de GASTIN, COSTILL, LAWSON, KRZEMINSKI e McCONELL (1995) não era significativa $(r=-0,05 ; p>0,05)$.

Todavia, GASTIN (1994) chamou atenção para as limitações em se aceitar a biópsia muscular como método padrão ouro e, conseqüentemente, a sua aplicação para a validação de outras técnicas que se propõem mensurar a CAN. Segundo esse autor, a biópsia muscular proporciona informações acerca das mudanças metabólicas de apenas uma pequena amostra do músculo exercitado, portanto, essa técnica é altamente dependente da estimativa da massa muscular envolvida na tarefa analisada. Porém a estimativa da musculatura exercitada é subordinada ao tipo de exercício físico, além dela não ser igualmente envolvida durante todo o período de realização do esforço. Além disso, GASTIN (1994) indicou que possivelmente a contribuição anaeróbia pode ser subestimada por essa técnica, pois algumas mudanças metabólicas tais como, a ressíntese de CP e a oxidação do lactato, continuam ocorrendo entre o fim do exercício e a obtenção da amostra do tecido muscular. Logo, parece que a comparação do MAOD com variáveis obtidas de uma porção específica de apenas um músculo esquelético deve ser realizada com cautela.

Ao utilizarem o MAOD ou a somatória de constantes para estimarem as participações dos metabolismos anaeróbios lático $\left(3 \mathrm{ml}\right.$ de $\mathrm{O}_{2} \cdot \mathrm{mmol} / \mathrm{l}$ de acúmulo de lactato sangüíneo ${ }^{-1} \cdot \mathrm{kg}$ de peso corporal $\left.{ }^{-1}\right)$ e alático $\left(37 \mathrm{ml}\right.$ de $\mathrm{O}_{2} \cdot \mathrm{kg}$ massa muscular ativa $^{-1}$ ) durante as corridas de 100 e $200 \mathrm{~m}$ em pista, DUFFIELD, DAWSON e GOODMAN (2004) demonstraram que se pode obter valores percentuais distintos das contribuições dos sistemas bioenergéticos dependendo da metodologia empregada $(p<0,05)$. Por exemplo, na prova de $100 \mathrm{~m}$ rasos masculino foram 
obtidos os valores de $20,6 \pm 7,9 \%$ e $8,9 \pm 3,3 \%$ do metabolismo aeróbio e 79,4 \pm $7,9 \%$ e $91,1 \pm 3,3$ dos metabolismos anaeróbios determinados pelo MAOD ou pela somatória das constantes supracitadas, respectivamente. Porém, as medidas antropométricas empregadas na estimativa da massa muscular ativa e na participação do MAA podem ter superestimado a participação anaeróbia, pois SLONIGER et al. (1997) demonstraram que apenas $\cong 67 \%$ da massa muscular dos membros inferiores é ativada durante a corrida horizontal até a exaustão em esteira.

De forma similar, alguns trabalhos demonstraram que $O$ MAOD não se correlacionou significativamente com as [La] mensuradas após o exercício supramáximo (MEZZANI et al., 2006; PIZZA et al., 1996; MAXWELL \& NIMMO, 1996; BANGSBO et al. 1993; OLESEN, 1992). Em linhas gerais, a principal explicação para a dissociação entre essas duas variáveis é dada pelo fato das [La'] não representarem os valores reais da concentração desse metabólito no músculo exercitado. Porém, ressalta-se que o MAOD é utilizado para a mensuração da CAN, a qual inclui a contribuição da CP para a ressíntese anaeróbia da ATP. Logo, a ausência da exclusão do metabolismo alático do MAOD pode ter afetado os resultados desses estudos (GASTIN, 1994).

Em resumo, a maioria dos estudos que analisou transversal e longitudinalmente os efeitos do treinamento predominantemente anaeróbio no MAOD, bem como o seu nível de associação com outros testes anaeróbios e o seu comportamento mediante a duração do exercício e a hipóxia, indica que esse índice fisiológico é valido para a mensuração da CAN. Porém, poucos trabalhos investigaram a sua associação com variáveis bioquímicas musculares indicativas do metabolismo anaeróbio. Embora o MAOD seja baseado em princípios metodológicos que podem ser questionados (BANGSBO, 1996a, 1996b), ele tem sido considerado o método mais promissor para a avaliação da CAN, haja vista que as técnicas que se propõem mensurar o metabolismo anaeróbio durante o esforço físico possuem limitações mais acentuadas (GASTIN, 1994).

\subsection{Variáveis intervenientes no MAOD}

Ao analisar a influência do consumo prévio de cafeína sobre O MAOD, DOHERTY (1998) constatou que, ao consumir $5 \mathrm{mg}$ de cafeína por quilograma de 
peso corporal uma hora antes do exercício supramáximo, o grupo formado por atletas de diversas modalidades esportivas teve um aumento significante do MAOD de aproximadamente 10\%, quando comparado ao consumo de placebo. Segundo DOHERTY (1998), a cafeína estimularia a liberação de epinefrina pela medula adrenal, a qual seria capaz de aumentar a glicólise anaeróbia no músculo esquelético e, conseqüentemente, o MAOD.

Esse achado foi parcialmente corroborado em um trabalho posterior (BELL et al., 2001). Porém, além da mudança proporcionada pelo consumo prévio da cafeína, BELL et al. (2001) tinham interesse em verificar um possível efeito aditivo proporcionado pelo consumo de efedrina. Para tanto, esses pesquisadores submeteram dois grupos de sujeitos fisicamente ativos ao teste de Wingate $(n=16)$ ou ao MAOD ( $\mathrm{n}=8$ ), após consumirem o placebo, ou a cafeína $\left(5 \mathrm{mg} \cdot \mathrm{kg}^{-1}\right)$, ou a efedrina $\left(1 \mathrm{mg} \cdot \mathrm{kg}^{-1}\right)$ ou a cafeína associada à efedrina. Ao se comparar com a ingestão do placebo, em todas as situações em que foram consumidas a cafeína ou a efedrina, constatou-se um aumento de aproximadamente 7\% do MAOD ( $p<0,05)$. Contudo, não foi detectada diferença no MAOD entre os valores gerados nas situações em que houve o consumo da cafeína. Além disso, constatou-se que a concentração da epinefrina plasmática era maior quando houve o consumo de cafeína, bem como o aumento da dopamina plasmática quando houve o consumo de efedrina $(p<0,05)$. Ao assumirem que a epinefrina é capaz de estimular a glicólise anaeróbia e que a dopamina é um importante neurotransmissor do sistema nervoso central, esses pesquisadores sugeriram que a mudança detectada no MAOD com o consumo da cafeína é devido às mudanças no metabolismo do músculo esquelético, ao passo que com o consumo da efedrina é resultado do aumento da condução neural.

Ao presumirem que a suplementação de creatina monohidratada também poderia ter efeito ergogênico na CAN, JACOBS et al. (1997) compararam os valores do MAOD de indivíduos que consumiram essa substância (20 g/dia) ou o placebo por um período de cinco dias. Foi constatado que o grupo que consumiu a creatina monohidratada teve um aumento significativo de aproximadamente 10\% do MAOD quando comparado ao grupo controle $(p<0,05)$. Além disso, essa diferença ainda se manteve após sete dias do término da suplementação $(p<0,05)$. Segundo esses 
autores, é provável que o aumento da concentração de creatina no músculo esquelético induzido pela suplementação seria capaz de aumentar a quantidade de ATP ressintetisada anaerobiamente durante o exercício supramáximo. Apesar de terse corroborada a hipótese previamente estabelecida por JACOBS et al. (1997), os mecanismos que levaram a essa mudança ainda são incertos, haja vista que nessa investigação não houve a mensuração de metabólitos do músculo esquelético.

Em relação à influência da massa muscular no MAOD, MEDBØ e BURGERS (1990) demonstraram que, ao se utilizar a inclinação de $10 \%$ durante a corrida em esteira, o valor do MAOD era $24 \%$ maior quando comparado com a inclinação de $5 \%$ ( $p=0,005)$. BANGSBO et al. (1993) confirmaram essa hipótese ao demonstrarem que o MAOD de remadores era estaticamente maior no remoergômetro ( $\cong 26 \%$ ) quando comparado com a esteira rolante $(p<0,05)$.

De forma similar, OLESEN (1992) constatou que o MAOD de atletas e do grupo controle eram aproximadamente 88-92\% maior durante a corrida na esteira com a inclinação entre $15-20 \%$ quando comparado à inclinação de $1 \%(p \leq 0,05)$. Além disso, as diferenças entre esses dois grupos só foi significativa a partir da inclinação de $15 \%$ ( $p \leq 0,05)$. Supostamente, essas mudanças ocorreram por causa do aumento da massa muscular recrutada e da diminuição da eficiência nas inclinações mais elevadas. Segundo esse pesquisador, a redução da eficiência na corrida durante a subida é devido à queda na proporção entre as ações excêntricas e concêntricas realizadas nessa situação, a qual diminuiria a capacidade do músculo esquelético de armazenar energia elástica. No entanto, naquela ocasião OLESEN (1992) não realizou medidas que permitissem sustentar essa relação causal.

Com o propósito de testar uma dessas hipóteses, SLONIGER et al. (1997) mensuraram a quantidade de massa muscular por meio de imagem de ressonância magnética e o MAOD durante a corrida horizontal ou com a inclinação de $10 \%$ na esteira. O principal achado desse estudo foi que durante a corrida na subida, além do MAOD (21\%), a massa muscular ativa era estatisticamente maior quando comparada com a corrida na horizontal (73\% e 67\%; $p<0,05$; respectivamente). Adicionalmente, foi constatada uma correlação moderada, mas significativa, entre a massa muscular envolvida no exercício e os valores do MAOD ( $r=0,63 ; p<0,05)$. Assim, esses resultados indicaram que, apesar da relação existente entre as essas duas variáveis, 
o aumento do MAOD na subida pode ser apenas parcialmente explicado pelo aumento da massa muscular envolvida na tarefa $\left(r^{2}=40 \%\right)$.

Ao utilizarem a fragmentação do nado crawl, OGITA, HARA e TABATA (1996) também detectaram a influência da massa muscular no MAOD. Para tanto, foram determinadas as frações do MAOD que eram requeridas durante a braçada ou a pernada do referido nado. Quando comparado ao nado completo, foi observada uma diferença significativa do MAOD utilizando somente a braçada $(78,2 \%$; $p<0,05)$, diferentemente da situação em que se empregou somente a pernada $(91,0 \% ; p>$ 0,05). Por outro lado, o MAOD do nado completo era estatisticamente menor que a somatória do MAOD da braçada com o da pernada (64\%; $p<0,05)$. Dessa forma, além de corroborarem os achados de outros estudos que indicaram a influência da massa muscular ativa sobre o MAOD, esses achados sugerem que os músculos responsáveis pela estabilização (por exemplo, os abdominais) e pela respiração durante a fragmentação do nado, podem ter sido os principais responsáveis pelas diferenças detectadas ao se comparar com o nado completo.

Por outro lado, o MAOD nem sempre tem se demonstrado diretamente relacionado ao tamanho da massa muscular envolvida no exercício físico. WEBER e SCHNEIDER (2002) evidenciaram que, mesmo após a correção pela massa muscular mensurada mediante a técnica de dual-energy $X$-ray absorptiometry (DEXA), os homens ainda possuíam o MAOD estatisticamente maior (17\%) que as mulheres ( $p=0,035)$. Além disso, não foi constatada diferença significativa nas concentrações de epinefrina ou norepinefrina entre esses dois grupos após a execução do teste supramáximo utilizado para mensurar o MAOD $(p=0,43)$. Portanto, esses pesquisadores sugeriam que as mudanças bioquímicas induzidas pelo esforço físico, tais como, o aumento das concentrações de fosfatos inorgânicos, do cálcio e da ADP intracelulares, são as principais responsáveis pelas diferenças do MAOD detectadas entre os sexos.

Similarmente, PIZZA et al. (1996) constataram que os atletas submetidos ao treinamento de força (musculação; 6-12 repetições; $12-20$ séries; com os exercícios de agachamento, leg press, flexão e extensão de joelhos), também possuíam o MAOD relativo à massa muscular dos membros inferiores, estatisticamente superior ao dos atletas de resistência e ao grupo controle $(p<0,05)$. Portanto, sugeriu-se que 
os ajustes metabólicos crônicos promovidos pelo treinamento de força, como por exemplo, o aumento da quantidade de enzimas do sistema glicolítico e dos fosfagênios (ATP e CP), são mais importantes na determinação do MAOD que a massa muscular envolvida na tarefa.

NAUGHTON, CARLSON, BUTTIFANT, SELIG, MELDRUM, McKENNA e SNOW (1997) sugeririam que as diferenças detectadas no MAOD encontradas em seu estudo foram devidas ao gênero. Naquela ocasião, esses pesquisadores compararam transversalmente o MAOD de atletas adolescentes do sexo masculino e feminino que possuíam a idade cronológica e os valores da escala de Tanner semelhantes. Entre os achados desse estudo, foi constatado que os adolescentes possuíam o MAOD absoluto e relativo ao peso corporal estatisticamente superior ao das adolescentes $(p<0,05)$. Além disso, os meninos também apresentaram maiores valores das [La'] e das concentrações plasmáticas de amônia quando comparados aos das meninas $(p<0,05)$. Dessa forma, assumindo-se que esses metabólitos são produtos exclusivos do metabolismo energético muscular, NAUGHTON et al. (1997) sugeriram que a degradação dos estoques da ATP e a utilização da glicólise não são similares entre os sexos, resultando nas desigualdades supracitadas do MAOD.

Por sua vez, FINN, WOOD e MARSDEN (2003) analisaram o efeito do aumento da temperatura ambiente (de 21,8 $\pm 0,5$ para $29,6 \pm 0,5^{\circ} \mathrm{C}$ ) sobre o MAOD de atletas aclimatados ao calor. A hipótese estabelecida a priori era que esses indivíduos possuíam uma adaptação fisiológica ao aumento da temperatura, a qual não resultaria no aumento do redirecionamento do fluxo sanguíneo para a pele e, conseqüentemente, seria mantido o mesmo valor da CAN. De fato, além de a temperatura retal não ter sido alterada sob essas condições $(37,4 \pm 0,2$ e 37,3 \pm 0,2 $\left.{ }^{\circ} \mathrm{C} ; \mathrm{p}=0,82\right)$, também foi constatado que tanto o $\operatorname{MAOD}(\mathrm{p}=0,58)$ como tempo até a exaustão no teste supramáximo utilizado para determinar esse índice fisiológico ( $p=$ 0,56 ) não eram estatisticamente modificados com a mudança da temperatura ambiente $(p>0,05)$. Contudo, cabe ressaltar que possivelmente o aumento da temperatura ambiente foi aquém do necessário para se verificar o efeito hipertérmico sobre as variáveis analisadas e que nesse estudo não houve a inclusão de um grupo controle.

HARGREAVES, FINN, WITHERS, HALBERT, SCROOP, MACKAY, SNOW e 
CAREY (1997) mensuraram o MAOD de ciclistas treinados com diferentes concentrações prévias de glicogênio muscular, as quais foram manipuladas pela quantidade de carboidrato contido na dieta (apenas $25 \%$ ) associada à realização de exercício físico vigoroso prévio (60 minutos de ciclismo estacionário a $70 \%$ do $\dot{\mathrm{V}}_{2}$ max e seis esforços máximos de $30 \mathrm{~s}$ ). Apesar de constatarem mudanças significativas na disponibilidade desse substrato energético (com depleção $=364 \pm$ $58 \mathrm{mmol} \cdot \mathrm{kg}^{-1}$ de músculo seco; sem depleção = $578 \pm 55 \mathrm{mmol} \cdot \mathrm{kg}^{-1}$ de músculo seco; $p<0,001)$, os valores do MAOD não foram estatisticamente modificados ( $p>0,05)$. Além disso, foi constatado que a potência em $1 \mathrm{~s}(1185 \pm 50 \mathrm{~W}$ e $1179 \pm 48 \mathrm{~W}$ com e sem depleção, respectivamente) e a potência média ( $547 \pm 5 \mathrm{~W}$ e $554 \pm 8 \mathrm{~W}$ com e sem depleção, respectivamente) durante um esforço máximo de $75 \mathrm{~s}$ também se mantiveram inalteradas $(p>0,05)$. Nesse sentido, esses pesquisadores sugeriram que o desempenho anaeróbio e, conseqüentemente, o MAOD não é dependente da disponibilidade de glicogênio muscular.

Com o intuito de analisar a possível influência do horário do dia sobre a CAN, HILL, LEIFERMAN, LYNCH, DANGELMAIER e BURT (1998) mensuraram o MAOD de sujeitos fisicamente ativos antes (07-08 h) e após (15-16 h) o meio-dia. A amostra desse trabalho foi composta por dois grupos, os quais foram submetidos a cinco semanas de treinamento predominantemente anaeróbio nos horários supracitados. $O$ grupo matutino não apresentou nenhuma alteração estatística no MAOD quando avaliado nas duas situações, ao passo que o grupo vespertino teve um aumento significativo (13\%) apenas no período após o meio-dia $(p=0,03)$. Dessa forma, sugeriu-se que a CAN e, consequentemente, o MAOD sofrem o efeito do horário do dia em que os sujeitos são submetidos ao treinamento físico, em especial ao grupo que se exercita no período vespertino. No entanto, ressalta-se que, além de não adquirirem informações acerca dessa possível interferência do horário do dia, HILL et al. (1998) não mensuraram o MAOD desses indivíduos antes do programa de treinamento, logo, esses fatos resultam no questionamento da relação causal supracitada. 


\subsection{Reprodutibilidade do MAOD}

Alguns trabalhos utilizaram tanto o coeficiente de correlação intra-classe (MEZZANI et al., 2006; WEBER \& SCHNEIDER, 2001; DOHERTY et al., 2000) como a plotagem de Bland e Altman (MEZZANI et al., 2006; DOHERTY et al., 2000) para investigar a reprodutibilidade do MAOD. De acordo com os resultados dos estudos reunidos por GASTIN (1994), o MAOD tem-se demonstrado um método reprodutível, com coeficientes de reprodutibilidade em torno de 0,98. JACOBS et al. (1997) detectaram coeficiente de correlação intra-classe de 0,97 do MAOD mensurado na intensidade de $120 \%$ do $\mathrm{V}_{2}$ pico em cicloergômetro. Mais recentemente, WEBER e SCHNEIDER (2001) demonstraram que o MAOD de homens e mulheres, estabelecido com intensidades de 110 e $120 \%$ do VัO $_{2}$ pico em cicloergômetro, apresentou o coeficiente de correlação intra-classe entre 0,95 e 0,97 ( $p<0,001)$, respectivamente.

Contudo, DOHERTY et al. (2000) questionaram a afirmação que o MAOD é um método reprodutível, pois segundo esses autores, a maior parte dos trabalhos utilizou análises estatísticas limitadas. Por isso, DOHERTY et al. (2000) empregaram tanto o coeficiente de correlação intraclasse como o limite de concordância (limits of agreement) de $95 \%$ entre três mensurações do MAOD feitas na intensidade de $125 \%$ do $\dot{\mathrm{W}} \mathrm{O}_{2}$ pico em esteira. Como nos demais estudos, o coeficiente de correlação intraclasse foi elevado $(0,91)$, porém o limite de concordância foi de $\pm 15,1$ $\mathrm{ml} \cdot \mathrm{kg}^{-1} \cdot \mathrm{min}^{-1}$ (teste $1=69,0 \pm 13,1$; teste $2=71,4 \pm 12,5$ e teste $3=70,4 \pm 15,0$ $\left.\mathrm{ml} \cdot \mathrm{kg}^{-1} \cdot \mathrm{min}^{-1}\right)$. Portanto, esses pesquisadores indicaram que a reprodutibilidade do teste em questão pode ser dependente da análise estatística empregada.

MEZZANI et al. (2006) determinaram o MAOD em cicloergômetro com intensidades que levaram à exaustão entre 1-3 min e constataram que ele é um teste reprodutível, tanto por meio do coeficiente de correlação intra-classe $(0,98)$ como pela inspeção visual da plotagem de Bland e Altman (coeficiente de variação = 8\%). Contudo, a comparação desses resultados com os do estudo de DOHERTY et al. (2000) é de difícil realização, haja vista que os sujeitos da amostra e o teste supramáximo tinham características distintas. Adicionalmente, a dificuldade de se medir o tempo até a exaustão no teste supramáximo e a falta de motivação para se manter exercitando em intensidades elevadas, talvez sejam fatores adicionais que 
comprometem a reprodutibilidade do MAOD (GASTIN, 1994). Apesar disso, MEDB $\varnothing$ et al. (1988) estimaram que somente $4 \%$ da variância do MAOD determinado em testes com menores durações (aproximadamente $120 \mathrm{~s}$ ) ocorrem por causa de erro metodológico.

\subsection{Ajustes metodológicos aplicados ao MAOD}

Como anteriormente descrito, o MAOD é estabelecido pela subtração do $\mathrm{VO}_{2}$ acumulado da demanda de $\mathrm{VO}_{2}$ estimada para o exercício supramáximo. O primeiro índice pode ser facilmente acessado pela mensuração do $\dot{\mathrm{V}}_{2}$, ao passo que o segundo é determinado mediante a projeção da relação $\mathrm{V}_{2}$-intensidade de vários testes submáximos. Portanto, uma das principais desvantagens de se utilizar o MAOD como medida da CAN, é a necessidade da elevada quantidade de sessões de coleta de dados para se compor um determinado desenho experimental (GARDNER, OSBORN, D'AURIA \& JENKINS, 2003). Nesse sentido, é possível se observar uma grande variação nas adaptações realizadas nos princípios metodológicos inicialmente formulados e propostos por MEDB $\varnothing$ et al. (1988).

Dessa forma, mediante a essas reformulações do método tradicional apresentado por MEDBØ et al. (1988), surge invariavelmente a seguinte questão: qual é o impacto desses ajustes nos resultados do MAOD? Por exemplo, a equação de regressão linear $\dot{\mathrm{V}}_{2}$-intensidade tem sido desenvolvida com uma quantidade de testes submáximos que varia entre dois (LEVINE \& STRAY-GUNDERSEN, 1997; MAXWELL \& NIMMO, 1996), cinco (CALBET et al., 1997), 10 (WEBER \& SCHNEIDER, 2002), 20 (MEDB $\varnothing$ et al. 1988) ou 35 (MEDB $\varnothing$ \& TABATA, 1989). Porém, ao se considerar que o coeficiente angular de uma reta gerada a partir dessa equação de regressão é dependente do número total de pontos empregados na modelagem (GREEN, 1995), é plausível pressupor que a demanda de $\mathrm{O}_{2}$ empregada no cálculo do MAOD também possa ser afetada pela quantidade de testes submáximos realizados. A tabela 3 apresenta um breve resumo dos ajustes realizados nos princípios metodológicos e os valores do déficit acumulado de oxigênio reportado nos estudos revisados.

No intuito de estabelecer o número mínimo de testes necessários, MEDB $\varnothing$ et al. (1988) mensuraram $\mathrm{O} \mathrm{VO}_{2}$ em vinte testes com intensidades que variaram entre 
$35-100 \% \quad \dot{\mathrm{VO}}_{2} \max$. As intensidades mais baixas $\left(35-40 \% \quad \dot{\mathrm{V}}_{2} \max \right)$ foram posteriormete eliminadas após inspeção visual com base nos seguintes critérios: 1) quando o valor do intercepto $Y$ era muito maior que o $\mathrm{V}_{2}$ de repouso, 2) quando havia grandes desvios na linearidade da equação de regressão, as quais chegaram a reduzir o déficit em aproximadamente $10 \%$. Subseqüentemente, eles utilizaram os seguintes procedimentos para identificar o número mínimo de testes submáximos: a) inicialmente, a equação de regressão foi gerada com apenas dois valores, b) o MAOD foi calculado; c) foram incluídos outros valores; d) as etapas "a" e "b" foram realizadas até a convergência aos valores obtidos com 20 testes. Dessa forma, constatou-se a necessidade de um número mínimo 10-15 testes. Com base nesses resultados, MEDB $\varnothing$ et al. (1988) sugeriram que os estudos futuros deveriam utilizar o valor comum de $5 \mathrm{ml} \cdot \mathrm{kg}^{-1} \cdot \mathrm{min}^{-1}$ para 0 intercepto $Y$ e o mínimo de dez testes submáximos (denominado de procedimento 3).

BUCK e NAUGHTON (1999a) também investigaram a influência da redução da quantidade de testes submáximos sobre o cálculo do MAOD, tendo como referência a utilização de dez cargas, como sugerido por MEDB $\varnothing$ et al. (1988). Os principais valores absolutos das variações máxima e mínima do MAOD estão presentes na tabela 4. Em suma, verificou-se que a remoção dos testes submáximos utilizados na equação de regressão aumentava progressivamente a diferença do MAOD. Por isso, BUCK e NAUGHTON (1999a) sugeriram que são necessários pelo menos dez testes submáximos para a mensuração do MAOD. 
TABELA 3. Ajustes metodológicos e valores do déficit acumulado de oxigênio.

\begin{tabular}{|c|c|c|c|c|c|c|c|}
\hline Estudo & Exercício & Sujeitos & $\begin{array}{c}\text { Quantidade de } \\
\text { testes de cargas } \\
\text { constantes }\end{array}$ & $\begin{array}{l}\text { Intensidades dos } \\
\text { testes de cargas } \\
\text { constantes }\end{array}$ & $\begin{array}{c}\text { Intensidades dos } \\
\text { testes } \\
\text { supramáximos }\end{array}$ & $\begin{array}{l}\text { Durações dos } \\
\text { testes } \\
\text { supramáximo (s) }\end{array}$ & $\begin{array}{c}\text { MAOD } \\
\left(\text { litros de } \mathrm{O}_{2}\right)\end{array}$ \\
\hline $\begin{array}{l}\text { MEZZANI et al. } \\
(2006)^{a}\end{array}$ & Bicicleta & $\begin{array}{l}\text { IC }(n=10) \\
D V(n=5) \\
C(n=5)\end{array}$ & 3 & $\begin{array}{l}\text { 30-90\% do } \\
\text { Limiar aeróbio }\end{array}$ & $\begin{array}{l}135 \pm 17 \% \\
118 \pm 12 \% \\
102 \pm 10 \% \\
\text { do } \dot{\mathrm{V}}_{2} \max \end{array}$ & $\begin{array}{c}60-120 \\
120-180 \\
>180\end{array}$ & $\begin{array}{l}1,04 \pm 0,31 \\
1,72 \pm 1,08 \\
2,27 \pm 0,87\end{array}$ \\
\hline $\begin{array}{l}\text { FINN et al. } \\
(2003)\end{array}$ & Bicicleta & CAC $(n=6)$ & 6 & $75-225 \mathrm{~W}$ & $\begin{array}{l}120 \% \text { do } \\
\text { VO }_{2} \max \end{array}$ & $\begin{array}{l}175 \pm 19^{\square} \\
170 \pm 18^{\circ}\end{array}$ & $\begin{array}{l}3,30 \pm 0,90^{\circ} \\
3,50 \pm 1,10^{\prime}\end{array}$ \\
\hline $\begin{array}{l}\text { GARDNER et } \\
\text { al. (2003) }\end{array}$ & Bicicleta & $C L(n=10)$ & 5 & $100-200 \mathrm{~W}$ & $\begin{array}{l}115 \% \text { do } \\
\dot{\mathrm{V}}_{2} \max \end{array}$ & $112,7 \pm 22,9$ & $\begin{array}{l}3,80 \pm 0,70^{\ddagger} \\
3,22 \pm 0,66^{*}\end{array}$ \\
\hline $\begin{array}{l}\text { WEBER } \\
\text { SCHNEIDER } \\
(2002)\end{array}$ & Bicicleta & $\mathrm{FAT}_{\mathrm{M}}(\mathrm{n}=7)$ & 6 & $\begin{array}{l}20-75 \% \text { do } \\
\dot{\mathrm{V}}_{2} \max \end{array}$ & $\begin{array}{l}120 \% \text { do } \\
\mathrm{V}_{2} \max \end{array}$ & $\begin{array}{l}175 \pm 16^{\circ} \\
303 \pm 42^{\text {\# }} \\
166 \pm 14^{\circ} \\
259 \pm 18^{\text {\# }}\end{array}$ & $\begin{array}{l}3,93 \pm 0,22^{\circ} \\
4,82 \pm 0,46^{\sharp}\end{array}$ \\
\hline
\end{tabular}


TABELA 3. Ajustes metodológicos e valores do déficit acumulado de oxigênio (continuação).

\begin{tabular}{|c|c|c|c|c|c|c|c|}
\hline Estudo & Exercício & Sujeitos & $\begin{array}{l}\text { Quantidade de } \\
\text { testes de cargas } \\
\text { constantes }\end{array}$ & $\begin{array}{l}\text { Intensidades dos } \\
\text { testes de cargas } \\
\text { constantes }\end{array}$ & $\begin{array}{l}\text { Intensidades dos } \\
\text { testes } \\
\text { supramáximos }\end{array}$ & $\begin{array}{l}\text { Durações dos } \\
\text { testes } \\
\text { supramáximo (s) }\end{array}$ & $\begin{array}{c}\text { MAOD } \\
\left(\text { litros de } \mathrm{O}_{2} \text { ) }\right.\end{array}$ \\
\hline $\begin{array}{l}\text { WEBER e } \\
\text { SCHNEIDER } \\
(2000)\end{array}$ & Bicicleta & $\begin{array}{l}\operatorname{FAT}_{M}(n=10) \\
\operatorname{FAT}_{F}(n=10)\end{array}$ & 6 & $\begin{array}{l}20-75 \% \text { do } \\
\mathrm{V}^{\circ} \mathrm{O}_{2} \max \end{array}$ & $\begin{array}{l}120 \% \text { do } \\
\dot{\mathrm{V}} \mathrm{O}_{2} \max \end{array}$ & $\begin{array}{l}161 \pm 16 \\
140 \pm 05\end{array}$ & $\begin{array}{l}3,60 \pm 0,20 \\
2,40 \pm 0,20\end{array}$ \\
\hline $\begin{array}{l}\text { WOOLFORD et } \\
\text { al. (1999) }\end{array}$ & Bicicleta & $C L F=(n=10)$ & 3 & $\begin{array}{l}31-90 \% \text { do } \\
\dot{\mathrm{V}}_{2} \mathrm{max}\end{array}$ & $482,1 \pm 24,5 \mathrm{~W}$ & 120 & $\begin{array}{l}2,79 \pm 0,43^{\prime \prime} \\
4,11 \pm 0,78^{\S} \\
4,06 \pm 0,84^{థ}\end{array}$ \\
\hline $\begin{array}{l}\text { DOHERTY } \\
(1998)\end{array}$ & Esteira & $A(n=9)$ & 3 & $\begin{array}{l}80-90 \% \text { do } \\
\dot{\mathrm{V} O} \mathrm{O}_{2} \max \end{array}$ & $\begin{array}{l}125 \% \text { do } \\
\dot{\mathrm{V}} \mathrm{O}_{2} \max \end{array}$ & $\begin{array}{c}181,0 \pm 9,4^{\circ} \\
208,2 \pm 13,6^{\ddagger}\end{array}$ & $\begin{array}{l}5,30 \pm 0,41^{\circ} \\
5,89 \pm 0,43^{\ddagger}\end{array}$ \\
\hline $\begin{array}{l}\text { HARGREAVES } \\
\text { et al. (1997) }\end{array}$ & Bicicleta & $\operatorname{CLV}(\mathrm{n}=9)$ & 4 & $100-250 \mathrm{~W}$ & NR & 75 & $4,30 \pm 0,18^{\circ}$ \\
\hline $\begin{array}{l}\text { CALBET et al. } \\
\text { (1997) }\end{array}$ & Bicicleta & $\mathrm{FAT}_{M}(\mathrm{n}=19)$ & $5-7$ & $\begin{array}{l}60-90 \% \text { do } \\
\mathrm{V}_{2} \max \end{array}$ & $\begin{array}{l}118 \% \text { do } \\
\dot{\mathrm{V}} \mathrm{O}_{2} \max \end{array}$ & NR & $5,02 \pm 0,27$ \\
\hline $\begin{array}{l}\text { JACOBS et al. } \\
(1997)\end{array}$ & Bicicleta & $\begin{array}{l}\operatorname{FAT}_{M}(n=14) \\
\operatorname{FAT}_{M}(n=12)\end{array}$ & 4 & $\begin{array}{l}50-85 \% \text { do } \\
\dot{\mathrm{VO}}{ }_{2} \max \end{array}$ & $\begin{array}{l}125 \% \text { do } \\
\dot{\mathrm{V}} \mathrm{O}_{2} \max \end{array}$ & $\begin{array}{l}130,9 \pm 6,7^{\circ} \\
140,6 \pm 7,1^{\ominus}\end{array}$ & $\begin{array}{l}4,02 \pm 0,37^{\circ} \\
4,40 \pm 0,34^{\ominus}\end{array}$ \\
\hline
\end{tabular}


TABELA 3. Ajustes metodológicos e valores do déficit acumulado de oxigênio (continuação).

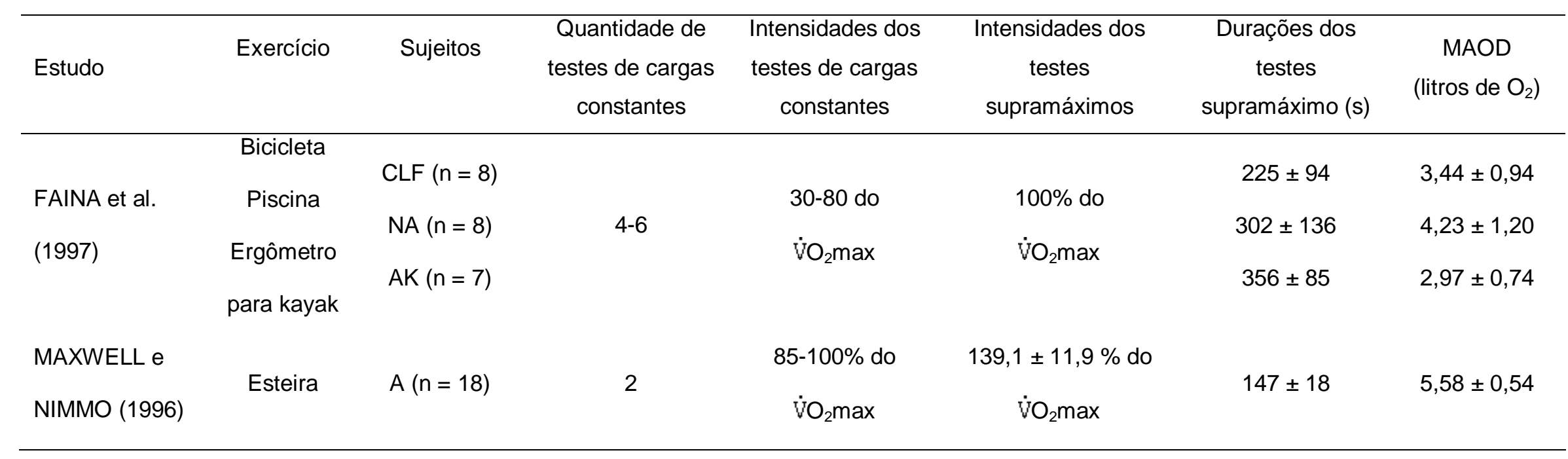

${ }^{\mathrm{a}}=\mathrm{o}$ valor reportado refere-se apenas aos testes descriminados na coluna "Intensidades dos testes supramáximos"; ${ }^{\square} \mathrm{e}$ " $=$ situação controle $\left(\cong 21,8^{\circ} \mathrm{C}\right)$ e calor $\left(\cong 29,6^{\circ} \mathrm{C}\right)$, respectivamente; ${ }^{\ddagger},{ }^{*}=$ calculado a partir de método tradicional modificado e por um método alternativo, respectivamente; ${ }^{\sharp}=$ após oito semanas de treinamento anaeróbio; ",,$_{,}^{\Phi}=$ valores estabelecidos por testes submáximos com a cadência do pedal entre 90-100, 120-130 e 90-130 rpm, respectivamente; ${ }^{\circ}=$ situação controle; ${ }^{\ddagger}$ = após o consumo de $5 \mathrm{mg} \cdot \mathrm{kg}^{-1}$ de cafeína; ${ }^{\theta}=$ após cinco dias de suplementação de creatina monohidratada (20 g/dia); $\mathrm{A}=$ atletas de várias modalidades esportivas; $\mathrm{AK}=$ atletas de kayak; $\mathrm{C}=$ controle; $\mathrm{CAC}=$ ciclistas aclimatados ao calor; $\mathrm{CL}=\mathrm{ciclistas} ; \mathrm{CLF}=\mathrm{ciclistas}$ participantes de diferentes provas; $C L V=$ ciclistas velocistas; $D V=$ sujeitos assintomáticos da disfunção do ventrículo esquerdo; FAT = sujeitos fisicamente ativos, onde $O_{\mathrm{M}}$ e $\mathrm{O}_{\mathrm{F}}$ denotam os sexos masculino e feminino, respectivamente; IC = sujeitos portadores de insuficiência cardíaca crônica; $N R=$ não reportado; $\mathrm{W}_{2} \max =$ consumo máximo de oxigênio. 
Por sua vez, GARDNER et al. (2003) não obtiveram sucesso ao comparar os valores do MAOD determinado com cinco testes submáximos com um novo método, o qual era constituído por um teste progressivo submáximo com cinco estágios, tendo o início com a carga de $100 \mathrm{~W}$ e o incremento de $25 \mathrm{~W}$ a cada 3 min. A média aritmética do $\dot{\mathrm{V}}_{2}$ nos dois minutos finais de cada estágio dos protocolos supracitados foi utilizada na equação de regressão linear empregada no cálculo do MAOD. Contudo, foi constatada uma diferença significativa de $\cong 15 \%$ entre esses dois métodos $(p=0,019)$. Segundo esses autores, um dos motivos para essa desigualdade foi a alteração detectada na equação de regressão, em virtude do elevado $\mathrm{v}_{2}$ nos estágios iniciais do método alternativo quando comparado ao método tradicional modificado.

TABELA 4. Diferenças absolutas do MAOD ao se comparar com os valores gerados por dez testes submáximos (adaptado de BUCK e NAUGHTON, 1999a).

\begin{tabular}{|c|c|c|}
\hline $\begin{array}{l}\text { Número de testes utilizados na } \\
\text { construção da regressão }\end{array}$ & $\begin{array}{c}\text { Mínimo } \\
\left(\mathrm{ml} \text { de } \mathrm{O}_{2} \cdot \mathrm{kg}^{-1}\right)\end{array}$ & $\begin{array}{c}\text { Máximo } \\
\left(\mathrm{ml} \mathrm{de} \mathrm{O}_{2} \cdot \mathrm{kg}^{-1}\right)\end{array}$ \\
\hline 9 & $0,2 \pm 0,2$ & $1,9 \pm 1,3$ \\
\hline 8 & $0,7 \pm 0,7$ & $3,7 \pm 2,8$ \\
\hline 7 & $0,9 \pm 0,9$ & $8,2 \pm 8,1$ \\
\hline 6 & $1,7 \pm 2,1$ & $13,1 \pm 5,2$ \\
\hline 5 & $1,5 \pm 0,9$ & $20,9 \pm 15,6$ \\
\hline 4 & $2,3 \pm 1,3$ & $23,8 \pm 16,8$ \\
\hline 3 & $2,7 \pm 1,5$ & $41,8 \pm 21,0$ \\
\hline 2 & $3,3 \pm 2,2$ & $34,4 \pm 15,8$ \\
\hline
\end{tabular}

Objetivando propor um método capaz de determinar o MAOD por meio de um esforço intenso, mas sem o estabelecimento prévio da carga, GASTIN et al. (1995) compararam os valores desse índice mensurado pelo método tradicional (110\% Wं $\mathrm{O}_{2} \max$ ) e um teste supramáximo com a resistência variável e com a duração de 90 s. Entre os principais achados desse estudo, foi verificado que a diferença constatada entre essas duas metodologias $\left(4,7 \pm 1,1 \mathrm{ml} \cdot \mathrm{kg}^{-1} \cdot \mathrm{min}^{-1}\right)$ não era 
estatisticamente significativa $(p>0,05)$. Além de demonstrar que a metodologia proposta era é eficaz na determinação do MAOD, esse achado corrobora o fato que o intervalo de tempo necessário para a mensuração da CAN deve ser superior a 1 min (MEDB $\varnothing$ et al. 1988; MEDB $\varnothing$ \& TABATA, 1989).

HILL (1996) também propôs um método alternativo que emprega modelagem matemática para eliminar a necessidade de se realizar um número demasiado de testes submáximos. Para tanto, é necessário assumir os mesmos pressupostos teóricos do método tradicional, tais como, o déficit máximo de $\mathrm{O}_{2}$ é independente da duração do exercício supramáximo; a eficiência não sofre influência da intensidade do esforço físico, e a demanda de $\mathrm{O}_{2}$ pode ser estabelecida em função da intensidade e do tempo do exercício. Em linhas gerais, cada sujeito deve realizar quatro testes de cargas constantes que levam a exaustão em aproximadamente 90 , 210, 360 e 600 s. Como durante esses testes o $\dot{\mathrm{V}}_{2}$, a potência externa e o tempo são mensurados, o MAOD pode ser determinado pela subtração do $\mathrm{V}_{2}$ no exercício supramáximo e a demanda total de $\mathrm{O}_{2}$ (equação 13). Além da forte correlação detectada entre o método padrão e o método proposto $(r=0,96 ; p<0,01)$, constatouse também que a diferença entre eles não era estatisticamente significativa $(p>$ 0,05). Embora esses resultados permitissem a HILL (1996) indicar que, além de válido, o método proposto teria potenciais vantagens em virtude de sua aplicabilidade, ressalta-se que naquela ocasião foram utilizados os valores do $\mathrm{V}_{2}$ de apenas quatro testes submáximos na equação de regressão que gerou o MAOD pelo método padrão.

$\mathrm{DTO}_{2}=\mathrm{DO}_{2}\left(\mathrm{ml} \cdot \mathrm{min}^{-1} \cdot \mathrm{W}^{-1}\right) \cdot \mathrm{PE}(\mathrm{W}) \cdot \mathrm{TE}(\mathrm{min})$ EQUAÇÃO 5

Onde $\mathrm{DTO}_{2}=$ demanda total de $\mathrm{O}_{2} ; \mathrm{DO}_{2}=$ demanda de $\mathrm{O}_{2} ; \mathrm{PE}=$ potência externa; $\mathrm{TE}=$ tempo até a exaustão.

No entanto, a principal crítica metodológica sobre o MAOD é assumir que a demanda energética durante o exercício supramáximo pode ser estabelecida pela extrapolação da relação ฟัO $_{2}$-intensidade dos testes submáximos. Em síntese, acredita-se que há uma diminuição da eficiência com o aumento da intensidade do 
esforço físico e, conseqüentemente, $\mathrm{o} \mathrm{V}^{\mathrm{V}} \mathrm{O}_{2}$ não se mantém estável até aproximadamente o terceiro e sexto minutos nas intensidades acima dos limiares metabólicos (WHIPP \& WASSERMAN, 1972). Do ponto de vista cinético, esse fenômeno tem sido denominado de componente lento do $\mathrm{W}_{2}$ (XU \& RHODES, 1999), o qual parece ser dependente de múltiplos eventos fisiológicos (GAESSER \& POOLE, 1996). Assim, a maior dificuldade está em se estabelecer o valor real do $\mathrm{V}_{2}$ que representará a demanda de $\mathrm{O}_{2}$ das intensidades mais elevadas (FIGURA 6).

A

B

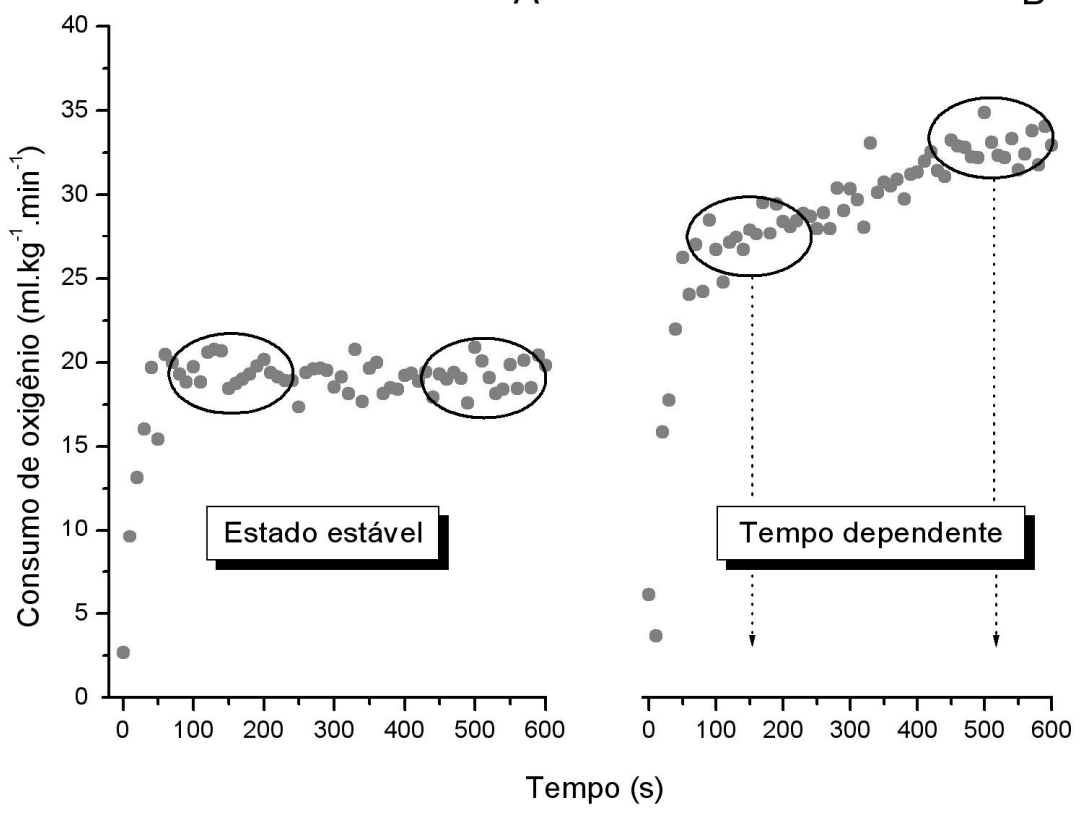

FIGURA 6 - Exemplo gráfico da resposta do $\dot{\mathrm{V}}_{2} \underline{\mathrm{O}}_{2}$ durante o exercício com a intensidade abaixo (painel A) e acima do limiar anaeróbio (painel B).

Embora essa problemática já tenha sido evidenciada (BANGSBO, 1996a), é possível se observar que os estudos têm utilizado uma ampla variação no tempo de duração dos testes submáximos, que compreendem entre 4 min (BELL et al., 2001; JACOBS et al., 1997), $5 \mathrm{~min}$ (FINN et al., 2003; WOOLFORD, WITHERS, CRAIG, BOURDON, STANEF e McKENZIE, 1999; SLONIGER et al., 1997; GASTIN et al., 1995), 6 min (DOHERTY, SMITH \& SCHRODER, 2000; WADLEY \& ROSSIGNOL, 1998; DOHERTY, 1998; OGITA et al.; 1996; OLESEN, 1992) e 10 minutos (WEBER \& SCHNEIDER, 2002; HARGREAVES et al., 1997; TABATA et al., 1996; MEDBØ \& TABATA, 1989). 
BUCK e McNAUGHTON (1999b) realizaram um trabalho que objetivou verificar a influência da redução do tempo dos exercícios submáximos no cálculo do MAOD. Para tanto, oito ciclistas de fundo foram submetidos a dez testes com cargas que variaram entre $30-90 \%$ do $\dot{\mathrm{V}} \mathrm{O}_{2} \max$ e com duração de dez minutos. Posteriormente, os valores do $\mathrm{V}_{2}$ empregados na equação de regressão linear foram gerados com base na análise de diferentes intervalos de tempo (2-4 min, 4-6 min, 6-8 min e 8-10 min). Entretanto, ao se comparar os valores do MAOD produzidos com o intervalo de tempo de 8-10 min, a única diferença estatisticamente inferior foi constatada no cálculo com o intervalo de 2-4 $\min (25,8 \pm 8,7 \%, p<0,05)$. Assim, além de recomendarem a duração de pelo menos oito minutos de exercício submáximo, BUCK e McNAUGHTON (1999b) concluíram que a utilização de períodos muito curtos de tempo pode ser inadequada para a determinação do MAOD.

Por outro lado, GARDNER et al. (2003) não constataram quaisquer diferenças significativas entre os valores do MAOD de ciclistas treinados, os quais foram gerados por testes submáximos que tiveram o tempo de análise do $\mathrm{V}_{2}$ entre 1-3 $\min , 4-6 \min$ ou 8-10 $\min (p=0,132)$. Segundo esses autores, possivelmente esse intervalo de tempo tenha sido suficiente para a estabilização do $\mathrm{V}_{2}$ nas intensidades escolhidas para os testes submáximos (100-200 W). Porém cabe ressaltar que no estudo em questão, os valores do $\mathrm{v}_{2}$ utilizados na equação de regressão linear foram obtidos por apenas cinco testes de cargas constantes.

No intuito de analisar o impacto da inclusão de cargas que apresentassem o componente lento no cálculo do MAOD, REIS, SILVA, ASCENSÃO e DUARTE (2005) compararam os parâmetros da regressão linear $\dot{\mathrm{VO}}_{2}$-intensidade em quatorze corredores fundistas, com ou sem a inclusão de exercícios realizados em intensidades acima do limiar de concentração fixa de $4 \mathrm{mmol}^{-1}$ de lactato. Constatou-se que não havia diferenças significativas entre o intercepto no eixo y, no coeficiente angular da reta e, conseqüentemente, no MAOD utilizando as duas estratégias $(p>0,05)$. Todavia, o erro padrão (sem inclusão $=1,34$; com inclusão $=$ 1,77 ) e o coeficiente de correlação (sem inclusão $=0,998$; com inclusão $=0,996$ ) foram estatisticamente diferentes $(p \leq 0,05)$. Dessa forma, esses pesquisadores sugeriam que pode haver apenas uma tendência à subestimação do MAOD quando 
se utiliza somente intensidades abaixo do limiar de concentração fixa de lactato.

ÖZYENER, ROSSITER, WARD e WHIPP (2003) compararam os valores do déficit acumulado de $\mathrm{O}_{2}$ em três intensidades supra-limiares de lactato, tendo esses testes a duração de cinco, 10 ou 15 minutos. Para tanto, os ajustes cinéticos mono ou biexponencial foram utilizados para estabelecer individualmente os valores de estado estável do $\mathrm{v}_{2}$ em cada carga sub-limiar. Em seguida, o déficit acumulado de $\mathrm{O}_{2}$ das cargas supra-limiares pôde ser estabelecido por meio da subtração do ฟे $_{2}$ projetado do valor do $\mathrm{V}_{2}$ dos diferentes períodos de duração. Entre os principais achados dessa investigação, foi demonstrado que devido ao surgimento do componente lento, o $\mathrm{V}_{2}$ mensurado excedeu os valores projetados do $\mathrm{V}_{2}$ das cargas sub-limiares. Isso resultou em valores negativos do déficit acumulado de $\mathrm{O}_{2} \mathrm{a}$ partir do décimo minuto de exercício. Dessa forma, esses pesquisadores chamaram a atenção para a necessidade de se considerar as propriedades cinéticas do $\mathrm{\cup ̆}_{2}$ no cálculo do déficit acumulado de $\mathrm{O}_{2}$, sobretudo durante os exercícios de cargas constantes com as intensidades supra-limiares.

BEARDEN e MOFFAT (2000) também verificaram a influência da resposta cinética do $\mathrm{V}_{2}$ no exercício em intensidades acima do limiar anaeróbio no cálculo do déficit acumulado de $\mathrm{O}_{2}$. Os cálculos do déficit acumulado de $\mathrm{O}_{2}$ nas diferentes intensidades foram realizados com ou sem a exclusão do componente lento do $\mathrm{v}_{2}$, o qual foi estabelecido mediante um ajuste matemático biexponencial. Foi constato que ao se excluir o componente lento do $\dot{\mathrm{V}}_{2}$, o déficit acumulado de $\mathrm{O}_{2}$ era estatisticamente menor quando comparado ao método tradicional $(p<0,05)$, mas similar ao $\mathrm{V}_{2}$ após o exercício $(p>0,05)$. Dessa forma, ao se assumir que o déficit acumulado de $\mathrm{O}_{2}$ e o $\dot{\mathrm{VO}} \mathrm{O}_{2}$ após o exercício deveriam ser equivalentes, BEARDEN e MOFFAT (2000) sugeriram que o método tradicional não é um método válido para o cálculo do déficit acumulado de $\mathrm{O}_{2}$. No entanto, vale ressaltar que essa afirmação foi baseada na comparação do déficit de $\mathrm{O}_{2}$ com débito total de $\mathrm{O}_{2}$, o qual não representa apenas a contribuição anaeróbia durante o exercício (GAESSER \& BROOKS, 1984).

Embora a freqüência do pedal pareça ser uma outra variável que pode interferir na relação ${ }^{\mathrm{V}} \mathrm{O}_{2}$-intensidade dos testes submáximos e supramáximo (GASTIN, 1994), os estudos que mensuraram o MAOD adotaram ritmos do pedal do 
cicloergômetro que variam entre 60 (MEZZANI et al., 2006), 70 (WEBER \& SCHNEIDER, 2002), 80 (CALBET et al., 1997), 90 (GASTIN et al., 1995), 100 (GARDNER et al., 2003; BELL et al., 2001) e 110 rpm (FINN et al., 2003; JACOBS et al., 1997). Todavia, apenas um estudo verificou sistematicamente a influência dessa variável sobre o MAOD. Ao utilizarem diferentes variações na cadência do pedal nos testes submáximos, WOOLFORD et al. (1999) constataram que o MAOD determinado pela freqüência entre 90-100 rpm era estatisticamente menor quando comparado aos ritmos de 90-130 rpm (31,5\%) e 120-130 rpm $(32,2 \%)$ ( $<<0,05)$. Segundo esses autores, a existência dessa diferença possivelmente ocorre em virtude do recrutamento adicional de músculos responsáveis pela a estabilização do tronco e dos membros superiores, bem como a diminuição da eficiência do músculo esquelético devido ao aumento da participação das fibras de contração rápida. Contudo, além da grande amplitude de variação das cadências utilizadas, cabe ressaltar que nesse estudo a relação $\mathrm{V}_{2}$-intensidade foi obtida por meio de um teste progressivo até exaustão. Como anteriormente citado, GARDNER et al. (2003) demonstram que é possível obter valores estatisticamente diferentes do MAOD ao se estabelecer a relação $\mathrm{vंO}_{2}$-intensidade por meio de testes de cargas constantes ou progressivo. Assim, apesar da informação sobre a influência do ritmo do pedal ser relevante, a relação causal supracitada deve ser contemplada com cautela.

Adicionalmente, tem-se sugerido que durante a transição repouso-exercício, a medida do $\dot{\mathrm{V}}_{2}$ pulmonar pode subestimar a respiração celular devido aos estoques de $\mathrm{O}_{2}$ contidos nas moléculas de hemoglobina e mioglobina (GASTIN, 1994). Assim, MEDBØ et al. (1988) sugeriram a subtração de 10\% do valor total do MAOD no intuito de realizar a correção dos estoques corporais de $\mathrm{O}_{2}$. Porém, esse cálculo tem sido utilizado apenas por alguns estudos (WEBER \& SCHNEIDER, 2002; SLONIGER et al., 1997; MEDB $\varnothing$ et al., 1988), enquanto outros têm apresentado o valor total do MAOD (JACOBS et al., 1997; GASTIN et al., 1995; DOHERTY, 1998). Outras adaptações metodológicas têm sido adotadas sem o devido questionamento ou investigação sistematizada sobre o seu impacto na mensuração do MAOD. As principais adequações detectadas foram: a) a realização do teste progressivo e dos testes submáximos na mesma sessão experimental (GARDNER et al., 2003; DOHERTY, 1998; JACOBS et al., 1997; SLONIGER et al., 1997); b) quando 
realizados em sessões diferentes, os critérios para o estabelecimento dos intervalos de tempo entre os testes submáximos foram de dez minutos (DOHERTY, 1998; OGITA et al., 1996), entre 3-5 min (CALBET et al., 1997), entre 2-10 minutos (BANGSBO et al., 1993) ou até o $\mathrm{vO}_{2}$ atingir os valores de repouso (REIS et al., 2005).

Por fim, parece que os valores do MAOD são influenciados pela massa muscular envolvida na tarefa analisada, bem como as mudanças bioquímicas crônicas que ocorrem nesse tecido. Por outro lado, em razão do número restrito de estudos realizados, ainda é incerta a interferência da temperatura ambiente, da disponibilidade de glicogênio muscular e do ritmo cicardiano sobre o MAOD. Além disso, a grande variedade das reformulações do método tradicional apontada nessa sessão da revisão de literatura indica a necessidade de novos estudos que objetivem a proposição de procedimentos de padronização para o MAOD. Isso inclui o número ótimo de testes submáximos, a duração de cada teste submáximo, o ritmo do pedal do cicloergômetro, a amplitude de variação das intensidades dos testes submáximos, a comparação dos valores do $\mathrm{V}_{2}$ mensurados nos testes submáximos realizados de forma contínua, descontínua e com a realização prévia do teste progressivo até a exaustão. Porém, é possível observar que a maioria dos estudos mais recentes adotaram 4-6 testes submáximos, com 8-10 minutos de duração para cada teste e $\mathrm{com}$ as intensidades estabelecidas de forma percentual ao $\mathrm{v}_{2} \max$ ou à potência externa correspondente ao $\mathrm{V}_{2} \max \left(\mathrm{WviO}_{2} \mathrm{max}\right)$.

\subsection{Caracterização da resposta cinética off do consumo de oxigênio}

O EPOC RÁPIDO é uma das medidas fisiológicas que tem sido utilizada para se estimar a contribuição do metabolismo anaeróbio alático durante o exercício físico (GUIDETTI et al., 2007; SCOTT, 2006a; SCOTT, 2006b; BENEKE et al., 2004; BENEKE et al., 2002; FRANCESCATO et al., 1995). Do ponto de vista temporal, sugere-se que assim como $\circ \mathrm{V}_{2}$ aumenta em relação aos valores de repouso nos momentos iniciais do esforço físico [(resposta cinética on do $\left.\dot{\mathrm{V}}_{2}\left(\mathrm{~V}_{2} \mathrm{O}_{2 o n}\right)\right]$, ele também se mantém elevado após o término dessas tarefas [(resposta cinética off do $\dot{\mathrm{V}}_{2}$ ( $\left.\left(\mathrm{V}_{2 \text { off }}\right)\right]$. Conseqüentemente, alguns pesquisadores têm utilizado modelagens matemáticas no intuito de caracterizar e compreender as causas do EPOC RÁ́PIDO 
(KILDING, CHALLIS, WINTER \& FYSH, 2005; ARSAC, THIAUDIÈRE, DIOLEZ \& GERVILLE-RÉACHE, 2004; di PRAMPERO, MAHLER, GIEZENDANNER \& CERRETELLI, 1989; PATERSON \& WHIPP, 1991).

A $\mathrm{VO}_{20 F F}$ é comumente subdividida em duas fases que perfazem o período de recuperação. O primeiro estudo a caracterizá-las e a sugerir uma relação casual desse comportamento bifásico foi o de MARGARIA et al. (1933), que atribuiu ao $E_{\text {POC }}$ RIDO à ressíntese de $\mathrm{CP}$ e à restauração dos estoques de $\mathrm{O}_{2}$, ao passo que a fase lenta foi associada à degradação das [La] induzidas pelo esforço. Após a apresentação desse pressuposto teórico, PIIPER e SPILLER (1970) provavelmente foram os primeiros pesquisadores a analisarem simultaneamente o comportamento do $\tilde{V}_{2}$ durante a recuperação e a ressíntese de CP em uma mesma tarefa. Naquela ocasião, os gastrocnêmios de cães foram estimulados eletricamente durante sete minutos, seguidos por dez minutos de recuperação. Amostras do tecido foram adquiridas por meio de biópsia muscular durante o período de recuperação, além da mensuração do $\mathrm{V}_{2}$ mediante a diferença artério-venosa. Durante os dois primeiros minutos de recuperação $0 \mathrm{~V}_{2}$ diminuiu rapidamente, ficando em torno de $8 \%$ do valor observado durante as estimulações, enquanto no terceiro minuto o valor ficou muito próximo do final de recuperação. As ressínteses de ATP e CP tiveram comportamentos bastante semelhantes ao do $\mathrm{v}_{2}$.

Nesse sentido, existem pontos relevantes a serem considerados em relação à análise cinética do $\mathrm{W}_{2}$. Por exemplo, acredita-se que em exercícios de intensidade moderada, as repostas da $\dot{\mathrm{V}}_{2 \mathrm{ON}}$ e da $\dot{\mathrm{VO}}_{2 \mathrm{OFF}}$ possuem comportamentos exponenciais com as $\tau$ da primeira fase similares em aproximadamente 30 segundos (WHIPP \& ÖZYENER, 1998; XU \& RHODES, 1999). Segundo WHIPP e ÖZYENER (1998), os princípios da VO $_{2 O N}$ também se aplicam à ${ }^{\circ} O_{2 O F F}$, pelo simples fato de possuírem comportamentos semelhantes, porém em sentidos inversos.

Em outras palavras, na $\mathrm{V}_{20 F F}$ pode-se atribuir os conceitos cinéticos às variáveis de análise e às suas respectivas técnicas de modelagem matemática, apresentados na resposta on. Além disso, os termos das equações aplicadas em ambas as respostas cinéticas do $\mathrm{V}_{2} \mathrm{O}_{2}$ também demonstraram ser reprodutíveis em diversas intensidades do esforço físico (KILDING et al., 2005). A figura 7 apresenta um exemplo dos termos da equação comumente utilizada na modelagem da $\mathrm{V}_{2} \mathrm{OFF}$. 


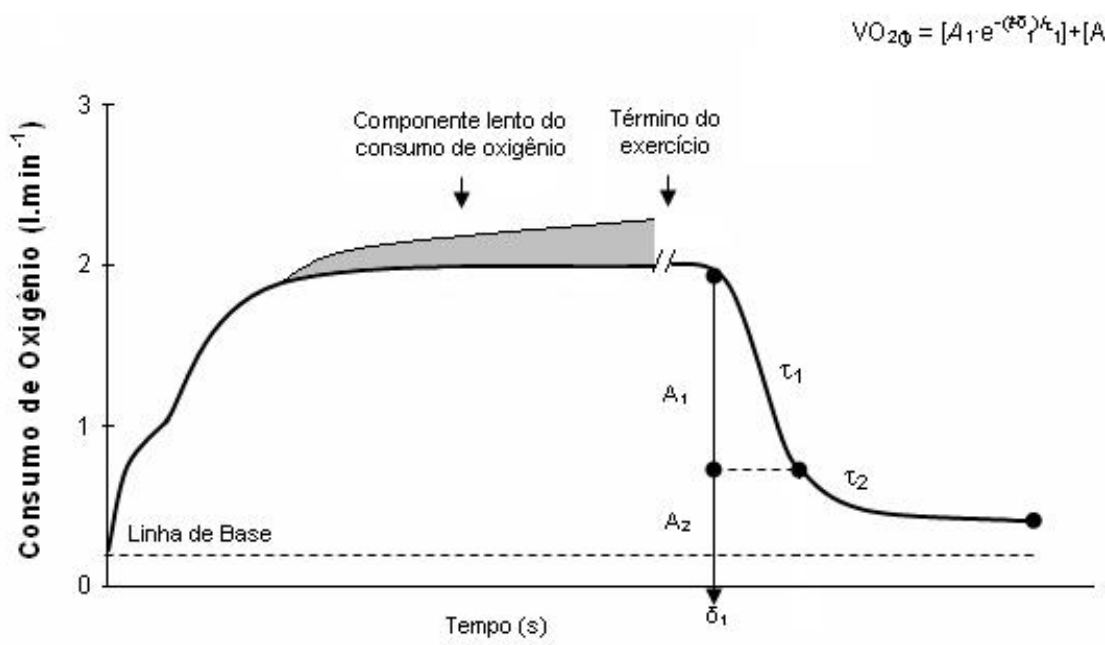

FIGURA 7 - Representação gráfica das variáveis cinéticas comumente analisadas na resposta cinética off do $\dot{\mathrm{v}} \underline{\mathrm{O}}_{2} . \mathrm{A}=$ amplitude; $\tau=$ constante de tempo e $\delta=$ tempo de atraso. Os valores subscritos 1 e 2 denotam os termos da fase rápida e lenta do $\underline{\mathrm{V}}_{2}$ após o exercício, respectivamente.

Mediante os achados do estudo de di PRAMPERO et al. (1989), é possível confirmar a presença das duas fases da ${ }^{\circ} O_{2 O F F}$ após aproximadamente 10 minutos de exercício a $60 \%$ da potência máxima gerada em protocolos desenvolvidos em cicloergômetro e banco. Nesse trabalho também foi notado que: a) a fase lenta da $\dot{\mathrm{V}} \mathrm{O}_{2 \mathrm{FF}}$ estava correlacionada significativamente com o delta das [ $\mathrm{La}^{\circledR}$ ] após o exercício $(r=0,97 ; p<0,001)$, b) uma menor variação do $\mathrm{V}_{2}$ analisado respiração a respiração na $\dot{\mathrm{V}} \mathrm{O}_{2 \mathrm{FF}}$ do que na $\dot{\mathrm{V}} \mathrm{O}_{2 \mathrm{ON}}$, e c) que o $\mathrm{t} 1 / 2$ da $\dot{\mathrm{V}} \mathrm{O}_{2 \mathrm{OFF}}$ tanto da fase lenta quanto da fase rápida não diferiram estatisticamente em virtude das tarefas adotadas (TABELA 5).

TABELA 5 - Valores do $\mathrm{t} 1 / 2$ na fase rápida e lenta da resposta off do ${ }_{\mathrm{V}} \underline{\mathrm{O}}_{2} \underline{\text { no ciclismo }}$ e no teste em banco (adaptado de di PRAMPERO et al., 1989).

\begin{tabular}{lll}
\hline & Ciclismo & Teste no Banco \\
$\mathrm{t} 1 / 2$ Fase rápida (s) & $22,3 \pm 6,7$ & $20,8 \pm 5,8$ \\
$\mathrm{t} 1 / 2$ Fase lenta (s) & $91,4 \pm 47,0$ & $93,6 \pm 45,0$ \\
\hline
\end{tabular}

Os valores são médias \pm desvios padrão. 
O estudo de CARTER, JONES, BARSTOW, BURNLEY, WILLIAMS e DOUST (2000) também teve por objetivo caracterizar a $\mathrm{V}_{2 O F F}$ em diferentes tarefas. Para isso, eles avaliaram sete sujeitos fisicamente ativos em cicloergômetro e esteira rolante. Os indivíduos foram submetidos a testes de cargas constantes, constituídos por dois minutos de repouso e seis minutos se exercitando nas intensidades de $80 \%$ do limiar aeróbio $\left(\theta_{\mathrm{L}}\right)$ e $25 \%, 50 \%$ e $75 \%$ da diferença entre $\mathrm{V}_{2 \max }$ e o $\theta_{\mathrm{L}}$. As $\tau$ da primeira fase não diferiram estatisticamente em virtude do ergômetro e da intensidade. Contudo, as amplitudes foram maiores na esteira quando comparadas com o cicloergômetro, para a maioria das intensidades, com a tendência de aumentar para ambas tarefas em virtude do esforço. Uma possível explicação para esses resultados é que o consumo de oxigênio na esteira, tanto no $\mathrm{V}_{2 \max }$ como no $\theta_{\mathrm{L}}$, eram superiores quando comparados ao do cicloergômetro, fato que implicou diferentes valores absolutos do $\mathrm{v}_{2}$ entre as tarefas. Além disso, os diferentes tipos de ações musculares podem ter interferido no $\mathrm{v}_{2}$ ao final do exercício, o que conseqüentemente influenciou na $A_{1}$ da $\dot{\mathrm{V}}_{2 \mathrm{OFF}}$, já que as $\tau$ eram semelhantes. Acredita-se que durante a corrida, cerca de $34 \%$ do tempo total é constituído por ações musculares excêntricas, as quais solicitam preferencialmente as unidades motoras do tipo Ilb. Nesse sentido, associou-se a maior $A_{1}$ ao recrutamento das fibras do tipo Ilb, já que elas ressintetizam cerca de $18 \%$ menos fosfatos para a mesma taxa do $\mathrm{V}_{2}$.

Com o intuito de verificar a influência do conteúdo de $\mathrm{O}_{2}$ nas $\dot{\mathrm{V}}_{2 \mathrm{OFF}}$ e $\mathrm{V}^{\mathrm{V}} \mathrm{O}_{2 \mathrm{~N}}$, ENGELEN, PORSZASZ, RILEY, WASSERMAN, MAEHARA, e BARSTOW (1996) avaliaram oito sujeitos (sete homens e uma mulher) em condições de normóxia (21\% $\left.\mathrm{O}_{2}\right)$, hipóxia leve $\left(15 \% \mathrm{O}_{2}\right)$ e moderada $\left(12 \% \mathrm{O}_{2}\right)$. Os sujeitos foram submetidos a um exercício de carga constante com duração de oito minutos e com a intensidade estabelecida a $50 \%$ da diferença entre o $\theta_{\mathrm{L}}$ e o $\mathrm{v}^{\circ} \mathrm{O}_{2 p i c o}$. Antecedendo aos testes, os sujeitos pedalaram durante quatro minutos com o cicloergômetro sem carga para o estabelecimento da linha de base do $\mathrm{V}_{2}$ e após o exercício, realizaram o mesmo procedimento por dez minutos para a análise da $\dot{\mathrm{V}}_{2 \mathrm{OFF}}$. Quando comparada com as demais situações, a hipóxia moderada apresentou alteração significativa do comportamento $\mathrm{V}_{2 \mathrm{FF}}$, sendo mais lenta quando comparada às demais situações $(\tau$ 
normóxia $=26,0 \pm 6,2 \mathrm{~s} ; \tau$ hipóxia leve $=23,0 \pm 9,9 \mathrm{~s}$ e $\tau$ hipóxia moderada $\tau=40,6$ $\pm 9,9 \mathrm{~s} ; \mathrm{p}<0,01)$. Em relação à $\mathrm{V}_{20}$, foram observadas diferenças significativas quando comparadas com as diferentes frações inspiradas de $\mathrm{O}_{2}$ ( $\tau$ normóxia $=23,0 \pm$ $9,0 \mathrm{~s} ; \tau$ hipóxia leve $=25,2 \pm 5,4 \mathrm{~s}$ e $\tau$ hipóxia moderada $=38,5 \pm 13,3 \mathrm{~s} ; \mathrm{p}<0,01)$. A cinética mais lenta da resposta on estava correlacionada ao atraso do ponto de queda da CP e à elevação das [La']. Entretanto, os autores sugeriram mais investigações sobre as simetrias notadas entre os períodos de respostas, sem maiores informações para a resposta off.

O artigo de ÖZYENER, ROSSITER, WARD e WHIPP (2001) apresentou evidências sobre as possíveis similaridades entre as $\dot{\mathrm{V}} \mathrm{O}_{2 \mathrm{OFF}}$ e $\dot{\mathrm{V}} \mathrm{O}_{2 \mathrm{ON}}$ em cicloergômetro. Eles avaliaram seis sujeitos não atletas em protocolos de cargas constantes, que iniciaram com a intensidade de $20 \mathrm{~W}$ durante 3 e 4 minutos, seguido por 10 minutos do exercício realizado no domínio Moderado, Pesado, Muito Pesado e Severo, com subseqüente recuperação ativa de 20 minutos também a $20 \mathrm{~W}$. A $\dot{\mathrm{V}} \mathrm{O}_{2 \mathrm{FF}}$ foi melhor representada por um ajuste monoexponencial para o exercício realizado no domínio Moderado (abaixo do limiar aeróbio) e Pesado (entre o limiar aeróbio e anaeróbio), ao passo que para os domínios Muito Pesado (entre o limiar anaeróbio e o $\mathrm{V}_{2} \max$ ) e Severo (acima do $\mathrm{V}_{2} \max$ ) por um ajuste biexponencial. Já a $\dot{\mathrm{V}}_{2 \mathrm{ON}}$ foi expressa por ajustes monoexponenciais para os domínios Moderado e Severo, e os domínios Pesado e Muito Pesado, por biexponenciais. Entre os demais achados desse estudo, foi possível constatar que a $\tau_{1}$ da primeira fase da resposta $\dot{\mathrm{V}} \mathrm{O}_{2 \mathrm{FF}}$ não diferiu estatisticamente nos diferentes domínios de intensidade de esforço e que, nas intensidades mais elevadas, houve o surgimento de um segundo componente representado pela $\tau_{2}$ (TABELA 6). Logo, concluiu-se que a intensidade do esforço físico também pode interferir nas estratégias de modelagem da resposta $\mathrm{V}_{2 \mathrm{OFF}}$, porém com o primeiro componente sendo menos sensível a essa variável. 
TABELA 6 - Constantes de tempo da resposta on e off do $\dot{\mathrm{v}}_{2} \mathrm{Z}_{2}$ em diferentes intensidades. As $\tau_{1}$ e $\tau_{2}$ são referentes às constantes de tempo do primeiro e da segunda exponencial (adaptado de ÖZYENER et al., 2001).

\begin{tabular}{lllll}
\hline Domínio & \multicolumn{2}{c}{ On } & \multicolumn{2}{c}{ Off } \\
& $\tau_{1}(\mathrm{~s})$ & $\tau_{2}(\mathrm{~s})$ & $\tau_{1}(\mathrm{~s})$ & $\tau_{2}(\mathrm{~s})$ \\
\hline Moderado & $33 \pm 16$ & - & $29 \pm 6$ & - \\
Pesado & $32 \pm 17$ & $170 \pm 49^{*}$ & $42 \pm 11$ & - \\
Muito Pesado & $34 \pm 11$ & $163 \pm 46^{*}$ & $33 \pm 5$ & $460 \pm 123^{\ddagger}$ \\
Severo & $34 \pm 7$ & - & $35 \pm 11$ & $539 \pm 379^{\ddagger}$
\end{tabular}

Os valores são médias \pm desvios padrão; * maior que $\tau_{1}$ on; ${ }^{\ddagger}$ maior que $\tau_{1}$ off $(p<0,05)$.

\subsection{Resposta cinética off do consumo de oxigênio e metabolismo anaeróbio alático}

Mais recentemente, os estudos que monitoraram o esforço físico por meio de Imagens de Ressonância Magnética Nuclear de Fósforo ( $\left.{ }^{31} \mathrm{P}-\mathrm{NMR}\right)$ têm demonstrado que os estoques dos fosfatos de alta energia (ATP e CP) restauram cerca de $70 \%$ no trigésimo segundo e $100 \%$ no terceiro minuto da recuperação (TOMLIN \& WENDER, 2001).Todavia, SPRIET (1995) citou que os estudos conduzidos com ${ }^{31} \mathrm{P}-\mathrm{NMR}$ geralmente apresentam valores superiores de $\mathrm{CP}$ quando comparados com valores obtidos em trabalhos que utilizaram biópsia muscular. Uma possível explicação apresentada pelo autor é que durante a retirada da amostra do tecido muscular pela técnica de biópsia as membranas celulares são rompidas, elevando a liberação de cálcio, que por sua vez ativaria a actnomiosina ATPase, a qual subseqüentemente degradaria a CP no intuito de manter as concentrações de ATP.

Por outro lado, IDSTRÖM, SUBRAMANIAN, CHANCE, SCHERSTEN e BYLUND-FELLENIUS (1985) demonstraram que independentemente da técnica empregada (biópsia ou ${ }^{31} \mathrm{P}-\mathrm{NMR}$ ) o sistema oxidativo desempenha um papel fundamental na ressíntese da CP após o esforço físico. Entre os achados desse estudo, detectaram-se correlações significativas entre a taxa de recuperação da $\mathrm{CP}$ e o transporte de $\mathrm{O}_{2}(r=0,83 ; p<0,001)$ após a estimulação elétrica $(2-4 \mathrm{~V})$ nos 
gastrocnêmios de ratos (Sprague-Dawley). Por esse motivo, os autores apontaram enfaticamente para a dependência do transporte de $\mathrm{O}_{2}$ na restauração do sistema energético referido.

O trabalho de JANSSON et al. (1990) também indicou a participação do sistema oxidativo na ressíntese da CP em seres humanos durante o período inicial da recuperação. Eles obtiveram correlações significativas do lactato $(r=-0,76)$, da creatina $(r=-0,84)$ e da CP $(r=0,79)(p<0,05)$ com a atividade da enzima citrato sintase. Naquela ocasião, as amostras do tecido muscular foram obtidas por meio de biópsia em sujeitos fisicamente ativos $(n=11)$, após a execução de três séries de trinta repetições em uma tarefa considerada de força (flexão e extensão de joelho à $\left.180^{\circ} \cdot \mathrm{s}^{-1}\right)$, com intervalo de sessenta segundos entre as séries. Assim, os músculos que possuíam alta atividade da enzima citrato sintase tiveram uma concentração menor de lactato e de creatina, ao passo que houve maior ressíntese de $\mathrm{CP}$. Concluiu-se, então, que a recuperação dessas variáveis metabólicas após a referida tarefa, é dependente da capacidade oxidativa do músculo esquelético.

McCULLY, IOTTI, KENDRICK, WANG, POSNER, LEIGH e CHANCE (1994) notaram um comportamento semelhante ao do estudo de JANSSON et al. (1990). Eles avaliaram cinco sujeitos em um exercício com flexão plantar que induziu a redução de $\cong 50 \%$ dos valores de $\mathrm{CP}$ em repouso e, posteriormente, na maior velocidade possível durante 64 segundos. Durante esse procedimento e 0 subseqüente período de recuperação, os gastrocnêmios dos sujeitos foram monitorados por meio de ${ }^{31} \mathrm{P}-\mathrm{NMR}$ e espectroscopia de raios infravermelhos. As constantes de tempo $(\tau)$ da CP e da oxihemoglobina $(68,3 \pm 10,5$ segundos e 29,4 \pm 5,5 segundos, respectivamente) foram estatisticamente mais lentas para o exercício máximo quando comparado ao submáximo $(36,0 \pm 6,5$ segundos e 27,6 \pm 6,0 segundos, respectivamente) $(p<0,05)$. Entretanto, não foram encontradas diferenças entre as $\tau$ das variáveis no exercício submáximo, ao passo que houve correlação significativa entre os valores de $\mathrm{pH}$ e as $\tau$ de CP. Portanto, os autores concluíram que a ressíntese de CP logo após o exercício de intensidade moderada é dependente do transporte de $\mathrm{O}_{2}$, ao passo que em tarefas em que ocorre a alteração de $\mathrm{pH}$ (para $\cong 6,62)$ esse comportamento pode ser mais lento, em virtude da 
alteração da atividade das enzimas do sistema oxidativo.

Com o intuito de analisar, entre outras variáveis, o comportamento da $\tau$ da ressíntese da CP após uma tarefa com cargas constantes, MEYER (1988) estimulou eletricamente os gastrocnêmios de ratos (Sprague-Dawley) durante oito minutos, a $0,25 \mathrm{~Hz}, 0,50 \mathrm{~Hz}$ e $0,75 \mathrm{~Hz}$, assumindo que essa intensidade estava abaixo da capacidade oxidativa máxima desse grupo muscular. No período de repouso, durante os oito minutos de estimulação elétrica e após dez minutos de recuperação, foram adquiridas as imagens de ${ }^{31} \mathrm{P}$-NMR. Em linhas gerais, constatou-se que a ressíntese da $\mathrm{CP}$ durante a recuperação teve o comportamento monoexponencial e as suas respectivas $\tau$ não sofreram influência da intensidade do estímulo, já que os valores não diferiram estatisticamente $(0,25 \mathrm{~Hz}=1,45 \pm 0,19 \mathrm{~s} ; 0,5 \mathrm{~Hz}=1,68 \pm 0,09 \mathrm{~s} ; 0,75$ $\mathrm{Hz}=1,34 \pm 0,05 \mathrm{~s})$.

Objetivando verificar a influência da participação do sistema oxidativo na cinética da ressíntese da CP, HASELER, HOGAN e RICHARDSON (1999) avaliaram seis sujeitos em testes de cargas constantes de flexão plantar a $60 \%$ da potência máxima gerada em um teste realizado previamente até a exaustão. Os testes de cargas constantes foram constituídos de ciclos idênticos de cinco minutos para os períodos de repouso, exercício e recuperação. Durante essas tarefas, os sujeitos respiraram o ar com concentrações diferentes de $\mathrm{O}_{2}(10 \%, 21 \%$ e $100 \%)$ e em todas as situações foram constantemente adquiridas informações dos gastrocnêmios por meio de ${ }^{31} \mathrm{P}$-NMR. Com base nos resultados obtidos foi possível notar que a cinética da CP era estatisticamente mais lenta $(\tau=33,5 \pm 4,1 \mathrm{~s})$ para a situação de hipóxia e mais rápida ( $\tau=20,0 \pm 1,8 \mathrm{~s}$ ) para a situação de hiperóxia quando comparada à normóxia ( $\tau=25,0 \pm 2,7 \mathrm{~s}$ ) ( $\mathrm{p} \leq 0,05$ ). Concluiu-se que, de fato, a cinética da ressíntese de $\mathrm{CP}$ após esforço moderado é dependente da fração inspirada de $\mathrm{O}_{2}$, 0 que corrobora a hipótese da ressíntese de CP ser altamente dependente do sistema oxidativo. Além disso, pôde-se observar que a $\tau$ da ressíntese da CP é bastante semelhante à $\tau$ do $\dot{\mathrm{V}}_{2}$ do primeiro processo exponencial durante a recuperação do esforço físico, como apresentado nos demais estudos.

YOSHIDA (2002) realizou um estudo que também analisou a relação entre a resposta off da $\mathrm{CP}$ e o metabolismo aeróbio. Os indivíduos possuíam níveis 


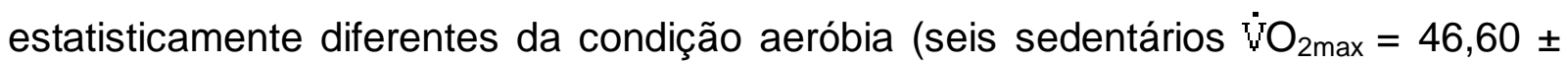
$1,70 \mathrm{ml} \cdot \mathrm{kg}^{-1} \cdot \mathrm{min}^{-1}$; cinco corredores de longas distâncias ฟेO $_{2 \max }=73,62 \pm 2,24$ $\mathrm{ml} \cdot \mathrm{kg}^{-1} \cdot \mathrm{min}^{-1}$ e cinco velocistas $\left.{ }^{\mathrm{V}}{ }_{2 \max }=56,16 \pm 2,52 \mathrm{ml} \cdot \mathrm{kg}^{-1} \cdot \mathrm{min}^{-1} ; \mathrm{p}<0,05\right)$ e foram avaliados em um ergômetro que permitia a realização da flexão e a extensão plantar com o monitoramento contínuo da CP por meio do ${ }^{31} \mathrm{P}-\mathrm{NMR}$. O protocolo adotado era constituído de dois testes de cargas constantes com duração de quatro minutos nas intensidades de $18 \%$ e $23 \%$ (moderado) e de $54 \%$ e $70 \%$ (pesado) da potência máxima gerada em um teste incremental realizado previamente. Durante a recuperação passiva os corredores de longas distâncias apresentaram a cinética da ressíntese de $\mathrm{CP}$ estatisticamente mais rápida que os velocistas e os sedentários tanto no exercício moderado $(\tau=26,4 \pm 1,8 \mathrm{~s} ; \tau=29,9 \pm 4,0 \mathrm{~s} ; \tau=43,2 \pm 5,0 \mathrm{~s}$, respectivamente; $p<0,05)$ quanto no exercício pesado $(\tau=27,6 \pm 4,6 \mathrm{~s} ; \tau=43,1 \pm$ $4,4 \mathrm{~s} ; \tau=45,2 \pm 8,3 \mathrm{~s}$, respectivamente; $p<0,05)$. Logo, o principal achado desse estudo foi que, independentemente da intensidade do exercício, a velocidade de ressíntese de $\mathrm{CP}$ foi mais rápida para os sujeitos que tinham maior condição aeróbia. Adicionalmente, o comportamento da $\mathrm{CP}$ durante a recuperação foi mais bem expressa pela modelagem matemática monoexponencial. Esses achados corroboram os de outro trabalho do mesmo autor (YOSHIDA \& WATARI, 1993b), quando foi notado que ao realizarem quatro repetições de flexão e extensão de joelho em uma intensidade de $20 \mathrm{~kg} \cdot \mathrm{m} \cdot \mathrm{min}^{-1}$, com intervalos de dois minutos entre as repetições, os atletas de corrida de média distância $(5 \mathrm{~km})$ tinham a cinética mais rápida da ressíntese da CP que os sedentários.

Todavia, o primeiro estudo a comparar a cinética intracelular on e off de creatina ( $\mathrm{CP}$ e $\mathrm{Pi}$ ) com a cinética do $\dot{\mathrm{V}}_{2}$ pulmonar durante o mesmo exercício em humanos foi realizado somente na década de 1990 (McCREARY et al., 1996). Naquela ocasião, foram avaliados 11 sujeitos fisicamente ativos durante o exercício de flexão plantar com intensidade relativa à carga do limiar de acidose intracelular. Todos os indivíduos iniciaram a tarefa com seis minutos sem carga, porém seis sujeitos exercitaram-se cinco minutos após o aumento abrupto da carga a aproximadamente $90 \%$ da carga do limiar de acidose, ao passo que os outros cinco sujeitos realizaram o exercício a aproximadamente $50 \%$ das suas respectivas 
potências de pico. A justificativa para as diferenças entre os métodos estabelecidos para identificar a carga foi a ocorrência de contratempos com o equipamento utilizado, entretanto, independentemente da forma utilizada, a intensidade relativa não diferia entre os procedimentos. Durante essas situações foram adquiridas imagens de ${ }^{31} \mathrm{P}-\mathrm{NMR}$, e as medidas do $\mathrm{W}_{2}$ foram obtidas no mesmo teste de carga constante, mas em um outro dia. As análises cinéticas das variáveis foram realizadas por meio de ajuste monoexponencial, tanto para a resposta on quanto para a resposta off. Entre os resultados, as $\tau$ da resposta off do $\dot{\mathrm{V}}_{2}$ e da $\mathrm{CP}$ não diferiram estatisticamente $(33,4 \pm 3,3$ segundos e 44,8 \pm 4,8 segundos, respectivamente), além da correlação inversamente proporcional observada entre as $\tau$ da resposta off da CP com o pH $(r=-0,60 ; p<0,05)$. Logo, concluiu-se que a $\tau$ da resposta off do $\dot{\mathrm{V}} \mathrm{O}_{2}$ é similar à $\tau$ da ressíntese da CP durante a recuperação no exercício de flexão plantar. Adicionalmente, os autores apresentam em sua discussão que a ressíntese de CP é razoavelmente descrita por um ajuste monoexponencial após exercício de baixa intensidade (abaixo do limiar de acidose intracelular) e que as alterações de pH intramuscular promovidas pelo exercício tendem a tornar a cinética da ressíntese da CP mais lenta.

Posteriormente, ROSSITER et al. (2002) também analisaram as características cinéticas do $\mathrm{W}_{2}$ e da $\mathrm{CP}$, com a diferença de que em seu experimento as variáveis foram adquiridas simultaneamente e em grupos musculares maiores (quadríceps femoral). Nove sujeitos foram avaliados em dois testes de cargas constantes de intensidades elevada e moderada, os quais constituíram de quatro minutos em repouso, seis minutos de exercício e mais seis minutos de recuperação. Durante todos esses procedimentos foram obtidas imagens de ${ }^{31} \mathrm{P}-\mathrm{NMR}$ e do $\mathrm{V}_{2}$ respiração a respiração. Parte dos resultados do referido estudo está presente na tabela 7. Como se pode notar, as $\tau$ das variáveis apresentadas na fase off não diferiram em virtude da intensidade do exercício, sugerindo que do ponto de vista temporal a $\mathrm{CP}$ e $\mathrm{O} \mathrm{V}_{2}$ estão intimamente associados, possivelmente indicando que a cinética off do $\mathrm{V}_{2}$ é determinada por mecanismos intramusculares. Conforme o esperado, o exercício moderado proporcionou uma amplitude inferior do $\dot{\mathrm{V}} \mathrm{O}_{2}$ e da CP quando comparado ao de alta intensidade. Esse fato poderia indicar 
que, além das $\tau$ serem semelhantes para as tarefas adotadas, $\mathrm{o} \mathrm{V}_{2}$ do primeiro processo exponencial da fase off tende a possuir o mesmo comportamento da CP durante a fase de recuperação.

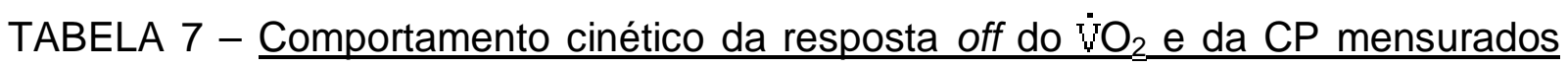
continuamente. $A_{1}$ da CP foi expressa em porcentagem do valor de controle obtido ao início do teste (adaptado de ROSSITER et al., 2002).

Intensidade

$\mathrm{VO}_{2}$

$\mathrm{CP}$

\begin{tabular}{lllll} 
& $A_{1}\left(\mathrm{I} \cdot \mathrm{min}^{-1}\right)$ & $\tau_{1}(\mathrm{~s})$ & $A_{1}(\%)$ & $\tau_{1}(\mathrm{~s})$ \\
\hline Moderada & $0,43 \pm 0,2$ & $50 \pm 12,7$ & $11,1 \pm 2,6$ & $51 \pm 13,1$ \\
Alta Intensidade & $0,95 \pm 0,3$ & $51 \pm 6,3$ & $26,7 \pm 11,2$ & $47 \pm 10,6$
\end{tabular}

Os valores são médias \pm desvios padrão.

Em contrapartida, YOSHIDA e WATARI (1993a) questionaram essa relação entre o sistema oxidativo e a ressíntese de CP durante a recuperação. Entre os resultados obtidos, foi possível observar que a ressíntese de CP dois minutos após a execução de quatro repetições de flexão e extensão de joelho em uma intensidade de $20 \mathrm{~kg} \cdot \mathrm{m}^{-1} \cdot \mathrm{min}^{-1}$ observada por ${ }^{31} \mathrm{P}-\mathrm{NMR}$, era de apenas $\cong 79,0 \%$ dos valores de repouso $(n=6)$. Todavia, os autores não realizaram estimativas do $\mathrm{pH}$ intramuscular, o qual poderia influenciar esses resultados (McMAHON \& JENKINS, 2002).

De forma similar, ARNOLD, MATTHEWS e RADDA (1984) constataram que ao realizar exercícios de cargas constantes com músculos dos antebraços em alta (500 $\mathrm{mmHg}$ ) e baixa pressão $(100 \mathrm{mmHg}$ ), a ressíntese da CP foi mais rápida nos primeiro e segundo minutos inicias da recuperação. Adicionalmente, observou-se que a ressíntese da CP diminuiu em $33 \pm 4 \%$ e $55 \pm 8 \%$ com o pH acompanhando este comportamento, sendo reduzido para 6,88 \pm 0,02 e 6,23 \pm 0,08 nos exercícios de baixa e alta pressão, respectivamente. A possível relação existente ente $\mathrm{pH}$ e a CP após o esforço é que a atividade das enzimas do sistema oxidativo, responsável pela ressíntese da ATP, é sensível à alteração do $\mathrm{pH}$ intracelular. Nesse sentido, os autores sugeriram que a taxa de ressíntese de $\mathrm{CP}$ é dependente do $\mathrm{pH}$. 
Adicionalmente, essa possível relação entre a ressíntese de $\mathrm{CP}$ e o pH intramuscular pode comprometer a aplicação do ajuste monoexponencial para representar 0 comportamento do restabelecimento dos estoques dos fosfatos de alta energia após o exercício físico intenso (ARSAC et al., 2004).

Em resumo, a maior parte dos achados obtidos por meio de biópsia muscular ou pela mensuração das mudanças metabólicas via ${ }^{31} \mathrm{P}$-NMR sugere que os metabolismos oxidativo e da CP são interdependentes, sobretudo nos instantes iniciais da recuperação. Adicionalmente, estudos demonstraram transversalmente que a ressíntese da CP após o esforço físico é superior em sujeitos com maior aptidão aeróbia. Todavia, cabe ressaltar que as mudanças do $\mathrm{pH}$ induzidas pelo exercício podem afetar a similaridade temporal frequentemente observada entre as respostas cinéticas off do $\mathrm{V}_{2}$ e da CP.

\section{MATERIAIS E MÉTODOS}

\subsection{Amostra}

Dez indivíduos do sexo masculino, fisicamente ativos, aparentemente saudáveis, com idades entre 20 e 35 anos e já familiarizados com exercício exaustivo participaram voluntariamente desse estudo após a leitura e assinatura do termo de consentimento livre e esclarecido (ANEXO I). Todos os sujeitos estavam isentos de tratamentos farmacológicos, não eram fumantes e estavam livres de qualquer tipo de distúrbio neuromuscular ou cardiovascular. Adicionalmente, os participantes responderam a um questionário que objetiva detectar alguma anomalia que os impedisse de realizarem exercícios físicos extenuantes (ANEXO II). Os procedimentos adotados no presente estudo foram previamente aprovados pelo Comitê de Ética em Pesquisa da Escola de Educação Física e Esporte da Universidade de São Paulo (ANEXO III).

\subsection{Desenho experimental}

Todos os sujeitos foram submetidos a cinco sessões experimentais, as quais tiveram o intervalo mínimo de 72 horas e máximo de três semanas. Na primeira sessão, foram realizadas as medidas antropométricas empregadas na caracterização 
da amostra, bem como um teste progressivo até a exaustão voluntária em um cicloergômetro para a mensuração do $\mathrm{V}_{2} \max$, da potência externa correspondente ao limiar anaeróbio (WLan) e a $\mathrm{WV}_{2}$ max. Na segunda e na terceira sessões os sujeitos foram submetidos a seis testes de cargas constantes com intensidades abaixo da $\mathrm{WW}_{2}$ max. Na quarta sessão foi realizado um teste de carga constante com a intensidade acima da $\mathrm{WVO}_{2} \max$. Na quinta sessão os sujeitos foram submetidos ao teste anaeróbio de Wingate. O teste de Wingate foi realizado no Laboratório do Curso de Educação Física do Centro de Ciências Biológicas e da Saúde da Universidade Presbiteriana Mackenzie, ao passo que os demais testes foram realizados no Laboratório de Determinantes Energéticos do Desempenho Esportivo (LADESP) da Escola de Educação Física e Esporte da Universidade de São Paulo. A ordem das sessões 2-5, bem como a dos testes sub-W $\mathrm{W}_{2} \mathrm{O}_{2}$ max foi estabelecida aleatoriamente. Os testes foram realizados com a temperatura ambiente semelhante $\left(20-24^{\circ} \mathrm{C}\right)$ e duas horas após a última refeição. Os sujeitos foram solicitados a não praticarem exercícios físicos extenuantes e a não ingerirem álcool nas 48 horas que antecederam as coletas dos dados. No intuito de evitar possíveis influências ergogênicas (DOHERTY, 1998) e do ritmo cicardiano (MARTH, WOODS \& HILL, 1998) no MAOD, todos os testes foram realizados no mesmo período do dia e os sujeitos foram instruídos a não consumirem substâncias que possuísse cafeína nas 48 horas que precediam os testes.

\subsection{Antropometria}

Todas as mensurações antropométricas foram feitas por um único avaliador experiente, conforme os procedimentos sugeridos por NORTON e OLDS (1996). A massa corporal total foi medida com uma balança eletrônica com precisão de $0,1 \mathrm{~kg}$ (Filizola, modelo ID 1500, São Paulo, Brasil), ao passo que a estatura foi mensurada com um estadiometro de madeira com precisão $0,1 \mathrm{~cm}$. As dobras cutâneas foram medidas em quatro pontos anatômicos (tríceps, suprailíaca, abdominal e coxa) por meio de um compasso da marca Harpenden (West Sussex, UK). A mediana dos valores dessas medidas, as quais foram realizadas em triplicata e ao lado direito do corpo, foi empregada na estimativa da composição corporal. Quando a diferença entre as três medidas foi maior do que $10 \%$, uma quarta mensuração foi realizada. A 
densidade corporal foi estimada pela equação generalizada de JACKSON e POLLOCK (1985), ao passo que o percentual de gordura foi estabelecido pela equação de BROZEK et al. (1963).

\subsection{Determinação do consumo máximo de oxigênio e do limiar anaeróbio}

$O$ teste incremental até o limite de tolerância foi realizado em um cicloergômetro eletromagnético de membros inferiores (Godart-Holland, LANNOY). A altura do selim foi individualmente ajustada, tendo como referência a extensão quase total dos joelhos dos sujeitos em um ciclo completo do pedal. Antes do início do teste os participantes permaneceram cinco minutos sentados no cicloergômetro para 0 estabelecimento da linha de base do $\mathrm{V}_{2}\left(\dot{\mathrm{V}} \mathrm{V}_{2\llcorner\mathrm{~B}}\right.$ ), a qual foi determinada a partir da média aritmética do $\mathrm{V}_{2}$ nos trinta segundos finais desse período. Após o aquecimento de 3 minutos apenas com a resistência inercial do equipamento, os sujeitos se exercitaram com o ritmo em $60 \mathrm{rpm}$ e com o incremento da intensidade de $30 \mathrm{~W} \cdot \mathrm{min}^{-1}$. O teste foi interrompido quando a cadência do pedal era menor que 50 rpm. Durante todo o teste as trocas gasosas e a freqüência cardíaca (FC) foram mensuradas respiração a respiração. Amostras de sangue foram coletas imediatamente após o teste, no segundo e no terceiro minutos da recuperação para se mensurar as concentrações sangüíneas lactato de pico ([La]pico), ao passo que a freqüência cardíaca máxima ( $F C \max$ ) foi estabelecida pelo maior valor medido ao final do teste. $\mathrm{O}$ ทं ${ }_{2}$ max foi determinado a partir da obtenção de, pelo menos, três dos seguintes critérios: exaustão do sujeito, o aumento do $\dot{\mathrm{w}}_{2}$ menor que 2,1 $\mathrm{ml} \cdot \mathrm{kg}^{-1} \cdot \mathrm{min}^{-1}$ mediante o incremento da intensidade, a razão de trocas respiratórias maior que 1,10, concentração de lactato sangüíneo após o teste maior que 8,0 mmol. $\left.\right|^{-1}$, a freqüência cardíaca máxima predita pela idade (220-idade) (HOWLEY, BASSET \& WELCH, 1995). A WW'O ${ }_{2}$ max foi estabelecida como a potência externa máxima em que $\mathrm{O} \mathrm{V}_{2} \max$ foi alcançado. O Lan foi estabelecido visualmente mediante o segundo ponto de inflexão da curva da ventilação, com concomitante queda da $\mathrm{PCO}_{2}$ (MILLET, JAQUEN, BORRANI \& CANDAU, 2002) 


\subsection{Testes com cargas constantes}

O cicloergômetro, o ajuste da altura do selim, o ritmo do pedal, o aquecimento, o critério de interrupção e a mensuração do $\mathrm{V}_{2}$ nos exercícios com cargas constantes foram idênticos aos empregados no teste progressivo até a exaustão. Os sujeitos se exercitaram por dez minutos, ou até a exaustão voluntária, em seis testes de intensidades abaixo da $\mathbf{W}^{\circ} \mathrm{O}_{2} \max \left(40-90 \% \mathbf{W v}_{2} \max \right)$ e em um teste com a intensidade acima da $\mathrm{WV}^{\circ} \mathrm{V}_{2} \max \left(110 \% \mathrm{~W}^{\mathrm{V}} \mathrm{O}_{2} \max \right)$. O período de recuperação entre essas tarefas foi de aproximadamente dez minutos, ou até atingir o valor individual do $\dot{\mathrm{V}}_{2 L B}$. A média do $\overline{\mathrm{V}}_{2}$ no último minuto dessas tarefas foi utilizada para representar o valor de pico do $\mathrm{V}_{2}$ nessas tarefas. O pico da FC foi medido ao final dos testes. Além disso, amostras contendo $25 \mu \mathrm{l}$ de sangue foram coletadas do lóbulo da orelha antes de cada teste ([La]]repouso), imediatamente após o término e no terceiro, no quinto e no sétimo minutos de recuperação para a mensuração das [La`]. O maior valor após o exercício foi utilizado para representar o lactato de pico.

\subsection{Teste de Wingate}

Para a aplicação do teste anaeróbio de Wingate foram seguidas as recomendações descritas por INBAR et al. (1996). Brevemente, antes da execução desse teste, os sujeitos realizaram um aquecimento de $5 \mathrm{~min}$ com a resistência inercial do equipamento tendo a inclusão de dois tiros, cada um de $4 \mathrm{~s}$, realizados no segundo e no quarto minutos. Após 10 minutos de repouso, os sujeitos foram verbalmente encorajados a pedalarem na maior velocidade possível durante $30 \mathrm{~s}$ contra a resistência de $0,09 \mathrm{kp} \cdot \mathrm{kg}^{-1}$ da massa corporal. A potência externa foi calculada a cada $1 \mathrm{~s}$ por meio de um software (Wingate Test, Cefise, Brasil). A maior potência externa gerada no início do teste foi utilizada para representar a potência de pico (PP), enquanto a média aritmética da potência gerada durante os $30 \mathrm{~s}$ foi utilizada para representar a potência média (PM).

\subsection{Coleta dos dados fisiológicos}

$\mathrm{O} \mathrm{W}_{2}$ foi mensurado continuamente por meio de um analisador de gases portátil ( $\mathrm{K} 4 \mathrm{~b}^{2}$ Cosmed, Roma, Itália), ao passo que a $\mathrm{FC}$ foi medida por um cardiofreqüencímetro (Polar, Kempele, Finlândia) acoplado a esse equipamento. 
Uma máscara de silicone com baixa resistência que mantém o nariz e a boca cobertos (Hans Rudolph, Kansas City, USA) foi empregada na coleta do ar utilizado nas análises da ventilação, das frações do oxigênio e do dióxido de carbono. Antecedendo cada sessão de coleta de dados, o analisador de gases foi calibrado utilizando o ar ambiente e com um gás de composição conhecida $\left(20,9 \%\right.$ de $\mathrm{O}_{2}$ e $5 \%$ de $\mathrm{CO}_{2}$ ). A calibração do fluxo de ar foi realizada com uma seringa com volume de 3 litros (Quinton Instruments, Seattle, WH). A calibragem do tempo de atraso para a análise da amostra de ar expirada foi realizada de acordo com as especificações do fabricante ( $\mathrm{K} 4 \mathrm{~b}^{2}$ instruction manual). Esse tempo de atraso é de aproximadamente 500 ms e automaticamente considerado nos cálculos das trocas gasosas. As concentrações sangüíneas de lactato foram determinadas por meio de um analisador automático de lactato (Yellow Springs 1500 Sport, Ohio, USA), o qual foi calibrado a cada dez análises, tendo como referência a concentração de lactato de $5 \mathrm{mmol} \cdot{ }^{-1}$.

\subsection{Cálculos}

A média aritmética do $\mathrm{v}_{2}$ nos trinta segundos finais dos exercícios sub- $\mathrm{W}^{\mathrm{H}} \mathrm{O}_{2}$ max foi plotada sobre as suas respectivas intensidades para desenvolver individualmente as equações de regressão linear. Os coeficientes angulares gerados a partir dessas equações foram empregados na estimativa da demanda de oxigênio $\left(\dot{\mathrm{V} O} \mathrm{O}_{2 \mathrm{DEM}}\right.$ ) do exercício supra-WنัO ${ }_{2} \max$ (equação 6). O método dos trapézios foi utilizado no cálculo da área do $\mathrm{v}_{2}$ em relação ao tempo de duração do exercício supra- $\mathrm{W}_{\mathrm{V}} \mathrm{O}_{2}$ max. Em seguida, o $\dot{\mathrm{W}} \mathrm{O}_{2}$ acumulado ( $\dot{\mathrm{V}} \mathrm{O}_{2 \mathrm{ACUM}}$ ) foi determinado a partir da exclusão do $\dot{V}_{2 L B}(M E Z Z A N I$ et al., 2006). O MAOD foi estabelecido a partir da subtração do $\dot{\mathrm{V}}_{2 A C U M}$ do $\mathrm{V}_{2 D E M}$.

$$
\left.\mathrm{VO}_{2 \mathrm{DEM}}=\left[\left(b^{*} 110\right) / 60\right) \cdot t\right]
$$

EQUAÇÃO 6

Onde VัO $_{2 D E M}$ é a demanda de $\mathrm{O}_{2}$ estimada para o exercício supra-WVंO $\mathrm{W}_{2} \max ; 110$ é a intensidade do exercício supra- $\mathrm{WVO}_{2} \max ; b$ é o coeficiente angular em I. $\mathrm{min}^{-1}$ gerado a partir da regressão linear estabelecida entre $\mathrm{V}_{2}$-intensidade dos testes sub-WنंO ${ }_{2}$ max; $t$ é o tempo de duração do exercício expresso em segundos. 
Em todos os testes de carga constante $0 M^{M O O D_{C P}}$ foi assumido como sendo 0 EPOC $_{\text {RÁPIDO }}$ (BENEKE et al., 2004; BENEKE et al., 2002). Conforme descrito previamente (ÖZYENER et al., 2001), a análise da resposta cinética off do $\mathrm{V}_{2}$ nas intensidades abaixo do limiar anaeróbio foi ajustada por um modelo monoexponencial (Equação 7), ao passo que nas intensidades acima do Lan foi aplicado um modelo biexponencial (Equação 8) (Origin, Microcal, USA). Assim, a contribuição do sistema anaeróbio alático pode ser determinada pela integração da parte exponencial do componente rápido do excesso do consumo após o exercício (Equação 9).

$\dot{\mathrm{v}} \mathrm{O}_{2(t)}=\mathrm{y} 0+\left(\mathrm{A}_{1} \mathrm{e}^{-\left(t-\delta_{1}\right) / \tau_{1}}\right)$

EQUAÇÃO 7

$\dot{\mathrm{v}} \mathrm{O}_{2(t)}=\mathrm{y} 0+\left(\mathrm{A}_{1} \mathrm{e}^{-(t-\delta) / \tau_{1}}\right)+\left(\mathrm{A}_{2} \mathrm{e}^{-(t-\delta) / \tau_{2}}\right)$

EQUAÇÃO 8

$M A O D_{C P}=\tau_{1} \cdot\left(A_{1} / 60\right)$

EQUAÇÃO 9

Onde ${ }_{1} \mathrm{e}_{2}$ denotam, respectivamente, o componente rápido e lento do excesso do consumo de oxigênio após o exercício; $\mathrm{y} 0=$ linha de base; $\mathrm{A}, \tau$ e $\delta$ são referentes à amplitude em $\mathrm{ml} \cdot \mathrm{min}^{-1}$, à constante de tempo (s) e ao tempo de atraso (s), respectivamente.

O MAOD ${ }_{\text {LA-1 }}$ foi determinado pela área remanescente do MAOD após a subtração do $M A O D_{C P}\left(M A O D_{L A-1}=M A O D-M A O D_{C P}\right)$. Essas estimavas também foram expressas percentualmente ao MAOD. OMAOD $D_{L A-2}$ foi calculado assumindo que $1 \mathrm{mmol} \cdot \mathrm{l}^{-1}$ dos $\Delta\left[\mathrm{La}^{-}\right]$no exercício supra- $\mathrm{WV}^{\mathrm{O}}{ }_{2} \mathrm{max}$ equivale ao valor fixo de $3 \mathrm{ml}$ de $\mathrm{O}_{2} \cdot \mathrm{kg}^{-1}$ de massa corporal (di PRAMPERO \& FERRETTI, 1999) (MAOD somatória do $M A O D_{C P}$ com $M A O D_{L A-2}$ foi realizada na determinação do $M A O D_{M O D}$. 


\subsection{Análises estatísticas}

Todas as análises foram feitas utilizando o programa computadorizado SPSS (versão 13.0, Chicago, USA). A distribuição dos dados foi verificada por meio do teste de Shapiro-Wilk e apresentaram distribuição normal. Os dados foram reportados como médias e desvios padrão (SD). A comparação entre os dois métodos adotados para se estimar o componente lático do MAOD, bem como a comparação entre o MAOD e o MAOD ${ }_{\text {MOD }}$ foi realizada por meio do teste $t$ de Student para dados pareados. Além disso, a plotagem de BLAND e ALTMAN (1986) foi empregada para a análise visual da diferença entre $O M A O D$ e $O M_{M O D}$ MOD. $A$ regressão linear foi empregada na análise da relação entre os índices do teste de Wingate com $\circ \mathrm{MAOD}$, com $M A O D_{C P}$ e $\circ M M D_{L A-2}$. A análise de variância com medidas repetidas a um fator (intensidade) seguido pelo teste para comparações múltiplas de Bonferroni foi utilizada na comparação das variáveis mensuradas nos testes sub-Wvi ${ }_{2} \max$. A esfericidade dos dados foi verificada previamente pelo teste de Mauchly. O nível de significância adotado foi de $5 \%(p<0,05)$. O resumo das principais análises estatísticas encontra-se ao final da Tese (ANEXO IV).

\section{RESULTADOS}

A idade, os dados antropométricos e as variáveis analisadas no teste progressivo até a exaustão estão presentes na tabela 8. A tabela 9 apresenta os dados obtidos no exercício supra- $\mathrm{W}^{\mathrm{V}} \mathrm{O}_{2} \mathrm{max}$, ao passo que a tabela 10 demonstra os resultados dos termos da equação utilizada para ajustar a resposta cinética off do WंO . O VेO $_{2}$ pico no exercício supramáximo não era estatisticamente diferente do $\dot{\mathrm{v}}_{2} \max (p<0,05)$. A figura 9 apresenta um exemplo típico da resposta do $\mathrm{v}_{2}$ nessa tarefa. 
TABELA 8 - Idade, antropometria e variáveis analisadas no teste progressivo até a exaustão $(n=10)$.

\begin{tabular}{|c|c|}
\hline Idade (anos) & $23 \pm 4$ \\
\hline Estatura $(\mathrm{cm})$ & $176,4 \pm 6,8$ \\
\hline Massa corporal $(\mathrm{kg})$ & $72,4 \pm 8,2$ \\
\hline Percentual de gordura corporal (\%) & $12,0 \pm 4,5$ \\
\hline$\dot{\mathrm{V}} \mathrm{O}_{2\llcorner\mathrm{~B}}\left(1 \cdot \mathrm{min}^{-1}\right)$ & $0,28 \pm 0,57$ \\
\hline$\dot{\mathrm{V}} \mathrm{O}_{2} \max \left(I \cdot \mathrm{min}^{-1}\right)$ & $3,0 \pm 0,5$ \\
\hline$\dot{\mathrm{v}} \mathrm{O}_{2} \max \left(\mathrm{ml} \cdot \mathrm{kg}^{-1} \cdot \mathrm{min}^{-1}\right)$ & $41,5 \pm 5,7$ \\
\hline $\mathrm{WV}_{2} \max (\mathrm{W})$ & $250 \pm 40$ \\
\hline $\mathrm{R}$ & $1,29 \pm 0,09$ \\
\hline FCmax (bpm) & $179 \pm 9$ \\
\hline$[$ La] $] p i c o\left(m m o l \cdot l^{-1}\right)$ & $10,28 \pm 1,42$ \\
\hline Potência no Lan (W) & $180 \pm 30$ \\
\hline Potência no Lan (\% $\left.\mathrm{WV}^{2} \mathrm{O}_{2} \max \right)$ & $72 \pm 8$ \\
\hline
\end{tabular}


TABELA 9 - Variáveis mensuradas durante o exercício na intensidade de $110 \%$ do consumo máximo de oxigênio $(n=10)$.

\begin{tabular}{|c|c|}
\hline Tempo (s) & $161 \pm 40$ \\
\hline Intensidade (W) & $276 \pm 43$ \\
\hline$\dot{\mathrm{V}}_{2}$ pico (I) & $2,71 \pm 0,49$ \\
\hline$\dot{\mathrm{V}}_{2}$ pico $\left(\mathrm{ml} \cdot \mathrm{kg}^{-1} \cdot \mathrm{min}^{-1}\right)$ & $37,78 \pm 6,34$ \\
\hline FCpico (bpm) & $174 \pm 13$ \\
\hline$[$ La] $]$ pico $\left(\mathrm{mmol} \cdot \mathrm{I}^{-1}\right)$ & $10,89 \pm 1,20$ \\
\hline$[\mathrm{La}]$ ]repouso $\left(\mathrm{mmol} \cdot \mathrm{I}^{-1}\right)$ & $0,73 \pm 0,15$ \\
\hline Demanda de $\mathrm{O}_{2}(\mathrm{I})$ & $8,53 \pm 2,24$ \\
\hline Consumo de $\mathrm{O}_{2}$ acumulado (I) & $5,50 \pm 2,18$ \\
\hline MAOD (I) & $3,03 \pm 0,62$ \\
\hline MAOD $\left(\mathrm{ml}^{\prime} \mathrm{kg}^{-1}\right)$ & $42,17 \pm 9,10$ \\
\hline $\mathrm{MAOD}_{\mathrm{CP}}(\mathrm{I})$ & $0,98 \pm 0,45$ \\
\hline $\operatorname{MAOD}_{\llcorner A-1}(\mathrm{I})$ & $2,40 \pm 0,66$ \\
\hline $\operatorname{MAOD}_{\llcorner A-2}(\mathrm{I})$ & $2,20 \pm 0,34$ \\
\hline MAOD $_{\text {MOD }}(\mathrm{I})$ & $2,84 \pm 0,41$ \\
\hline \multicolumn{2}{|c|}{$\begin{array}{l}\text { Os valores são expressos em médias } \pm \text { desvios padrão. } \mathrm{VO}_{2} \text { pico }=\text { consumo de oxigênio de } \\
\text { pico; FCpico = freqüência cardíaca de pico; [La]pico = concentrações sangüíneas de lactato } \\
\text { de pico; [La] ]repouso = concentrações sangüíneas de lactato em repouso; } M_{A O D_{C P}}= \\
\text { estimativa da contribuição do metabolismo anaeróbio alático no máximo déficit acumulado de } \\
\text { oxigênio. }\end{array}$} \\
\hline
\end{tabular}


TABELA 10 - Resposta cinética off do consumo de oxigênio no exercício executado na intensidade de $110 \%$ da potência externa correspondente ao consumo máximo de oxigênio $(n=10)$.

\begin{tabular}{ll}
\hline $\mathrm{A}_{1}\left(1 \cdot \mathrm{min}^{-1}\right)$ & $1,35 \pm 0,32$ \\
$\tau_{1}(\mathrm{~s})$ & $28 \pm 6$ \\
$\delta(\mathrm{s})$ & $13 \pm 3$ \\
$\mathrm{~A}_{2}\left(1 \cdot \mathrm{min}^{-1}\right)$ & $0,51 \pm 0,13$ \\
$\tau_{2}(\mathrm{~s})$ & $53 \pm 10$ \\
\hline
\end{tabular}

Os valores são expressos em médias \pm desvios padrão. $A=$ amplitude; $\tau=$ constante de tempo; 1 e 2 denotam a fase rápida e lenta da reposta cinética off, respectivamente; $\delta=$ tempo de atraso.

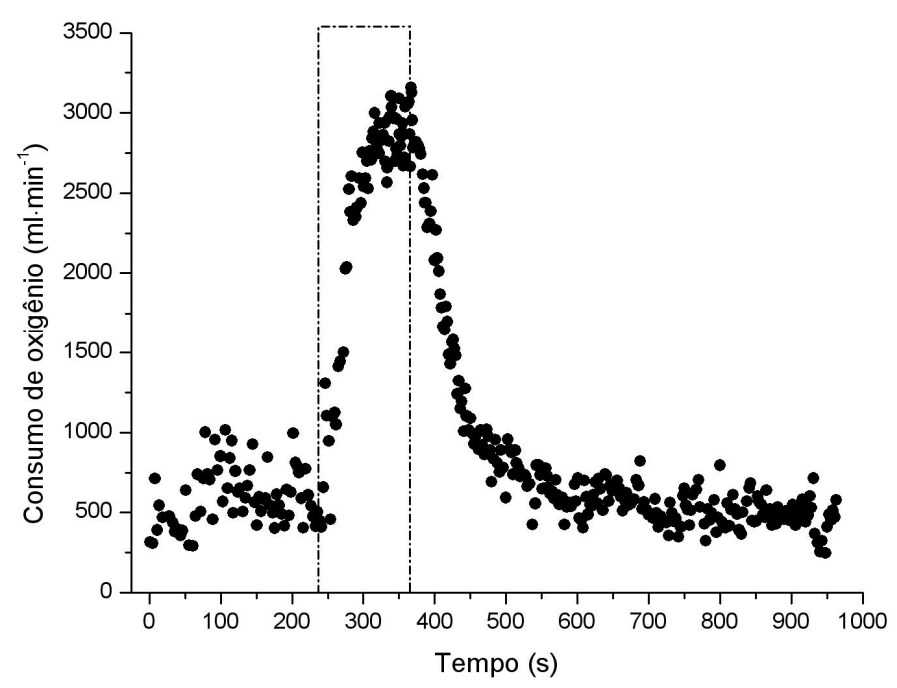

FIGURA 8 - Exemplo do comportamento típico do consumo de oxigênio respiração a respiração no teste com a intensidade de $110 \%$ da externa correspondente ao consumo máximo de oxigênio. As linhas pontilhadas marcam o início e o término do exercício.

A diferença detectada entre $\circ M A O D_{L A-1}$ e $\circ M A O D_{L A-2}$ não foi significativa $(p>$ $0,05)$. Consequentemente, $O M A O D_{M O D}$ também não diferiu estatisticamente do MAOD. A figura 10 apresenta os dados da plotagem de Bland-Altman para esses dados. Por sua vez, os valores percentuais do $M A O D_{L A-1}$ e do $M A O D_{C P}$ eram $78 \pm$ 
$9 \%$ e $22 \pm 9 \%$, respectivamente. De forma similar, os componentes lático e alático calculados para $\circ$ MAOD $_{\text {MOD }}$ representaram $78 \pm 6 \%$ e $22 \pm 6 \%\left(M_{A O D_{L A-2}}\right.$ e $\left.M A O D_{C P}\right)$, respectivamente.

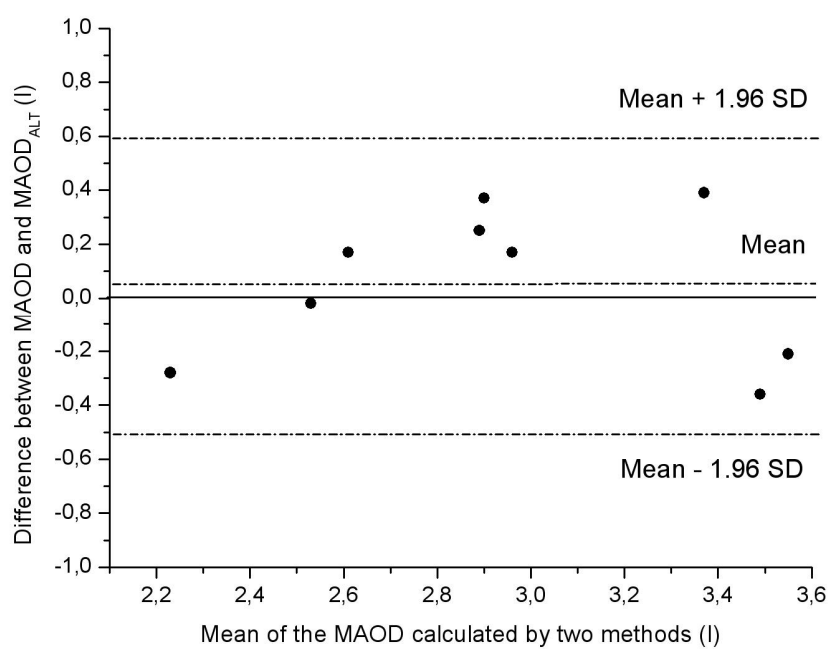

FIGURA 9 - $\underline{\text { Plotagem de Bland-Altman para o déficit máximo acumulado de } \mathrm{O}_{2}}$ (MAOD) e método alternativo proposto para estimá-lo (MAOD $\left.{ }_{\text {MOD }}\right)$ (n $=10$ ).

Os valores médios obtidos da PP e da PM foram $640 \pm 141 \mathrm{~W}$ e $474 \pm 90 \mathrm{~W}$, respectivamente. Tanto a PP $(r=0,10 ; p=0,78)$ como a $P M(r=0,25 ; p=0,48)$ não se correlacionaram com o MAOD $(p>0,05)$. Por outro lado, o MAOD ${ }_{M O D}$ estava positivamente correlacionado tanto com a PP $(r=0,85 ; p=0,002)$ como com a PM ( $r$ $=0,82 ; p=0,004)$. Ao se considerar as estimativas dos componentes anaeróbios do $M A O D$, constatou-se que $M A O D_{C P}$ estava estatisticamente associado à $P P(p<$ $0,05)$, ao passo que correlação detectada entre $M A O D_{L A-1}$ e a $P M$ não era significativa $(p>0,05)$ (figura 11$)$. Adicionalmente, O MAOD $D_{\text {LA-2 }}$ também estava correlacionado positivamente com a PM $(r=0,73 ; p=0,016)$. 

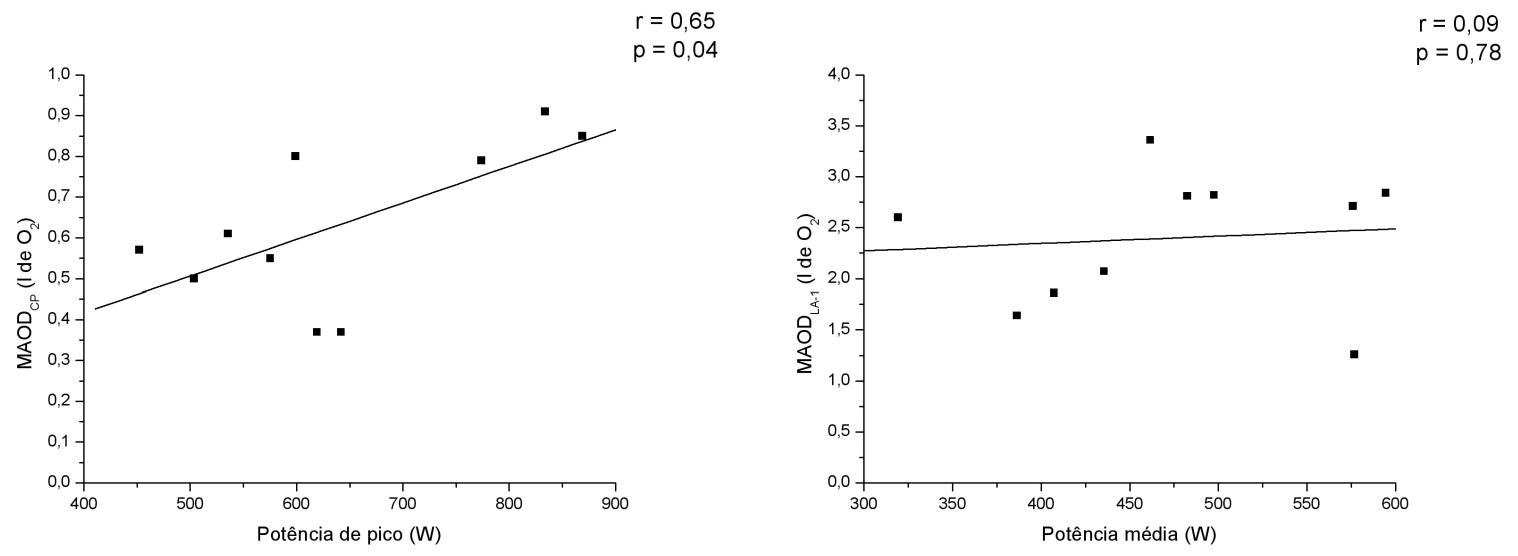

FIGURA 10 - Relação entre a participação alática estimada no Déficit Máximo Acumulado de $\mathrm{O}_{2}\left(\mathrm{MAOD}_{\mathrm{CP}}\right.$ ) com a potência de pico do teste de Wingate (painel à esquerda) e da participação lática do Máximo Déficit Acumulado de $\mathrm{O}_{2}$ (MAOD $\left.L A-1\right)$ com a potência média no teste de Wingate (painel à direita) $(n=10)$.

A tabela 11 apresenta os valores do pico do $\mathrm{V}_{2}$, da $\mathrm{FC}$ e das [La'], bem como o tempo de duração dos testes sub-Wvं ${ }_{2}$ max. A figura 12 apresenta um exemplo típico da resposta do $\mathrm{V}_{2}$ durante essas tarefas. A partir da intensidade de $50 \%$ WVंO ${ }_{2} \max$ foi constatado o aumento significativo do $\mathrm{v}_{2}(F=152,17 ; p<0,001)$ e das [La'] $(F=53,81 ; p<0,001)$ quando comparados à intensidade de $40 \%$ $\mathrm{WV}_{2} \mathrm{~V}_{2}$ max. A FC teve o aumento estatístico apenas a partir da intensidade de $60 \%$ $\mathrm{WviO}_{2} \max (\mathrm{F}=52,12 ; \mathrm{p}<0,001)$, ao passo que a primeira intensidade em que um sujeito não conseguiu completar dez minutos de exercício foi $70 \% \mathrm{WV}^{\mathrm{V}} \mathrm{O}_{2} \max$. Os valores médios do intercepto, do coeficiente angular e do $R^{2}$ das equações de regressão linear gerada a partir da relação VOO$_{2}$-intensidade, eram $0,67 \pm 0,12 \mathrm{I}, 0,29$ $\pm 0,041 \% \%$ da $\mathrm{WV}_{2} \mathrm{max}^{-1}$ e $0,93 \pm 0,03$, respectivamente $(\mathrm{p}<0,05)$. Adicionalmente, as diferentes detectadas das [La] em repouso nos testes de carga constante não eram estatisticamente significativas $(p>0,05)$. 
TABELA 11 - Respostas do pico do consumo de oxigênio, da freqüência cardíaca, das concentrações sangüíneas de lactato e do tempo de duração do exercício executado nas intensidades abaixo da potência externa correspondente ao consumo máximo de oxigênio $(n=10)$.

\begin{tabular}{lcccc}
\hline $\begin{array}{l}\text { Intensidade } \\
\left(\% \text { WvंO }_{2} \text { max }\right)\end{array}$ & $\begin{array}{c}\mathrm{W}_{2} \\
\left(1 \cdot \mathrm{min}^{-1}\right)\end{array}$ & $\begin{array}{c}\mathrm{FC} \\
(\mathrm{bpm})\end{array}$ & $\begin{array}{c}{[\mathrm{La}]} \\
\mathrm{mmol} \cdot \cdot^{-1}\end{array}$ & $\begin{array}{c}\text { Duração } \\
(\mathrm{s})\end{array}$ \\
\hline $40 \%$ & $1,71 \pm 0,18$ & $123 \pm 8$ & $2,59 \pm 1,45$ & $600 \pm 0$ \\
$50 \%$ & $2,19 \pm 0,22^{\mathrm{d}}$ & $145 \pm 9$ & $4,84 \pm 1,89^{\mathrm{d}}$ & $600 \pm 0$ \\
$60 \%$ & $2,51 \pm 0,27^{\mathrm{c}}$ & $155 \pm 18^{\mathrm{c}}$ & $6,97 \pm 1,67^{\mathrm{c}}$ & $600 \pm 0$ \\
$70 \%$ & $2,71 \pm 0,25^{\mathrm{b}}$ & $175 \pm 10^{\mathrm{b}}$ & $8,59 \pm 1,30^{\mathrm{c}}$ & $577 \pm 72$ \\
$80 \%$ & $2,97 \pm 0,31^{\mathrm{e}}$ & $179 \pm 9^{\mathrm{b}}$ & $10,22 \pm 1,30^{\mathrm{b}}$ & $444 \pm 139$ \\
$90 \%$ & $3,17 \pm 0,31^{\mathrm{a}}$ & $177 \pm 10^{\mathrm{a}}$ & $9,90 \pm 1,21^{\mathrm{b}}$ & $306 \pm 128$
\end{tabular}

Os valores são expressos em médias \pm desvios padrão. a = maior que 40, 50, 60, 70 e 80\%; $b=$ maior que 40,50 e $60 \%$; c = maior que 40 e $50 \%$; $d$ maior que $40 \%$; e = 40, 50, 60 e 70 $\%$. Nível de significância $p<0,05$.

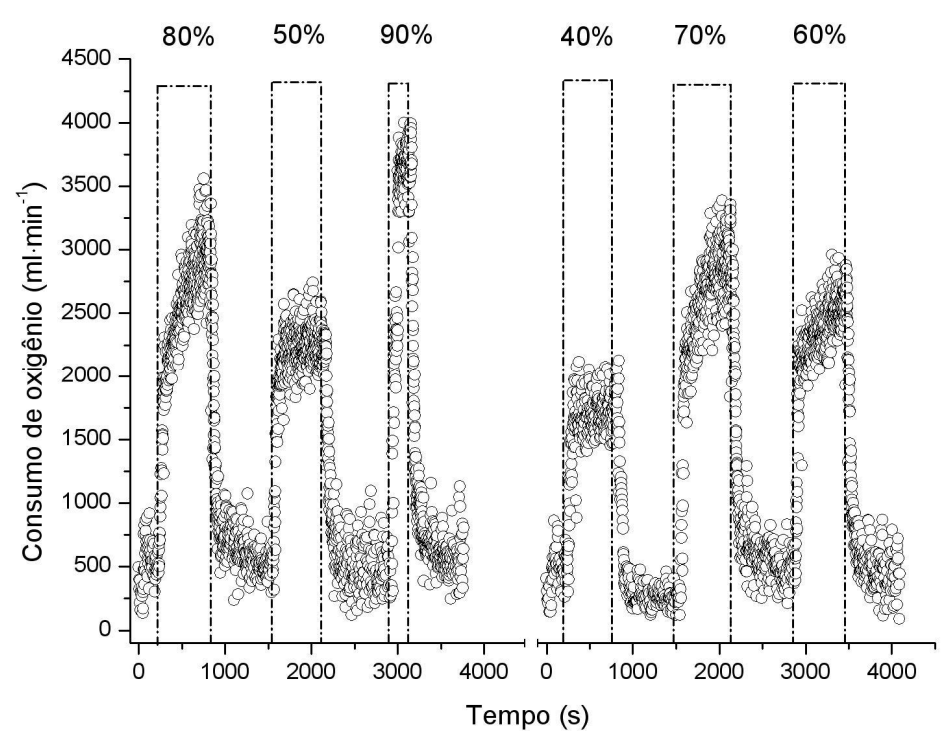

FIGURA 11 - Exemplo do comportamento típico do consumo de oxigênio nos testes abaixo da potência externa correspondente ao consumo máximo de oxigênio (\%) em duas sessões experimentais distintas. As linhas pontilhadas marcam o início e o término do exercício. 
Em relação à resposta cinética off do $\dot{\mathrm{VO}}_{2}$ nas intensidades sub- $\mathrm{WV}_{2} \mathrm{max}$, a análise de variância foi empregada apenas nos termos da fase rápida, haja vista que o ajuste biexponencial foi aplicado para todos os sujeitos apenas na intensidade de $90 \% \mathrm{WvO}_{2} \max$ (tabela 12). A $\mathrm{A}_{1}$ era estatisticamente maior a partir da intensidade de $60 \% \mathrm{WviO}_{2} \max (\mathrm{F}=30,01 ; \mathrm{p}<0,001)$, ao passo que a $\tau$ era significativamente menor na intensidade de $40 \% \mathrm{WviO}_{2}$ max quando comparada às demais $(F=3,31 ; p=0,01)$. Por outro lado, o $\delta$ não era diferente entre as situações $(F=5,78 ; p>0,05)$, além de estar muito próximo à zero.

TABELA 12 - Resposta da cinética off do consumo de oxigênio nas intensidades abaixo da potência externa correspondente ao consumo máximo de oxigênio $(n=10)$.

\begin{tabular}{|c|c|c|c|c|c|}
\hline $\begin{array}{l}\text { Intensidade } \\
\left(\% \mathrm{WWO}_{2} \max \right)\end{array}$ & $\begin{array}{c}A_{1} \\
\left(1 \cdot \min ^{-1}\right)\end{array}$ & $\begin{array}{l}\tau_{1} \\
(\mathrm{~s})\end{array}$ & $\begin{array}{c}\delta \\
(\mathrm{s})\end{array}$ & $\begin{array}{c}\mathrm{A}_{2} \\
\left(1 \cdot \mathrm{min}^{-1}\right)\end{array}$ & $\begin{array}{l}\tau_{2} \\
(\mathrm{~s})\end{array}$ \\
\hline 40 & $1,13 \pm 0,13$ & $39 \pm 7$ & $0,7 \pm 0,4$ & - & - \\
\hline 50 & $1,25 \pm 0,69$ & $51 \pm 12^{d}$ & $0,9 \pm 0,5$ & - & - \\
\hline 60 & $1,32 \pm 0,14^{d}$ & $57 \pm 15^{d}$ & $0,9 \pm 0,1$ & $0,49^{*}$ & $129^{*}$ \\
\hline 70 & $1,78 \pm 0,18^{b}$ & $52 \pm 21^{d}$ & $1,0 \pm 0,1$ & $0,61^{*}$ & $137^{*}$ \\
\hline 80 & $1,84 \pm 0,46^{b}$ & $52 \pm 15^{d}$ & $1,3 \pm 0,8$ & $0,41^{*}$ & $80^{*}$ \\
\hline 90 & $2,17 \pm 0,45^{b}$ & $42 \pm 10^{d}$ & $2,5 \pm 1,7$ & $0,41 \pm 0,22$ & $86 \pm 46$ \\
\hline \multicolumn{6}{|c|}{$\begin{array}{l}\text { A = amplitude; } \tau=\text { constante de tempo; } 1 \text { e } 2 \text { denotam a fase rápida e lenta da reposta } \\
\text { cinética off, respectivamente; } \delta=\text { tempo de atraso; } b=\text { maior que } 40,50 \text { e } 60 \% \text {; } d=\text { maior } \\
\text { que } 40 \% \text {; - = não mensurado; * }=0 \text { ajuste biexponencial não foi aplicado para todos os } \\
\text { sujeitos nessas cargas, portanto não foi realizada a análise estatística para esses termos da } \\
\text { equação. Nível de significância } p<0,05 \text {. }\end{array}$} \\
\hline
\end{tabular}

A figura 13 apresenta o comportamento das contribuições percentuais dos metabolismos anaeróbios durante o exercício realizado abaixo da $\mathrm{WV}_{2} \mathrm{O}_{2} \mathrm{max}$. A transição da predominância do MAA para o MAL se inicia em, aproximadamente, $70 \% \mathrm{WViO}_{2}$ max. Essa carga corresponde à média do valor da intensidade do Lan (tabela 1). 


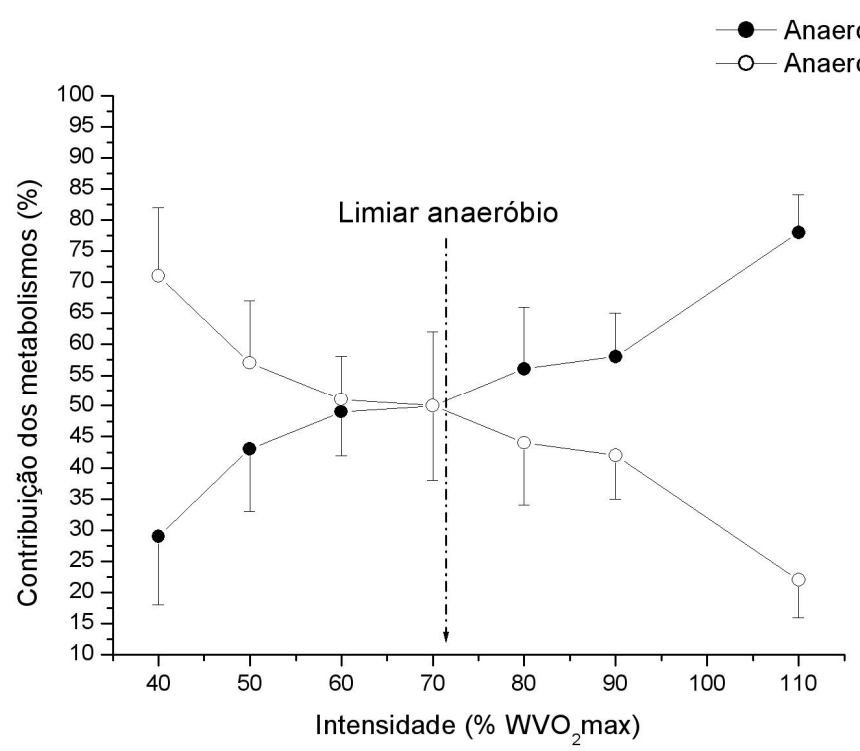

FIGURA 12 - $\underline{\text { Contribuição percentual dos metabolismos anaeróbios alático e lático }}$ durante o exercício realizado nas intensidades abaixo e acima da potência externa correspondente ao consumo máximo de oxigênio (n $=10)$.

\section{DISCUSSÃO}

Até o presente momento, esse é o primeiro estudo que se propôs analisar a possibilidade de se estimar os componentes lático e alático do MAOD mediante a

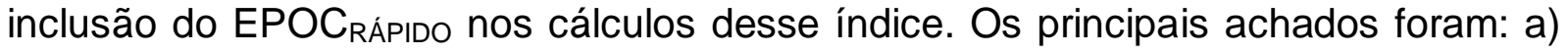
os dois métodos empregados na estimativa da contribuição do MAL no MAOD geraram valores estatisticamente similares e, conseqüentemente, O MAOD ${ }_{M O D}$ também não diferiu significativamente do MAOD; b) o $M A O D_{C P}$ também estava positiva e significativamente correlacionado com a PP; c) de forma similar, o MAOD $_{\text {MOD }}$ estava estatisticamente correlacionado com a PP e com a PM; c) os valores percentuais do $\mathrm{MAOD}_{\mathrm{LA}-1}$ e do $\mathrm{MAOD}_{\mathrm{CP}}$ eram aproximadamente 78 e 22\%, respectivamente; d) a predominância do MAL sobre o MAA durante os exercícios submáximos ocorre a partir da intensidade do Lan.

Independentemente das vantagens e das limitações apontadas previamente (BAGSBO, 1996a; GRAHAM, 1996), o MAOD tem sido considerado o procedimento mais aceitável para avaliação indireta da CAN desde o início da década de 1990 (MAXWELL \& NIMMO, 1996; MEDB $\varnothing$ \& TABATA, 1993). A sua validade tem sido 
estabelecida a partir de diferentes perspectivas, tais como, a capacidade de acompanhar as mudanças proporcionadas pelo treinamento predominantemente anaeróbio (WEBER \& SCHNEIDER, 2002), nas correlações significativas constatadas com outros testes anaeróbios (SCOTT, 2006b; MAXWELL \& NIMMO, 1996; SCOTT et al., 1991) e em virtude de se manter inalterado mediante a situação de hipóxia (MEDB $\varnothing$ et al., 1988).

Os valores do MAOD obtidos no presente estudo são similares aos descritos para sujeitos saudáveis em cicloergômetro (WEBER \& SCHNEIDER, 2001). Além disso, o MAOD, o tempo de permanência e a potência externa utilizada no teste supramáximo eram substancialmente menores que os reportados para ciclistas profissionais (BUCK \& NAUGHTON, 1998; HARGREAVES et al., 1997). De certa forma, corroboram-se outros achados que demonstraram a capacidade do MAOD em diferenciar sujeitos com diferentes níveis de aptidão anaeróbia (GASTIN \& LAWSON, 1994; SCOTT et al., 1991).

Estudos prévios detectaram o aumento de aproximadamente 10\% no MAOD após a suplementação com a creatina monohidratada (JACOBS et al., 1997) ou com a cafeína (DOHERTY, 1998), sugerindo-se que os principais efeitos ergogênios dessas substâncias estão no acréscimo da contribuição do MAA e do MAL, respectivamente. No entanto, essas inferências foram realizadas sem a devida obtenção de dados experimentais, haja vista que a versão tradicional do MAOD não permite estimar os seus componentes anaeróbios. Na presente investigação, os dados obtidos acerca das contribuições percentuais do MAL e do MAA no MAOD e do $M A O D_{M O D}$ são similares aos resultados obtidos por meio de biópsia muscular (MEDB $\varnothing$ \& TABATA, 1993) ou por estimativas feitas com base em dados das mudanças metabólicas no músculo esquelético descritos na literatura científica (MEDBØ et al., 1988). Dessa forma, parece que a adição do EPOC RÁPIDo nos cálculos do MAOD ou o próprio $M A O D_{M O D}$ podem auxiliar futuros estudos, à medida que eles viabilizam valores percentuais satisfatórios das contribuições dos componentes anaeróbios durante o exercício de alta intensidade. Entretanto, a plotagem de Bland-Altman revela que existe uma tendência do MAOD MOD $_{\text {de gerar }}$ valores menores quando comparados ao MAOD. Isso pode levar a duas possíveis hipóteses: a) o MAOD tradicional pode ser influenciado pela diminuição da eficiência 
dos testes de cargas constantes; b) o MAOD $\mathrm{MOD}$ pode subestimar a CAN. Logo, outros estudos devem ser elaborados, com 0 intuito de se testar essas duas hipóteses.

Similarmente ao estudo de CALBET et al. (1997), o MAOD não estava associado aos índices proporcionados pelo teste de Wingate. Adicionalmente, a correlação entre o MAOD $\mathrm{LA}_{-1}$ e a PM não era significativa, ao passo que a correlação

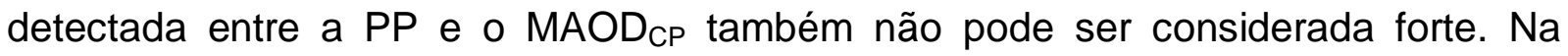
presente investigação o coeficiente de variação do MAOD foi de aproximadamente $20 \%$. Essa elevada variabilidade também tem sido observada em outras investigações e associada à pouca experiência dos sujeitos com o ergômetro utilizado (SCOTT et al., 1991), à baixa motivação em se exercitar intensamente por muito tempo (MEDBØ et al., 1988), à variabilidade diária da CAN (HILL et al., 1998) e à heterogeneidade dos grupos (SCOTT et al., 1991). Estatisticamente, tem se considerado que isso poderia influenciar o nível de associação do MAOD com os demais testes utilizados para avaliação do metabolismo anaeróbio (HILL et al., 1998). No entanto, os índices do teste de Wingate apresentaram um coeficiente de variação similar ao do MAOD ( $\cong 20 \%$ ), o qual poderia favorecer a detecção de correlação significativa entre esses testes. Nesse sentido, parece que a variabilidade dos dados não explica plenamente os resultados obtidos.

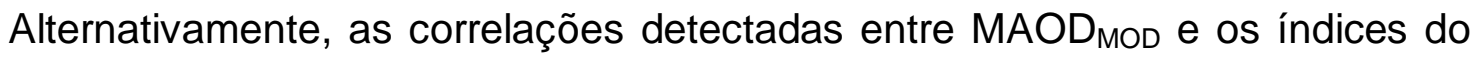
teste de Wingate, bem como a do $\mathrm{MAOD}_{\mathrm{LA}-2}$ com a PM poderiam indicar que os pressupostos utilizados no cálculo do MAOD também tenham influenciado esses achados. A determinação do MAOD depende diretamente da estimativa da demanda de $\mathrm{O}_{2}$ do exercício supramáximo. Para isso, é estabelecida uma relação linear entre $\dot{\mathrm{V}} \mathrm{O}_{2}$-intensidade dos testes submáximos, a qual tem sido objeto de algumas críticas (BEARDEN \& MOFFAT, 2000; BAGSBO, 1996a). Em linhas gerais, acredita-se que o surgimento do componente lento da cinética do $\mathrm{V}_{2}$ nas intensidades acima do limiar de lactato pode afetar a determinação do estado estável do $\dot{\mathrm{V}}_{2}$ e, conseqüentemente, o cálculo do déficit de $\mathrm{O}_{2}$ (BEARDEN \& MOFFAT, 2000). Assim, diferentemente do MAOD tradicional, o cálculo do $M A O D_{M O D}$ não seria influenciado pela alteração da eficiência dos exercícios submáximos. Nesse sentido, a principal vantagem do $M A O D_{M O D}$ é não ser dependente da estimativa da demanda de $\mathrm{O}_{2}$ no 
exercício supramáximo e, conseqüentemente, não ser influenciado pelo estabelecimento da relação linear entre $\mathrm{V}^{\circ} \mathrm{O}_{2}$-intensidade dos testes submáximos.

Os procedimentos utilizados no estabelecimento do MAOD também têm sido considerados morosos, sobretudo pelo fato de envolver muitas sessões experimentais (MAXWELL \& NIMMO, 1996). Logo, outras investigações foram conduzidas no intuito de propor métodos alternativos capazes de determinarem 0 MAOD sem a necessidade de estimar a demanda de $\mathrm{O}_{2}$ do exercício de alta intensidade (HILL et al., 1998; HILL, 1996). David W. Hill sugeriu que a demanda de $\mathrm{O}_{2}$ e o déficit de $\mathrm{O}_{2}$ podem ser derivados matematicamente baseando-se apenas nos resultados de testes supramáximos realizados em cicloergômetro (HILL, 1996) ou esteira rolante (HILL et al., 1998). Porém, de forma similar ao método tradicional sugerido por MEDB $\varnothing$ et al. (1988), esse método assume que a eficiência durante os testes de cargas retangulares é constante. Além disso, é necessária a execução de quatro testes de altas intensidades que variam entre 95 e $110 \%$ da $\mathrm{Wv}_{2}$ max. Portanto, parece que a execução de apenas um teste de carga constante (supramáximo) e o menor coeficiente de variação (aproximadamente 14\%) quando comparado ao MAOD tradicional podem ser considerados vantagens adicionais do MAOD $_{M O D}$.

Evidentemente, em virtude da inexistência de um método universalmente aceito como padrão ouro para a avaliação do metabolismo anaeróbio (GASTIN, 1994), os resultados dessa investigação estão condicionados à aceitação da validade dos métodos empregados nas estimativas dos componentes anaeróbios do MAOD. Trabalhos prévios apresentaram algumas restrições acerca da utilização do EPOC $_{\text {RÁPIDO }}(T O M L I N \&$ WENDER, 2001), das [La”] (VANDEWALLE et al., 1987) e do teste de Wingate (VANDEWALLE et al., 1987). Em linhas gerais, elas convergem para o fato da estimativa da demanda metabólica dos músculos ativos ser realizada mediante a análise da resposta sistêmica de variáveis fisiológicas (whole body) ou pela utilização da potência externa gerada durante um esforço intenso. Por outro lado, outros trabalhos sugeriram fortes evidências de validade desses métodos. Após a proposição inicial de MARGARIA et al. (1933), estudos posteriores evidenciaram que a ressíntese dos fostatos de alta energia é dependente do $\mathrm{W}_{2}$ após o exercício, tanto em animais (PIIPER \& SPILLER, 1970; IDSTRÖM et al., 1985) como em seres 
humanos (ROSSITER et al., 2002; JANSSON et al., 1990). Os achados dos trabalhos reunidos por BAR-OR (1987) indicam que a PP e a PM estavam positivamente correlacionadas com o percentual e a área de secção transversa das fibras de contração rápida. Similarmente, as [La] parecem estar associadas ao desempenho em provas de curta duração (JACOBS, 1981).

Em relação à resposta cinética off do $\mathrm{V}_{2}$, os resultados obtidos na presente investigação corroboram parcialmente os dados apresentados na literatura científica. Os valores médios da $A_{1}$ na intensidade de $110 \% W_{W} \mathrm{~W}_{2}$ max eram similares aos dados obtidos na intensidade de $60 \% \mathrm{WV} \mathrm{W}_{2} \max$, ao passo que a $\tau_{1}$ detectada na intensidade de $110 \% \mathrm{WV}_{2}$ max era inferior a demais intensidades. ÖZYENER et al. (2001) detectaram que a $A_{1}$ e a $\tau_{1}$ da resposta cinética off do $\mathrm{V}_{2}$ também não eram estatisticamente modificadas em virtude da intensidade do exercício físico (domínios moderado, pesado, muito pesado e severo). Logo, esses pesquisadores concluíram que a resposta cinética off do $\mathrm{V}_{2}$ não é modulada apenas pela demanda metabólica imposta pela tarefa realizada (por exemplo, o acúmulo de lactato).

O $\delta$ foi diferente de zero, sobretudo, na intensidade de $110 \% \mathrm{~W}^{\mathrm{O}} \mathrm{O}_{2} \mathrm{max}$. Esse achado confirma os resultados de outro estudo que detectou $0 \delta$ de aproximadamente $25 \mathrm{~s}$ na resposta cinética off do $\mathrm{V}_{2}$ na corrida intensa $(18 \mathrm{~km} / \mathrm{h}$ com 20\% de inclinação) (di PRAMPERO, PEETERS \& MARGARIA, 1973). Isso poderia indicar a existência de uma fase cardiodinâmica ao término do exercício físico exaustivo de curta duração. Em outras palavras, talvez o elevado débito cardíaco induzido pela atividade física intensa prévia seja um dos responsáveis pelo $\mathrm{V}_{2}$ elevado durante os segundos iniciais da recuperação. Todavia, as colocações supracitadas devem ser contempladas com cautela, uma vez que as investigações conduzidas acerca da resposta cinética off do $\mathrm{v}_{2}$ possuem procedimentos experimentais diferentes aos adotados no presente estudo. As principais diferenças a serem destacadas são: a) nesses estudos os exercícios de cargas constantes são realizados em sessões experimentais distintas; b) a determinação da intensidade do esforço é frequentemente realizada por meio dos domínios metabólicos; c) é comum se aplicar algum tipo de filtro (média de tempo, média móvel a cada cinco respirações ou interpolação a cada um segundo) na resposta respiração a respiração 
do $\dot{\mathrm{V}} \mathrm{V}_{2}$, objetivando eliminar possíveis ruídos.

Evidências mais recentes têm indicado que a degradação da CP não ocorre apenas para a manutenção da oferta da ATP durante o exercício de alta intensidade e de curta duração (GREENHAFF, 2001; GREENHAFF e TIMMONS, 1998). Assim, o comportamento das contribuições do MAA e do MAL durante os exercícios de cargas constantes reforça as hipóteses que foram estabelecidas acerca da relação entre 0 MAA e o metabolismo oxidativo no início e durante o exercício físico de intensidade moderada. Alguns trabalhos realizados com o interesse de compreender a dinâmica da resposta cinética on do $\mathrm{V}_{2}$, mais especificamente a fase II (ou componente primordial), têm demonstrado que a ativação do metabolismo oxidativo é dependente da degradação da ATP e da CP na fase inicial do exercício físico (ROSSITER et al., 2002; ROSSITER, WARD, DOYLE, HOWE, GRIFFITHS, \& WHIPP, 1999). Possivelmente, o aumento das concentrações de ADP, Pi e da creatina na forma livre seria um dos mecanismos responsáveis pela regulação da respiração mitocondrial (ROSSITER et al., 1999; GREENHAFF, 2001; WALSH, TIIVEL, TONKONOGI \& SAHLIN, 2002).

Isso é possível porque a $\mathrm{CP}$ tem a capacidade de atuar como um "transportador de energia" mediante o sistema de lançadeira de creatina (creatine shuttle) (GREENHAFF, 2001; GREENHAFF \& TIMMONS, 1998). Durante a contração muscular de baixa intensidade, a redução das concentrações da ATP é amenizada pela ativação da isoforma extramitocondrial da creatina quinase, a qual possibilita ressintetisar a ATP mediante a degradação da CP. Uma vez que a membrana externa da mitocôndria é permeável à creatina, o seu aumento no espaço entre as membranas mitocondriais resulta na produção de ADP com subseqüente ressíntese de $\mathrm{CP}$, graças ao aumento da atividade da isoforma mitocondrial da creatina quinase. Dessa forma, a CP pode ser deslocada para o citoplasma no intuito de ressintetisar a ATP sarcoplasmática (GRASSI, 2005). A figura 13 apresenta um esquema representativo da lançadeira de creatina. 


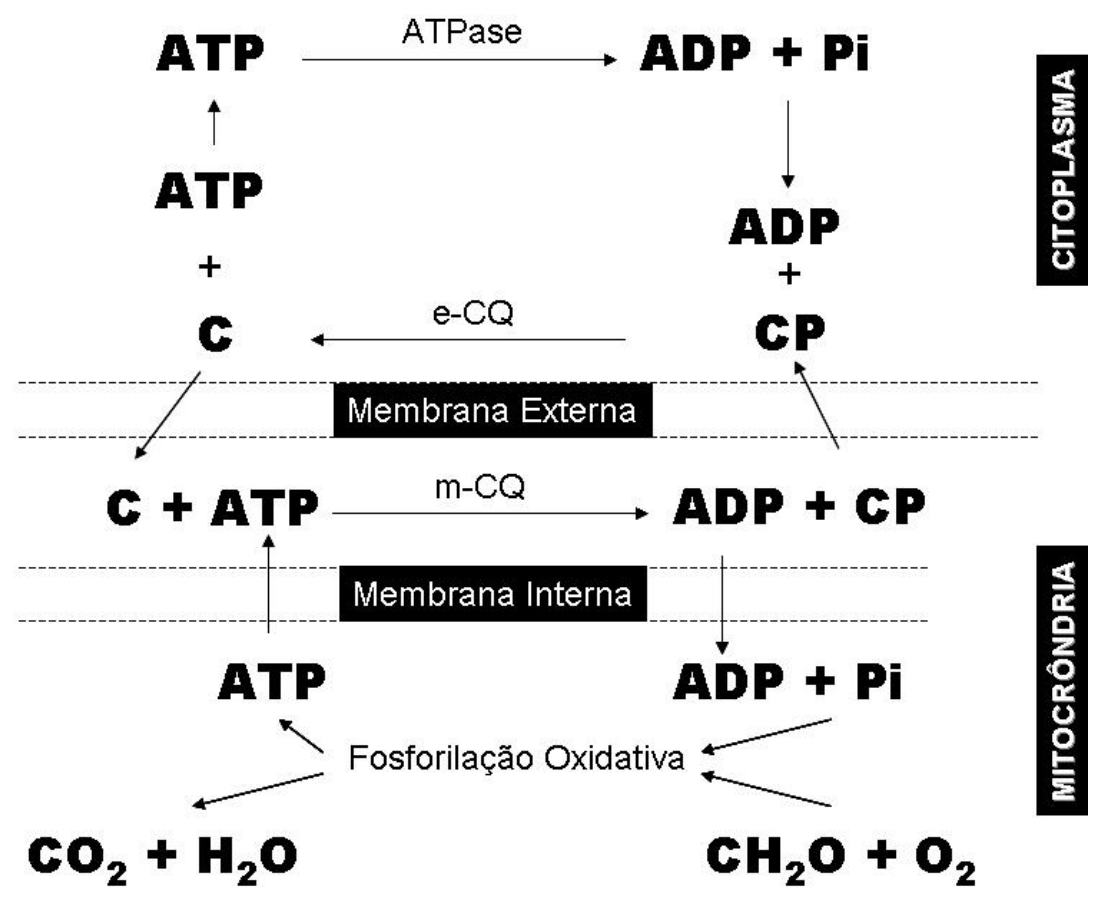

FIGURA 13 - Esquema representativo do sistema da lançadeira de creatina, sendo e-CQ = isoforma extramitocondrial da creatina quinase; $m-C Q=$ isoforma intramitocondrial da creatina quinase (adaptado de GRASSI, 2005).

Embora a sua origem tenha sido objetivo de recentes discussões (ROBERGS et al., 2004), é incontestável que o aumento das concentrações citoplasmáticas de $\mathrm{H}^{+}$ deve-se direta ou indiretamente à ativação do MAL. Em um estudo realizado com músculos isolados de ratos, constatou-se que o aumento excessivo do $\mathrm{Pi}(20 \mathrm{mM})$ e a queda acentuada do $\mathrm{pH}$ (6.6) são capazes de reduzirem a respiração mitocondrial (WALSH et al., 2002). Em outras palavras, demonstrou-se que pequenas mudanças nesses parâmetros podem ativar a fosforilação oxidativa, ao passo que grandes mudanças podem afetar a função mitocondrial. Teoricamente, isso se deve à ativação da isoforma extramitocondrial da creatina quinase ser gravemente prejudicada pelas elevadas concentrações de $\mathrm{Pi}$ e de $\mathrm{H}^{+}$(WALSH et al., 2002). Por sua vez, o conceito do Lan foi desenvolvido para estimar a intensidade do esforço na qual a energia fornecida pelo metabolismo aeróbio é complementada pelo MAL (SVEDAHL \& MacINTOSH, 2003). Logo, é atraente suspeitar que, devido ao 
aumento acentuado das concentrações de $\mathrm{H}^{+}$nas intensidades acima do Lan, haveria uma redução da respiração mitocondrial em virtude da redução no funcionamento do sistema de lançadeira de creatina. Como conseqüência, ocorreria a transição da predominância da contribuição percentual do MAA para o MAL. Entretanto, essa inferência dever ser apreciada com cautela pois, em algumas circunstâncias, as [La`] antes do segundo e do terceiro testes de uma dada sessão experimental eram visualmente maiores que as [La'] de repouso. De certa forma, isso pode ter influenciado os cálculos da contribuição do MAL nessas tarefas.

\section{LIMITAÇÕES}

Assim como outros trabalhos que objetivaram quantificar as contribuições dos metabolismos anaeróbios durante o exercício físico, o presente estudo tem como limitação principal a impossibilidade de se mensurar diretamente a validade e a precisão dos métodos empregados. Isso se deve à inexistência de um método universalmente aceito como padrão ouro (gold standard) para a mensuração dessas vias energéticas. Adicionalmente, as demais limitações mais relevantes que foram descritas na literatura científica são:

a) Todas as estimativas dos metabolismos energéticos envolvidas nesse estudo estão de alguma forma condicionadas ao $\mathrm{V}_{2}$, o qual foi mensurado de forma sistêmica durante o exercício (whole body). Portanto, as mudanças metabólicas de outros tecidos não podem ser contabilizadas pelo $\mathrm{V}_{2}$ pulmonar (GRAHAM, 1996). A relativização do $\mathrm{v}_{2}$ pela massa muscular envolvida na tarefa, seria uma opção para determinar a demanda de oxigênio imposta pelo músculo esquelético. Acredita-se que no ciclismo estacionário esse valor é de aproximadamente $25 \%$ do peso corporal (PIZZA et al., 1996). Entretanto, é impossível determinar com precisão a massa muscular utilizada nas tarefas esportivas (MEDBØ, 1996) e a quantidade de unidades motoras que seriam ativadas do valor total estimado (GRAHAM, 1996);

b) Como é sabido, nas intensidades mais elevadas dos exercícios sub-WنंO ${ }_{2}$ pico (acima do limiar anaeróbio) há o aumento da contribuição do sistema anaeróbio lático no processo de transferência da energia. Todavia, essa porção não é excluída dos cálculos do MAOD (BANGSBO, 1996); 
c) A estimativa da contribuição do metabolismo anaeróbio lático com base nas [La“] também pode ser subestimada, pois uma parte do lactato liberado no sangue é oxidada em outros tecidos, como o coração e os músculos inativos no exercício. Além disso, a sua produção no músculo esquelético é dependente de múltiplos eventos fisiológicos, no qual a disponibilidade de oxigênio é apenas um dos fatores relacionados às [La] (GLADDEN, 2004). Não obstante, o valor que se assume para o volume de diluição do lactato no sangue pode ser um problema adicional. Ao realizar os cálculos para os valores mínimo (6 litros) e máximo (30 litros) do volume de diluição, BANGSBO (1996) encontrou valores expressivamente distintos da contribuição percentual do sistema anaeróbio lático (8,4\% e 38,0\%, respectivamente) no exercício até a exaustão com duração entre 120 a 180 segundos.

d) Um outro aspecto importante a ser ressaltado sobre a cinética do $\mathrm{V}_{2}$ é que nas intensidades do esforço que elevam as [La], é possível se detectar um prolongado e contínuo aumento no $\mathrm{V}_{2}$ (XU \& RHODES, 1999). Esse fenômeno é comumente denominado de componente lento da cinética do $\dot{\mathrm{V}}_{2}$, o qual parece ser resultante de múltiplos eventos fisiológicos (GAESSER \& POOLE, 1996). Portanto, o MAOD parece ser dependente da janela de tempo empregada na determinação do $\mathrm{V}_{2}$ dos testes sub-p $\dot{V}_{2}$ pico (ÖZYENER et al., 2003), pois o componente lento, ou o $\mathrm{V}_{2}$ excessivo nos testes sub-p $\mathrm{pHO}_{2}$ pico mais intensos, pode superestimar a demanda de $\mathrm{O}_{2}$ quando determinada por meio da regressão linear entre $\mathrm{o} \mathrm{V}_{2}$ e as intensidades dos exercícios abaixo da potência aeróbia máxima (sub-p $\dot{V}_{2}$ pico). 


\section{CONCLUSÕES}

Baseado nos resultados e nas limitações da presente investigação, pôde-se concluir que:

a) Os componentes anaeróbios do MAOD podem ser estimados satisfatoriamente mediante a inclusão da resposta cinética off do $\dot{\mathrm{V}}_{2}$ nos cálculos desse índice fisiológico;

b) As contribuições realizadas acerca da contribuição do MAL não eram estatisticamente diferentes. Portanto, O MAOD tradicional pode ser estimado por meio do $M A O D_{M O D}$;

c) Porém, as correlações detectadas entre o MAOD ${ }_{M O D}$ e os índices do teste de Wingate podem indicar que ele possui a vantagem de não depender da relação linear $\mathrm{V}_{2}$-intensidade nos testes submáximos;

d) Os valores percentuais das contribuições dos MAL e MAA foram similares àqueles reportados na literatura científica. Logo, os procedimentos propostos na presente investigação podem auxiliar futuros trabalhos que porventura objetivem fragmentar as contribuições dos componentes anaeróbio do MAOD;

e) A redução da contribuição do MAA mediante o incremento da intensidade dos exercícios submáximos pode ter ocorrido em vrtude da redução do funcionamento do sistema de lançadeira de creatina, a qual sobre influência do $\mathrm{pH}$ intracelular. 


\section{REFERÊNCIAS}

ARNOLD, D.L.; MATTHEWS, P.M.; RADDA, G.K. Metabolic recovery after exercise and the assessment of mitochondrial function in vivo in human skeletal muscle by means of ${ }^{31} \mathrm{P}$ NMR. Magnetic Resonance in Medicine, Duluth, v.1, p.307-315, 1984.

ARSAC, L.M.; THIAUDIERE, E.; DIOLEZ, P.; GERVILLE-REACHE, L. Parameter estimation in modeling phosphocreatine recovery in human skeletal muscle. European Journal of Applied Physiology, Berlin, v.91, p.419-424, 2004.

BALDWIN, K.M. Comments on classical papers. Journal of Applied Physiology, Bethesda, v.99, p.1241-1242, 2005.

BANGSBO, J.; JUEL, C. Point:couterpoint: Lactic acid accumulation is an advantage/disadvantage during muscle activity. Journal of Applied Physiology, Bethesda, v.100, n.4, p.1412-1413, 2006.

BANGSBO, J. Oxygen deficit: a measure of the anaerobic energy production during intense exercise? Canadian Journal of Applied Physiology, v.21, n.5, p.350-363, 1996a.

BANGSBO, J. Bangsbo responds to Medbø's paper. Canadian Journal of Applied Physiology, v.21, n.5, p.384-388, 1996b.

BANGSBO, J.; MICHALSIK, L.; PETERSEN, A. Accumulated $\mathrm{O}_{2}$ deficit during intense exercise and muscle characteristics of elite athletes. International Journal of Sports Medicine, Stuttgart, v.14, n.4, p.207-213, 1993.

BANGSBO, J.; GOLLNICK, P.D.; GRAHAM, T.E.; JUEL, C.; KIENS, B.; MIZUNO, M.; SALTIN, B. Anaerobic energy production and $\mathrm{O}_{2}$ deficit-debt relationship during exhaustive exercise in humans. Journal of Physiology, London, n.422, p.539-559, 1990.

BANGSBO, J. Quantification of anaerobic energy production during intense exercise. Medicine and Science in Sports and Exercise, Madison, v.30, n.1, p.47-52, 1998.

BAR-OR, O. The Wingate anaerobic test: an update on methodology, reliability and validity. Sports Medicine, Auckland, v.4, p.381-394, 1987.

BASSET, D.R.; HOWLEY, E.T. Limiting factors for maximum oxygen uptake and determinants of endurance performance. Medicine and Science in Sports and Exercise, Madison, v.32, n.1, p.70-84, 2000. 
BEARDEN, S.E.; MOFFATT, R.J. $\dot{\mathrm{V}} \mathrm{O}_{2}$ kinetics and the $\mathrm{O}_{2}$ deficit in heavy exercise. Journal of Applied Physiology, Bethesda, v.88, n.4, p.1407-1412, 2000.

BELL, D.G.; JACOBS, I.; ELLERINGTON, K. Effect of caffeine and ephedrine ingestion on anaerobic exercise performance. Medicine and Science in Sports and Exercise, Madison, v.33, n.8, p.1399-1403, 2001.

BENEKE, R.; BEYER, T.; JACHNER, C.; ERASMUS, J; HÜTLER, M. Energetics of karate kumite. European Journal of Applied Physiology, Berlin, v.92, n. 4-5, p. 518-523, 2004.

BENEKE, R.; POLLMANN, C.; BLEIF, I.; LEITHÄUSER, R.M.; HÜTLER, M. How anaerobic is the Wingate anaerobic test for humans? European Journal of Applied Physiology, Berlin, v.87, n.4-5, p.388-392, 2002.

BERGH, U.; EKBLOM, B.; ASTRAND, P.O. Maximal oxygen uptake "classical" versus "contemporary" viewpoints. Medicine and Science in Sports and Exercise, Madison, v.32, n.1, p.85-88, 2000.

BERTUZZI, R.C.M.; FRANCHINI, E.; KOKUBUN, E.; KISS, M.A.D.M. Energy system contributions in indoor rock climbing. European Journal of Applied Physiology, Berlin, v.101, n.3, p.293-300, 2007.

BILLAT, L.V. Use of blood lactate measurements for prediction of exercise performance and control of training. Recommendations for long-distance running. Sports Medicine, Auckland, v.22, n.3, p.157-175, 1996.

BLAND, J.M.; ALTMAN, D.G. Statistical methods for assessing agreement between two methods of clinical measurement. Lancet. V. 8, n.1, p.307-10, 1986.

BOGDANIS, G.C.; NEVILL, M.E.; LAKOMY, H.K.; BOOBIS, L.H. Power output and muscle metabolism during and following recovery from 10 and $20 \mathrm{~s}$ of maximal sprint exercise in humans. Acta Physiological Scandinavia, Stockholm, v.163, p.261-272, 1998.

BÖNING, D.; STROBEL, G.;BENEKE, R.; MAASSEN, N. Lactic acid still remains the real cause of exercise-induced metabolic acidosis. American Journal of Physiology. Regulatory, Integrative and Comparative Physiology, v.289, n.3, p.R902-903, 2005.

BROOKS, G.A. The lactate shuttle during exercise and recovery. Medicine and Science in Sports and Exercise, Madison, v.18, n.3, p.360-368, 1986. 
Current concepts in lactate exchange. Medicine and Science in Sports and Exercise, Madison, v.23, n.8, p.895-906,1991. Intra- and extra-cellular lactate shuttles. Medicine and Science in Sports and Exercise, Madison, v.32, n.4, p.790-799, 2000.

BROZEK, J.; GRANDE, F.; ANDERSON, J.; KEYS, A. Densitometric analysis of body composition: revision of some quantitative assumptions. Annals of the New York Academy of Science, v.110, p.113-140, 1963.

BUCK, D.; MCNAUGHTON, L. Changing the number of submaximal exercise bouts effects calculation of MAOD. International Journal of Sports Medicine, Stuttgart, v.20, n.1, p.28-33, 1999a.

BUCK, D.; McNAUGHTON, L. Maximal accumulated oxygen deficit must be calculated using 10-min time periods. Medicine and Science in Sports and Exercise, Madison, v.31, n.9, p.1346-1349,1999b.

CAIRNS, S.P. Lactic acid and exercise performance: culprit or friend? Sports Medicine, Auckland, v.36, n.4, p.279-291, 2006.

CALBET, J.A.; CHAVARREN, J.; DORADO, C. Fractional use of anaerobic capacity during a 30- and a 45-s Wingate test. European Journal of Applied Physiology, Berlin, v.76, p.308-313, 1997.

CAMUS, G.; THYS, H. An evaluation of the maximal anaerobic capacity in man. International Journal of Sports Medicine, Stuttgart, v.12, n.4, p.349-355, 1991.

CARTER, H.; PRINGLE, J.S.M.; BARSTOW, T.J.; DOUST, J.H. Oxygen uptake kinetics during supra $\mathrm{VO}_{2} \max$ treadmill running in humans. International Journal of Sports Medicine, Stuttgart, 27, n. 2, p. 149-157, 2006.

CARTER, H.; JONES, A.M.; BARSTOW, T.J.; BURNLEY, M.; WILLIANS, C.A.; DOUST, J.H. Oxygen uptake kinetics in treadmill running and cycle ergometry: a comparison. Journal of Applied Physiology, Bethesda, v. 89, n.3, p. 899-907, 2000. CERRETELLI, P.; PENDERGAST, D.; PAGANELLI, W.C; RENNIE, D.W. Effects of specific muscle training on $\mathrm{VO}_{2}$ on-response and early blood lactate. Journal of Applied Physiology: Respiration Environment Exercise Physiology, Washington, v.47, n.4, p.761-769, 1979. 
CHATAGNON, M.; POUILLY, J.P.; THOMAS, V.; BUSSO, T. Comparison between maximal power in the power-endurance relationship and maximal instantaneous power. European Journal of Applied Physiology, Berlin, v.94, n.(5-6), p.711-717, 2005.

CRAIG, N.P.; PYKE, F.S.; NORTON, K.I. Specificity of test duration when assessing the anaerobic lactacid capacity of high-performance track cyclists. International Journal of Sports Medicine, Stuttgart, v.10, n.4, p.237-242, 1989.

de PAOLI, F.V.; OVERGAARD, K.; PEDERSON, T.H.; NIELSEN, O.B. Additive protective effects of the addition of lactic acid and adrenaline on excitability and force in isolated rat skeletal muscle depressed by elevated extracellular $\mathrm{K}^{+}$ Journal of Physiology, London, [Epub ahead of print], 2007.

di PRAMPERO, P.E.; PEETERS, L.; MARGARIA, R. Alactic $\mathrm{O}_{2}$ debt and lactic acid production after exhausting exercise in man. Journal of Applied Physiology, Bethesda, v.34, n.5, p.628-632, 1973.

di PRAMPERO. P.E. Energetics of muscular exercise. Review Physiology, Biochemistry and Pharmacology, London, v.89, p.143-222, 1981.

di PRAMPERO, P.E.; FERRETTI, G. The energetics of anaerobic muscle metabolism: a reappraisal of older and recent concepts. Respiration Physiology, Amsterdam, v.1, n.118, p.10-115, 1999.

di PRAMPERO, P.E.; MAHLER, P.B.; GIEZENDANNER, D.; CERRETELLI, P. Effects of priming exercise on $\mathrm{VO}_{2}$ kinetics and $\mathrm{O}_{2}$ deficit at the onset of stepping and cycling. Journal of Applied Physiology, Bethesda, v.66, n.5, p.2023-2031, 1989.

DOHERTY, M. The effects of caffeine on the maximal accumulated oxygen deficit and short-term running performance. International Journal of Sport Nutrition, v.8, n.2, p.95-104, 1998.

DOHERTY, M.; SMITH, P.M. SCHRODER, K. Reproducibility of the maximum accumulated oxygen deficit and run time to exhaustion during short-distance running. Journal of Sports Science, v.18, n.5, p.331-338, 2000.

DUBOUCHAUD, H.; BUTTERFIELD, G.E.; WOLFEL, E.E.; BERGMAN, B.C.; BROOKS, G.A. Endurance training, expression, and physiology of LDH, MCT1, and MCT4 in human skeletal muscle. American Journal of Physiology (Endocrinology Metabolism), Bethesda, v.278, n.4, p.E571-579, 2000. 
DUFFIELD, R.; DAWSON, B.; GOODMAN, C. Energy system contribution to 100and $200-\mathrm{m}$ track running events. Journal of Science and Medicine in Sport, v.7, n.3, p.302-313, 2004.

DUFFIELD, R.; DAWSON, B.; GOODMAN, C. Energy system contribuition to 1500and 3000-metre track running. Journal of Sport Sciences, v.23, n.10, p.993-1002, 2005.

ENGELEN, M.; PORSZASZ, J.; RILEY, M.; WASSERMAN, K.; MAEHARA, K.; BARSTOW, T. Effects of hypoxic hypoxia on $\mathrm{O}_{2}$ uptake and heart rate kinetics during heavy exercise. Journal of Applied Physiology, Bethesda, v.81, n.6, p.2500-2508, 1996.

FAINA, M.; BILLAT, V.; SQUADRONE, R.; ANGELIS, M.; KORALSZTEIN, J.P.; DAL MONTE, A. Anaerobic contribution to the time to exhaustion at the minimal exercise intensity at which maximal oxygen uptake occurs in elite cyclists, kayakists and swimmers. European Journal of Applied Physiology, Berlin, v.76, n.1, p.13-20, 1997.

FAVERO, T.G. Sarcoplasmic reticulum $\mathrm{Ca}^{+}$release and muscle fatigue. Journal of Applied Physiology, Bethesda, v.87, n.2, p.471-483, 1999.

FINN, J.P.; WOOD, R.J.; MARSDEN, J. Effect of $30^{\circ} \mathrm{C}$ heat on the anaerobic capacity of heat acclimatized athletes. Journal of Sports Science and Medicine, v.2, p.158162, 2003.

FITTS, R.H. Cellular mechanisms of fatigue muscle. Physiological Reviews, Baltimore, v.74, n.1, p.49-94, 1994.

FRANCESCATO, M.P.; TALON, T.; di PRAMPERO, P.E. Energy cost and energy sources in karate. European Journal of Applied Physiology and Occupational Physiology, Berlin, v.71, n.4, p.355-361, 1995.

GAESSER, A.G.; POOLE, D.C. The slow component of oxygen uptake kinetics in humans. Exercise and Sport Science Review, Koln, v.24, p.35-71, 1996.

GAESSER, A.G., BROOKS, G.A. Metabolic bases of excess post-exercise oxygen consumption: a review. Medicine and Science in Sports and Exercise, Madison, v.16, n.1, p.29-43, 1984. 
GARDNER, A.; OSBORNE, M.; D'AURIA, S.; JENKINS, D. A comparison of two methods for the calculation of accumulated oxygen deficit. Journal of Sports Science, v.21, n.3, p.155-162, 2003.

GASTIN, P.B.; COSTILL, D.L.; LAWSON, D.L.; KRZEMINSKI, K.; McCONELL, G.K. Accumulated oxygen deficit during supramaximal all-out and constant intensity exercise. Medicine and Science in Sports and Exercise, Madison, v.27, n.2, p.255263, 1995.

GASTIN, P. B. Quantification of anaerobic capacity. Scandinavian Journal of Medicine \& Science in Sports, Copenhagen, v.4, p.91-112, 1994.

. Energy system interaction and relative contribution during maximal exercise.

Sports Medicine, Auckland, v.31, n.10, p.725-741, 2001.

GASTIN, P.B.; LAWSON, D.L. Influence of training status on maximal accumulated oxygen deficit during all-out cycle exercise. European Journal of Applied Physiology and Occupational Physiology, Berlin, v.69, p.321-330, 1994.

GLADDEN, L.B. Lactate uptake by skeletal muscle. Exercise and Sport Science Review, Koln, v.17, p.115-155, 1989.

Lactate metabolism: a new paradigm for the third millennium. Journal of Physiology, London, v.1, n.558(Pt 1), p.5-30, 2004.

GRAHAM, T.E. Oxygen deficit: introduction to the assumptions and the skepticism. Canadian Journal of Applied Physiology, v.21, n.5, p.347-349, 1996.

GREEN, S. Maximal oxygen deficit of sprint and middle distance runners. European Journal of Applied Physiology, Berlin, v.70, p.192-193, 1995.

GREEN, S.; DAWSON, B. Measurement of anaerobic capacities in humans: definitions, limitations and unsolved problems. Sports Medicine, Auckland, v.15, n.5, p.312-327, 1993.

GREENHAFF, PF; TIMMONS, J.A. Interaction between aerobic and anaerobic metabolism during intense muscle contraction. Exercise and Sport Sciences Reviews, Madison, v. 26, n.1, p.1-30, 1998

GREENHAFF, P.L. The creatine-phosphocreatine system: there's more than one song in its repertoire. Journal of Physiology, London, v.15, n.537(Pt 3), p.657, 2001. 
GUIDETTI, L.; EMERENZIANI, G.P.; GALLOTA, M.C.; BALDARI. Effect of warm up on energy cost and energy sources of a ballet dance exercise. European Journal of Applied Physiology, v.99, n.3, p.275-281, 2007.

GRANIER, P.; DUBOUCHAUD, H.; MERCIER, B.; MERCIER, J. AHMAIDI, S.; PRÉFAUT, Ch. Lactate uptake by forearm skeletal muscles during repeated periods of short-term intense leg exercise in humans. European Journal of Applied Physiology, Berlin, v.72, n.3, p.209-214, 1996.

HAMANN, J.J.; KELLEY, K.M., GLADDEN, L.B. Effect of epinephrine on net lactate uptake by contracting skeletal muscle. Journal of Applied Physiology, Bethesda, v.91, n.6, p.2635-2641, 2001.

HECK, H.; MADER, A.; HESS, G., MUCKE, S; MULLER, R.; HOLLMANN, W.; Justification of $4 \mathrm{mmol} / /$ lactate threshold. International Journal of Sports Medicine, Stuttgart, v.6, n.3, p.117-130, 1985.

HASELER, L.J.; HOGAN, M.C.; RICHARDSON, R.S. Skeletal muscle phosphocreatine recovery in exercise-trained humans is dependent on $\mathrm{O}_{2}$ availability. Journal of Applied Physiology, Bethesda, v.86, n.6, p. 2013-2018, 1999.

HAUSSWIRTH, C.; BIGARD, A.X.; ARSAC, L.M; BITANGA, E.; THIRIET, P.; LACOUR, J.P. The Cosmed K4 telemetry system as an accurate device for oxygen uptake measurements during exercise. International Journal of Sports Science, Stuttgart, v.18, p. $449-453,1997$.

HARGREAVES, M.; FINN, J.P.; WITHERS, R.T.; HALBERT, J,A.; SCROOP, G.C.; MACKAY, M.; SNOW, R.J.; CAREY, M.F. Effect of muscle glycogen availability on maximal exercise performance. European Journal of Applied Physiology and Occupational Physiology, v.75, p.188-192, 1997.

HILL, A.V.; LUPTON, H. Muscular exercise, lactic acid, and the supply and utilization of oxygen, Quarterly Journal of Medicine, Oxford, v.16, p.135-171, 1923.

HILL, D.W. Determination of accumulated $\mathrm{O} 2$ deficit in exhaustive short-duration exercise Canadian Journal of Applied Physiology, v.21, n.1, p.63-74, 1996.

HILL, D.W.; FERGUNSON, C.S.; EHLER, K.L. An alternative method to determine maximal accumulated $\mathrm{O}_{2}$ deficit in runners. European Journal of Applied Physiology and Occupational Physiology, v.79, n.1, p.114-117, 1998. 
HILL, D.W.; LEIFERMAN, J.A.; LYNCH, N.A.; DANGELMAIER, B.S.; BURT, S.E. Temporal specificity in adaptations to high-intensity exercise training. Medicine and Science in Sports and Exercise, Madison, v.30, n.3, p.450-455, 1998.

HILL, D.W. Energy system contributions in middle-distance running events. Journal of Sports Science, v.17, n.6, p.477-483, 1999.

HILL, D.W.; DAVEY, K.M.; STEVENS, E.C. Maximal accumulated $\mathrm{O}_{2}$ deficit in running and cycling. Canadian Journal of Applied Physiology, v.27, n.5, p.463-78, 2002.

HOWLEY, E.T.; BASSET, D.T; WELCH, H.G. Criteria for mazimal oxygen uptake: review and commentary. Medicine and Science in Sports and Exercise, Madison, v.27, n.9, p.1292-1301, 1995.

IDSTRÖM, J.P.; SUBRAMANIAN, V.H.; CHANCE, B.; SCHERSTEN, T.; BYLUNDFELLENIUS, A.C. Oxygen dependence of energy metabolism in contracting and recovering rat skeletal muscle. American Journal of Physiology, Bethesda, 248 (Heart Circulation Physiology 17), p.H40-H48, 1985.

INBAR, O.; BAR-OR, O. Anaerobic characteristics in male children and adolescents. Medicine and Science and Sports and Exercise, Madison, v.18, n.3, p.264-269, 1986.

JACKSON, A.S.; POLLOCK, M.L. Practical assessment of body composition. Physical of Sport Med 19: 76-90, 1985.

JACOBS, I.; BLEUE, S.; GOODMAN, J. Creatine ingestion increases anaerobic capacity and maximum accumulated oxygen déficit. Canadian Journal of Applied Physiology, v.22, n.3, p.231-243, 1997.

JACOBS, I. Lactate concentrations after short, maximal exercise at various glycogen levels. Acta Physiological Scandinavian, Stockholm, v.111, n.4, p.465-469, 1981.

Blood lactate: implications for training and sports performance. Sports Medicine, Auckland, v.3, p.10-25, 1986.

JANSSON, E.; DUDLEY, G.A.; NORMAN, B.; TESCH, P.A. Relationship of recovery from intense exercise to the oxidative potential of skeletal muscle. Acta Physiological Scandinavia, Stockholm, v.139, n.1, p.147-152, 1990. 
JUEL, C.; HOLTEN, M.K.; DELA, F. Effects of strength training on muscle lactate release and MCT1 and MCT4 content in healthy and type 2 diabetic humans. Journal of Physiology, Lodon, v.1, n.556(Pt 1), p.297-304, 2004.

KEMP, G.; BÖNING, D.;BENEKE, R; MAASSEN, N. Explaining $\mathrm{pH}$ change in exercising muscle: lactic acid, proton consumption, and buffering vs. strong ion difference. American Journal of Physiology. Regulatory, Integrative and Comparative Physiology, v.291, p.R235-237, 2006.

KEMP, G. Lactate accumulation, proton buffering, and $\mathrm{pH}$ change in ischemically exercising muscle. American Journal of Physiology. Regulatory, Integrative and Comparative Physiology, v.289, p.R895-901, 2005.

KILDING, A.E.; CHALLIS, N.V.; WINTER, E.M.; FYSH, M. Characterisation, asymmetry and reproducibility of on- and off-transient pulmonary oxygen uptake kinetics in endurance-trained runners. European Journal of Applied Physiology, Berlin, v.93, p.588-597, 2005.

KROGH, A.; LINDHARD, J. The changes in respiration at the transition from work to rest. Journal of Physiology, London, v.18, n.53(6), p.431-439, 1920.

LEVINE, B.D.; STRAY-GUNDERSEN, J. "Living high-training low": effect of moderate-altitude acclimatization with low-altitude training on performance. Journal of Applied Physiology, Bethesda, v.83, n.1, p.102-112, 1997.

LINDINGER, M.I.; KOWALCHUK, J.M.; HEIGENHAUSER, G.J. Applying physicochemical principles to skeletal muscle acid-base status. American Journal of Physiology. Regulatory, Integrative and Comparative Physiology, v.289, n.3, p.R891-894, 2005.

MAGNUSSON, I.; SHULMAN, G.I. Pathways of hepatic glycogen synthesis in humans. Medicine and Science in Sports and Exercise, Madison, v.23, n.8, p.939943, 1991.

MARGARIA, R.; EDWARDS, H.T.; DILL, D.B. The possible mechanisms of contracting and paying the oxygen debt and the role of lactic acid in muscular contraction. American Journal of Physiology, Bethesda, v.106, p.689-715, 1933.

MARTH, P.D.; WOODS, R.R.; HILL, D.W. Influence of time of day on anaerobic capacity. Perceptual Motor Skills. v.86, n.2, p.592-4, 1998. 
MARZZOCO, A.; TORRES, B.B. Bioquímica básica. Rio de Janeiro: Guanabara Koogan, 1990.

MAXWELL, N.S.; NIMMO, M.A. Anaerobic capacity: a maximal anaerobic running test versus the maximal accumulated oxygen deficit. Canadian Journal of Applied Physiology, v.21, n.1, p.35-47, 1996.

McCULLY, K.K.; IOTTI, S.; KENDRICK. K.; WANG, Z.; POSNER, J.D.; LEIGH, J.; CHANCE, B. Simultaneous in vivo measurements of $\mathrm{HbO}_{2}$ saturation and $\mathrm{PCr}$ kinetics after exercise in normal humans. Journal of Applied Physiology, Bethesda, v.77, n.1, p.5-10, 1994.

McCREARY, C.R.; CHILIBECK, P.D.; MARSH, G.D.; PATERSON, D.H.; CUNNINGHAM, D.A., THOMPSON, R.T. Kinetics of pulmonary oxygen uptake and muscle phosphates during moderate-intensity calf exercise. Journal of Applied Physiology, Bethesda, v.81, n.3, p.1331-1338, 1996.

McMAHON, S.; JENKINS, D. Factors affecting the rate of phosphocreatine resynthesis following intense exercise. Sports Medicine, Auckland, v.32, n.2, p.761784, 2002.

MEDBØ, J.I.; MOHN, A.C.; TABATA, I.; BAHR, R.; VAAGE, O.; SEJERSTED, O.M Anaerobic capacity determined by maximal accumulated $\mathrm{O}_{2}$ deficit. Journal of Applied Physiology, Bethesda, v.64, n.1, p.50-60, 1988.

MEDBØ, J.I.; TABATA, I. Relative importance of aerobic and anaerobic energy release during short-lasting exhausting bicycle exercise. Journal of Applied Physiology, Bethesda, v.67, n.5, p.1881-1886, 1989.

MEDB $\varnothing$ J.I.; BURGERS, S. Effect of training on the anaerobic capacity. Medicine and Science in Sports and Exercise, Madison, v.22, n.4, p.501-507, 1990.

MEDBØ, J.I.; TABATA, I. Anaerobic energy release in working muscle during $30 \mathrm{~s}$ to 3 min of exhausting bicycling Journal of Applied Physiology, Bethesda, v.75, n.4, p.1654-1660, 1993.

MEDBØ, J.I. Medbø responds to Bangsbo's paper. Canadian Journal of Applied Physiology, v.21, n.5, p.364-369, 1996.

MEDB $\varnothing$, J.I. Is the maximal accumulated oxygen deficit an adequate measure of the anaerobic capacity? Canadian Journal of Applied Physiology, v.21, n.5, p.370383, 1996. 
MEYER, R.A. A linear model of muscle respiration explains monoexponential phospohocreatine changes. American Journal of Physiology, Bethesda, 254 (Cell Physiology 23): p.C548-C553, 1988.

MEZZANI, A.; CORRA, U.; SASSI, B.; COLOMBO, R.; GIORDANO, A.; GIANNUZZI, $P$. Maximal accumulated oxygen deficit in patients with chronic heart failure. Medicine and Science in Sports and Exercise, Madison, v.38, n.3, p.424-432, 2006.

MILLET, G.P.; JAQUEN, B.; BORRANI, F.; CANDAU, R. Effects of concurrent endurance and strength $\mathrm{VO}_{2}$ kinetics. Medicine and Science in Sports and Exercise, Madison, v.34, n.8, p.1351-1359, 2002.

NAUGHTON, G.A.; CARLSON, J.S.; BUTTIFANT, D.C.; SELIG, S.E.; MELDRUM, K.; McKENNA, M.J.; SNOW, R.J. Accumulated oxygen deficit measurements during and after high-intensity exercise in trained male and female adolescents. European Journal of Applied Physiology and Occupational Physiology, Berlin, v.76, p.525531, 1997.

NIELSEN, O.B.; de PAOLI, F.; OVERGAARD K. Protective effects of lactic acid on force production in rat skeletal muscle. Journal of Physiology, London, v.1, n. 536(Pt 1), p.161-166, 2001.

NIELSEN, K.; SORENSEN, P.G.; HYNNE, F. Chaos in Glycolysis. Journal of Theoretical Biology. v.186, n.3, p.303-206, 1997.

NORTON, K.; OLDS, T. Antropometrica. Rosário: Biosystem, 1996. p. 23-69.

OLESEN, H.L. Accumulated oxygen deficit increases with inclination of uphill running. Journal of Applied Physiology, Bethesda, v.73, n.3, p.1130-1134, 1992.

OGAWA, T.; HAYASHI, K.; ICHINOSE, M.; WADA, H.; NISHIYASU, T. Metabolic response during intermittent graded sprint running in moderate hypobaric hypoxia in competitive middle-distance runners. European Journal of Applied Physiology, Berlin, v. 99, p.39-46, 2007.

OGITA, F.; HARA, M.; TABATA, I. Anaerobic capacity and maximal oxygen uptake during arm stroke, leg kicking and whole body swimming. Acta Physiological Scandinavia, Stockholm, v.157, n.4, p.435-41, 1996. 
ÖZYENER, F.; ROSSITER, H.B.; WARD, S.A.; WHIPP, B.J. Negative accumulated oxygen deficit during heavy and very heavy intensity cycle ergometry in humans. European Journal of Applied Physiology, Berlin, v. 90, n.(1-2), p.185-190, 2003. ÖZYENER, F.; ROSSITER, H.B.; WARD, S.A.; WHIPP, B.J. Influence of exercise intensity on the on- and off-transient kinetics of pulmonary oxygen uptake in humans. Journal of Physiology, London, v.533, n.3, p.891-902, 2001.

PATERSON, D.H; WHIPP, B.J. Asymmetries of oxygen uptake transients at the onand offset of heavy exercise in humans. Journal of Physiology, London, v.443, p.575-586, 1991.

PEDERSE, T.H.; de PAOLI, F.; NIELSEN, O.B. Increased excitability of acidified skeletal muscle: role of chloride conductance. Journal of General Physiology, v.125, n.2, p.237-246, 2005.

PIIPER, J.; SPILLER, P. Repayment of $\mathrm{O}_{2}$ debt and resynthesis of high-energy phosphates in gastrocnemius muscle of the dog. Journal of Applied Physiology, Bethesda, v. 28, n.5, 657-662, 1970.

PIZZA, F.X.; NAGLIERI, T.A.; HOLTZ, R.W.; MITCHELL, J.B.; STARLLING, R.D.; PHILLIPS, M.D.; CAVENDER, D.L.; BRAUN, W.A. Maximal accumulated oxygen deficit of resistance-trained men. Canadian Journal of Applied Physiology, v.21, n.5, p.391-402, 1996.

PRIPSTEIN, L.P.; RHODES, E.C.; McKENZIE, D.C.; COUTTS, K.D. Aerobic and anaerobic energy during a $2-\mathrm{km}$ race simulation in female rowers. European Journal of Applied Physiology, Berlin, v.79, p.491-494, 1999.

REHUNEN, S.; NÄVERI, H.; KUOPPASALMI, K.; HÄRKÖNEN, M. High-energy phosphate compounds during exercise in human slow-twitch and fast-twitch muscle fibers. Scandinavian Journal of Clinical and Laboratory Investigation, Oslo, v.42, n.6, p.499-506, 1982.

REIS, V.M.; SILVA, A.J.; ASCENSÃO, A.; DUARTE, M. Inclusion of exercise intensities above the lactate threshold in $\mathrm{VO}_{2}$ /running speed regression does not improve the precision of accumulated oxygen deficit estimation in endurance-trained runners. Journal of Sports Science and Medicine, v.4, p.455-462, 2005. 
ROBERGS, R.A.; GHIASVAND, F.; PARKER, D. Biochemistry of exercise-induced metabolic acidosis. American Journal of Physiology. Regulatory, Integrative and Comparative Physiology, v.287, n.3, p.R502-516, 2004.

ROBERGS, R.A.; PARKER, D. Lingering construct of lactic acidosis. American Journal of Physiology. Regulatory, Integrative and Comparative Physiology, v.289, p.R904-910, 2005.

ROBERGS, A.D.; CLARK, S.A.; TOWNSEND, N.E.; ANDERSON, M.E.; GORE, C.J.; HAHN, A.G. Changes in performance, maximal oxygen uptake and maximal accumulated oxygen deficit after 5, 10 and 15 days of live high:train low altitude exposure. European Journal of Applied Physiology, Berlin, v.88, p.390-395, 2003. ROECKER, K.; PRETTIN, S.; SORICHTER, S. Gas exchange measurements with temporal resolution: the breath-by-breath approach. International Journal of Sports Science, Stuttgart, v.26, p.S11-S18, 2005.

ROSSITER, H.B; WARD, S.A.; DOYLE, V.L.; HOWE, F.A.; GRIFFITHS, J.R.; WHIPP, B.J. Inferences from pulmonary $\mathrm{O}_{2}$ uptake with respect to intramuscular [phosphocreatine] kinetics during moderate exercise in humans. Journal of Physiology, London, v.1, n.518.3, p.921-932, 1999.

ROSSITER, H.B; WARD, S.A.; KOWALCHUCK, J.M.; HOWE, F.A.; GRIFFITHS, J.R.; WHIPP, B.J. Dynamic asymmetry of phosphocreatine concentration and $\mathrm{O}_{2}$ uptake between the on- and off-transients of moderate- and high-intensity exercise in humans. Journal of Physiology, London, n.15, n.541.3, p.991-1002, 2002.

SCOTT, C.B. Contribution of blood lactate to the energy expenditure of weight training. Journal of Strength and Conditioning Research, v.20, n.2, p.404-411, 2006a.

SCOTT, C.B. Estimating energy expenditure for brief bouts of exercise with acute recovery. Applied Physiology and Nutrition Metabolism, v.31, n.2, p.144-149, 2006b.

SCOTT, C.B. Energy expenditure of heavy to severe exercise and recovery. Journal of Theoretical Biology, London, v.21, n.207, p.293-297, 2000. 
SCOTT, C.B. Re-interpreting anaerobic metabolism: an argument for the application of both anaerobic glycolysis and excess post-exercise oxygen consumption (EPOC) as independent sources of energy expenditure. European Journal of Applied Physiology, Berlin, v.77, p.200-205, 1998.

SCOTT, C.B.; ROBY, F.B.; LOHMAN, T.G.; BUNT, J.C. The maximally accumulated oxygen deficit as an indicator of anaerobic capacity. Medicine and Science and Sports Exercise, Madison, v.23, n.5, p.618-624, 1991.

SLONIGER, M.A.; CURETON, K.J.; PRIOR, B.M.; EVANS, E.M. Anaerobic capacity and muscle activation during horizontal and uphill running. Journal of Applied Physiology, Bethesda, v.83, n.1, p.262-9, 1997.

SPENCER, M.R.; GASTIN, P.B. Energy system contribution during 200- to 1500-m running in highly trained athletes. Medicine and Science in Sports and Exercise, Madison, v.33, n.1, p.157-162, 2001.

SPRIET, L.L. Anaerobic metabolism during high-intensity exercise. In: HARGREAVES, M., ed. Exercise metabolism. Champaign: Humans Kinetics, 1995. p.1-39.

STAINSBY, W.N. Biochemical and physiological bases for lactate production, Medicine and Science in Sports and Exercise, Madison, v.18, n.3, p.341-343, 1986.

STAINSBY, W.N.; BRECHUE, W.F.; O'DROBINAK, D.M. Regulation of muscle lactate production. Medicine and Science in Sports and Exercise, Madison, v.23, n.8, p.907-911, 1991.

STAINSBY, W.N.; BROOKS, G.A. Control of lactic acid metabolism in contracting muscle and during exercise. Exercise and Sports Science Review, Koln, v.18, p.2963, 1990.

STANLEY, W.C. Myocardial lactate metabolism during exercise. Medicine and Science in Sports and Exercise, Madison, v.23, n.8, p.920-924, 1991.

SVEDAHL, K.; MacINTOSH, BR. Anaerobic threshold: the concept and methods of measurement. Canadian Journal of Applied Physiology, v.28, n.2, p.299-323, 2003. 
TABATA, I.; IRISAWA, K.; KOUZAKI, M.; NISHIMURA, K.; OGITA, F.; MIYACHI, M. Metabolic profile of high intensity intermittent exercises. Medicine and Science in Sports and Exercise, Madison, v.29, n.3, p.390-395, 1997.

TABATA, I.; NISHIMURA, K.; KOUZAKI, M.; HIRAI, Y.; OGITA, F.; MIYACHI, M.; YAMAMOTO, K. Effects of moderate-intensity endurance and high-intensity intermittent training on anaerobic capacity and $\mathrm{VO}_{2} \mathrm{max}$. Medicine and Science in Sports and Exercise, Madison, v.28, n.10, p.1327-1330, 1996.

THOMAS, C.; PERREY, S.; LAMBERT, K.; HUGON, G.; MORNET, D.; MERCIER, J. Monocarboxylate transporters, blood lactate removal after supramaximal exercise, and fatigue indexes in humans. Journal of Applied Physiology, Bethesda, v.98, n.3, p.804-809, 2005.

TOMLIN, D.L.; WENDER, H.A. The relationship between aerobic fitness and recovery from high intensity intermittent exercise. Sports Medicine, Auckland, v.31, n.1, p.1$11,2001$.

VANDEWALLE, H.; PÉRÈS, G.; MONOD, H. Standard anaerobic exercise tests, Sports Medicine, Auckland, v. 4, p.268-289, 1987.

WADLEY, G.; Le ROSSIGNOL, P. The relationship between repeated sprint ability and the aerobic and anaerobic energy systems. Journal of Science and Medicine in Sport, v.1, n.2, p.100-110, 1998.

WALSH, B.; TIIVEL, T.; TONKONOGI, M.; SAHLIN, K. 2002Increased concentrations of $\mathrm{Pi}$ and lactic acid reduce creatine-stimulated respiration in muscle fibers. Journal of Applied Physiology, Bethesda, v.92, p.2273-2276, 2002.

WEBER, C.L.; SCHNEIDER, D.A. Reliability of MAOD measured at $110 \%$ and $120 \%$ of peak oxygen uptake for cycling. Medicine and Science in Sports and Exercise, Madison, v.33, n.6, p.1056-1059, 2001.

WEBER, C.L.; SCHNEIDER, D.A. Increases in maximal accumulated oxygen deficit after high-intensity interval training are not gender dependent. Journal of Applied Physiology, Bethesda, v.92, n.5, p.1795-801, 2002.

WESTERBLAD, H; ALLEN, D.E.; LÄNNERGREN, J. Muscle fatigue: lactic acid or inorganic phosphate the major cause? News in Physiological Science, Bethesda, v.17, p.17-21, 2002. 
WHIPP, B.J.; ÖZYENER, F. The kinetics of exertional oxygen uptake: assumptions and inferences. Medicina Dello Sport, Torino, v.51, p.139-149, 1998.

WHIPP, B.J. WASSERMAN, K. Oxygen uptake kinetics for various intensities of constant-load work. Journal of Applied Physiology, Bethesda, v.33, n.3, p.351-356, 1972.

WOOLFORD, S.M.; WITHERS, R.T.; CRAIG, N.P.; BOURDON, P.C.; STANEF, T.; McKENZIE, I. Effect of pedal cadence on the accumulated oxygen deficit, maximal aerobic power and blood lactate transition thresholds of high-performance junior endurance cyclists. European Journal of Applied Physiology, Berlin, v.80, p.285291, 1999.

XU, F.; RHODES, E. C. Oxygen uptake kinetics during exercise. Sports Medicine, Auckland, v.27, n.5, p. 313-327, 1999.

YOSHIDA, T. The rate of phosphocreatine hydrolysis and resynthesis in exercise muscle in humans using ${ }^{31} \mathrm{P}-\mathrm{MRS}$. Journal of Physiological Anthropology and Applied Human Science, v.21, n.5, p. 247-255, 2002.

YOSHIDA, T.; WATARI, H. ${ }^{31} \mathrm{P}-$ Nuclear magnetic resonance spectroscopy study of the time course of energy metabolism during exercise and recovery. European Journal of Applied Physiology and Occupational Physiology, Berlin, v.66, p.494499, 1993a.

- Metabolic consequences of repeated exercise in long distance runners. European Journal of Applied Physiology and Occupational Physiology, Berlin, v.67, p.261-265, 1993b.

ZIMMER, H.G. August Krogh. Clinical Cardiology, v.29, n.5, p.231-233, 2006. 
ANEXO I - Termo de consentimento informado.

\author{
ESCOLA DE EDUCAÇÃO FÍSICA E ESPORTE \\ DA
}

UNIVERSIDADE DE SÃO PAULO

TERMO DE CONSENTIMENTO LIVRE E ESCLARECIDO

\title{
I - DADOS DE IDENTIFICAÇÃO DO SUJEITO DA PESQUISA OU RESPONSÁVEL LEGAL
}

1. NOME DO INDIVÍDUO:

DOCUMENTO DE IDENTIDADE №: SEXO:

$\mathrm{M} \square \mathrm{F}$

DATA NASCIMENTO:

/...................

ENDEREÇO:

BAIRRO:

CEP:

TELEFONE: DDD (

CIDADE:

№

APTO

\section{II - DADOS SOBRE A PESQUISA CIENTÍFICA}

1. TÍTULO DO PROJETO DE PESQUISA: Estimativa dos metabolismos anaeróbios no déficit máximo acumulado de oxigênio.

2. PESQUISADOR RESPONSÁVEL: Maria Augusta Peduti Dal Molin Kiss.

3. CARGO/FUNÇÃO: Professora Titular.

4. AVALIAÇÃO DO RISCO DA PESQUISA:
RISCO MÍNIMO
RISCO MÉDIO
RISCO BAIXO 区
RISCO MAIOR

\section{III - EXPLICAÇÕES DO PESQUISADOR AO INDIVÍDUO OU SEU REPRESENTANTE LEGAL SOBRE A PESQUISA, DE FORMA CLARA E SIMPLES, CONSIGNANDO:}

1. Objetivos da pesquisa.

O objetivo desse estudo é propor um novo que seja capaz de estimar os componentes lático e alático do déficit máximo de oxigênio através da medida do consumo de oxigênio.

2. Procedimentos que serão utilizados e propósitos, incluindo a identificação dos procedimentos que são experimentais.

Você será submetido, inicialmente, a uma avaliação antropométrica, para a determinação do percentual de gordura corporal e a um teste de incremento progressivo da intensidade até a exaustão voluntária, com o objetivo de se mensurar a sua capacidade e potência aeróbias. Em outras visitas ao laboratório você realizará nove (6 testes em cargas constantes de 10 minutos, um teste supramáximo até a exaustão e um teste de Wingate. Durante os testes haverá a mensuração contínua do consumo de oxigênio e a coleta de microamostras de sangue $(25 \mu \mathrm{l})$. As coletas das microamostras de sangue serão realizadas após perfuração no lóbulo da orelha com uma lanceta descartável e serão utilizadas apenas para a determinação das concentrações de lactato sangüíneo. 


\section{ANEXO I - Termo de consentimento informado (continuação).}

\section{Desconfortos e riscos esperados.}

Os principais riscos envolvidos neste estudo estão relacionados ao teste progressivo até exaustão voluntária e à coleta de sangue. Dentre os possíveis desconfortos do teste máximo estão náuseas, vômitos e enjôos. Entretanto, menos de $1 \%$ da população americana apresenta desconforto extremo durante este tipo de teste (American College of Sports Medicine). O desconforto da coleta de sangue se refere à inserção da laneta no lóbulo da orelha. Entretanto, as análises descritas acima são rotineiras em laboratórios de avaliação física, com poucos casos de desconforto excessivo por parte dos pacientes. Além disso, antes da perfuração do lóbulo da orelha com a lanceta, o local será umedecido com álcool para assepsia, para evitar riscos de contaminação. Todos os procedimentos serão realizados com 0 responsável pelas coletas utilizando luvas cirúrgicas.

\section{Benefícios que poderão ser obtidos.}

Os benefícios do estudo estão, principalmente, em se obter índices fisiológicos que são freqüentemente utilizados por indivíduos que visam a manutenção da saúde ou o aprimoramento do rendimento esportivo (consumo máximo de oxigênio, limiares metabólicos e a capacidade anaeróbia). Este conhecimento poderá ser útil para uma melhor orientação e prescrição de atividades físicas. Além disso, você também receberá as informações sobre o seu percentual de gordura corporal, o qual está igualmente relacionado à manutenção da saúde ou ao desempenho esportivo.

\section{Procedimentos alternativos que possam ser vantajosos para o indivíduo.}

Deverá ser feito jejum de grandes refeições (exemplo: almoço) de aproximadamente 2 horas antes do teste progressivo até exaustão voluntária, para diminuir os riscos de desconforto. Ao sinal de qualquer sintoma de desconforto, durante qualquer fase do estudo, os procedimentos serão interrompidos.

\section{IV - ESCLARECIMENTOS DADOS PELO PESQUISADOR SOBRE GARANTIAS DO SUJEITO DA PESQUISA:}

1. Acesso, a qualquer tempo, às informações sobre procedimentos, riscos e benefícios relacionados à pesquisa, inclusive para dirimir eventuais dúvidas.

Os resultados obtidos durante este estudo serão mantidos em sigilo e apenas serão divulgados em publicações científicas, não sendo mencionados dados pessoais. Caso deseje, você poderá pessoalmente tomar conhecimento dos resultados ao final das etapas do estudo, e/ou eventuais esclarecimentos sobre todos os procedimentos em qualquer fase do trabalho.

2. Liberdade de retirar seu consentimento a qualquer momento e de deixar de participar do estudo, sem que isto traga prejuízo à continuidade da assistência.

Há a liberdade de desistir ou de interromper a colaboração neste estudo no momento em que desejar, sem necessidade de qualquer explicação. A desistência não causará nenhum prejuízo à saúde ou bem-estar físico, e ficamos à disposição para eventuais dúvidas, mesmo após o término do estudo ou da sua retirada dele.

\section{Salvaguarda da confidencialidade, sigilo e privacidade.}

Os resultados obtidos durante este estudo serão mantidos em sigilo, e apenas serão divulgados em publicações científicas, através de média e desvio padrão (ou outras medidas de tendência central), sem que os dados pessoais sejam mencionados.

\section{Disponibilidade de assistência no HU ou HCFMUSP, por eventuais danos à saúde, decorrentes da pesquisa.}

Qualquer possível desconforto provocado pelos procedimentos desta pesquisa será prontamente atendido no próprio local, e/ou em casos mais cuidadosos, terá assistência médica no HU ou na HCFMUSP, sem qualquer ônus. 
ANEXO I - Termo de consentimento informado (continuação).

V - INFORMAÇÕES DE NOMES, ENDEREÇOS E TELEFONES DOS RESPONSÁVEIS PELO ACOMPANHAMENTO DA PESQUISA, PARA CONTATO EM CASO DE INTERCORRÊNCIAS CLÍNICAS E REAÇÕES ADVERSAS.

Maria Augusta Peduti Dal' Molin Kiss

Endereço: Rua Itajaçu, no 106, Pacaembu.

Cep: $01247-030$

Fone: $3672-4336$

Rômulo Cássio de Moraes Bertuzzi

Endereço: Rua Clorindo de Oliveira Cajé, 91, Butantã.

Cep: 05371140

Fone: $3735-3353$

\section{VII - CONSENTIMENTO PÓS-ESCLARECIDO}

Declaro que, após convenientemente esclarecido pelo pesquisador e ter entendido o que me foi explicado, consinto em participar do presente Projeto de Pesquisa.

São Paulo, de de 20 . 
ANEXO II - Questionário de prontidão para a atividade física.

1 - Algum médico já lhe disse que você possui algum problema cardíaco e the recomendou que só fizesse atividade física sob supervisão médica?

$$
\text { ( ) SIM ( ) NÃO }
$$

2 - Você sente dor no peito induzida pela atividade física?

( ) SIM ( ) NÃO

3 - Você sentiu dor no peito no último mês?
( ) SIM
( ) NÃO

4 - Você perde o equilíbrio em virtude de vertigem, ou já perdeu a consciência?

( ) SIM ( ) NÃO

5 - Você tem algum problema ósseo ou articular que poderia ser agravado por uma mudança em sua atividade física?
( ) SIM
( ) NÃO

6 - Algum médico está prescrevendo atualmente medicamentos para pressão arterial alta ou para algum problema cardíaco?
( ) SIM
( ) NÃO

7 - Você está ciente de alguma outra razão pela qual não deveria realizar qualquer atividade física? 


\title{
ANEXO III - Imagem digitalizada do parecer do Comitê de Ética em Pesquisa da Escola de Educação Física e Esporte - USP.
}

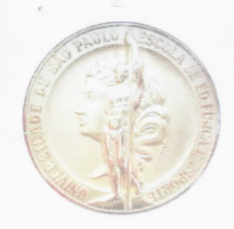

\author{
UNIVERSIDADE DE SÃO PAULO
}

ESCOLA DE EDUCAÇÃO FÍSICA E ESPORTE

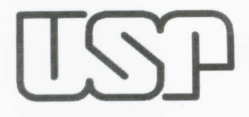

Of.CEP/0512006/EEFE/03052006

Senhor(a) Pesquisador(a)

O Comitê de Ética em Pesquisa (CEP) da Escola de Educação Física e Esporte da Universidade de São Paulo, em reunião ordinária realizada em 28 de abril de 2006, aprovou o Protocolo de Pesquisa n. 2006/06 - Utilização da resposta cinética off da freqüência cardíaca na estimativa do sistema energético anaeróbio alático, sob sua responsabilidade.

Solicitamos a observância da apresentação de relatório ao término do desenvolvimento da pesquisa em setembro de 2008.

Atenciosamente,

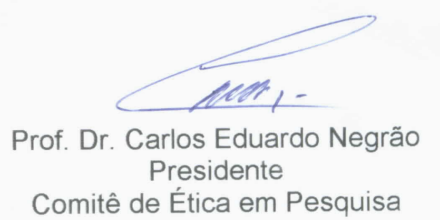

IImo(a). Sr(a).

Prof(a). Dr(a). Maria Augusta Peduti Dal'Molin Kiss

Departamento de Esporte da

EEFEUSP 
ANEXO IV - Resumo das análises estatísticas.

Análise descritiva da idade, das medidas antropométricas e das variáveis medidas durante o teste progressivo até a exaustão.

\begin{tabular}{|c|c|c|c|}
\hline \multicolumn{4}{|c|}{ Valores Extremos } \\
\hline Variável & & Sujeito & Valor \\
\hline \multirow[t]{2}{*}{ Idade (anos) } & Maior & 5 & 30 \\
\hline & Menor & 10 & 19 \\
\hline \multirow[t]{2}{*}{ Massa Corporal (kg) } & Maior & 3 & 90,0 \\
\hline & Menor & 2 & 59,9 \\
\hline \multirow[t]{2}{*}{ Estatura (cm) } & Maior & 4 & 189,0 \\
\hline & Menor & 7 & 169,0 \\
\hline \multirow[t]{2}{*}{ Potência de pico (W) } & Maior & 3 & 300 \\
\hline & Menor & 10 & 210 \\
\hline \multirow[t]{2}{*}{ Potência no Lan (W) } & Maior & 3 & 240 \\
\hline & Menor & 10 & 150 \\
\hline \multirow[t]{2}{*}{ Potência no Lan (\% Pot. Pico) } & Maior & 9 & 86 \\
\hline & Menor & 5 & 60 \\
\hline \multirow[t]{2}{*}{$\mathrm{VO}_{2} \max (\mathrm{ml} / \mathrm{kg} / \mathrm{min})$} & Maior & 7 & 48,70 \\
\hline & Menor & 8 & 30,14 \\
\hline \multirow[t]{2}{*}{$\mathrm{VO}_{2} \max (\mathrm{l} / \mathrm{min})$} & Maior & 5 & 3,60 \\
\hline & Menor & 8 & 2,20 \\
\hline \multirow[t]{2}{*}{$\mathrm{R}$} & Maior & 3 & 1,39 \\
\hline & Menor & 10 & 1,16 \\
\hline \multirow[t]{2}{*}{ FCpico (bpm) } & Maior & 8 & 194 \\
\hline & Menor & 1 & 163 \\
\hline \multirow[t]{2}{*}{ [La“]pico (mmol/l) } & Maior & 3 & 11,88 \\
\hline & Menor & 7 & 7,74 \\
\hline
\end{tabular}


ANEXO IV - Resumo das análises estatísticas (continuação).

Teste de Normalidade de Shapiro-Wilk.

\begin{tabular}{lccc}
\hline Variável & Estatística & gl & Sig. \\
\hline Idade (anos) &, 898 & 9 &, 206 \\
Massa Corporal (kg) &, 943 & 9 &, 587 \\
Estatura (cm) &, 895 & 9 &, 194 \\
Potência de pico (W) &, 806 & 9 &, 057 \\
Potência no Lan (W) &, 859 & 9 &, 074 \\
Potência no Lan (\% Pot. Pico) &, 957 & 9 &, 755 \\
VO $_{2} \max (\mathrm{ml} / \mathrm{kg} / \mathrm{min})$ &, 938 & 9 &, 534 \\
VO $_{2} \max (\mathrm{l} / \mathrm{min})$ &, 972 & 9 &, 909 \\
Q.R. $_{\text {FCpico (bpm) }}^{, 853}$ & 9 &, 063 \\
La]pico (mmol/l) &, 987 & 9 &, 992 \\
\hline
\end{tabular}


ANEXO IV - $\underline{\text { Resumo das análises estatísticas (continuação). }}$

Variáveis analisadas durante o exercício realizado na intensidade acima da potência correspondente ao consumo máximo de oxigênio (110\%).

Valores Extremos

\begin{tabular}{|c|c|c|c|}
\hline Variável & & Sujeito & Valor \\
\hline \multirow[t]{2}{*}{ Tempo (s) } & Maior & 9 & 236 \\
\hline & Menor & 7 & 113 \\
\hline \multirow[t]{2}{*}{ Intensidade (W) } & Maior & 3 & 330 \\
\hline & Menor & 10 & 230 \\
\hline \multirow[t]{2}{*}{$\mathrm{VO}_{2}$ pico $(\mathrm{I} / \mathrm{min})$} & Maior & 4 & 3,856 \\
\hline & Menor & 1 & 2,066 \\
\hline \multirow[t]{2}{*}{$\mathrm{VO}_{2}$ pico $(\mathrm{ml} / \mathrm{kg} / \mathrm{min})$} & Maior & 4 & 48,78 \\
\hline & Menor & 3 & 30,99 \\
\hline \multirow[t]{2}{*}{ FCpico (bpm) } & Maior & 2 & 191 \\
\hline & Menor & 1 & 151 \\
\hline \multirow[t]{2}{*}{ [La']pico (mmol/l) } & Maior & 9 & 13,27 \\
\hline & Menor & 1 & 9,53 \\
\hline \multirow[t]{2}{*}{ [La']repouso (mmol/l) } & Maior & 7 & 0,92 \\
\hline & Menor & 10 & 0,42 \\
\hline \multirow[t]{2}{*}{ Demanda de $\mathrm{O}_{2}\left(\mathrm{I}\right.$ de $\left.\mathrm{O}_{2}\right)$} & Maior & 4 & 12,47 \\
\hline & Menor & 6 & 6,06 \\
\hline \multirow[t]{2}{*}{ Consumo de $\mathrm{O}_{2}$ acumulado (I de $\mathrm{O}_{2}$ ) } & Maior & 4 & 10,36 \\
\hline & Menor & 6 & 3,38 \\
\hline \multirow[t]{2}{*}{$\mathrm{MAOD}_{\mathrm{CP}}\left(\mathrm{I}\right.$ de $\left.\mathrm{O}_{2}\right)$} & Maior & 5 & 0,91 \\
\hline & Menor & 10 & 0,37 \\
\hline \multirow[t]{2}{*}{$\mathrm{MAOD}_{\mathrm{LA}_{-} 1}\left(\mathrm{I} \mathrm{de} \mathrm{O}_{2}\right)$} & Maior & 9 & 3,36 \\
\hline & Menor & 4 & 1,26 \\
\hline \multirow[t]{2}{*}{$\mathrm{MAOD}_{\mathrm{LA} \_2}\left(\mathrm{I} \mathrm{de} \mathrm{O}_{2}\right)$} & Maior & 4 & 2,62 \\
\hline & Menor & 2 & 1,60 \\
\hline \multirow[t]{2}{*}{$\operatorname{MAOD}_{\mathrm{MOD}}\left(\mathrm{I}\right.$ de $\left.\mathrm{O}_{2}\right)$} & Maior & 4 & 3,48 \\
\hline & Menor & 1 & 2,32 \\
\hline \multirow[t]{2}{*}{ MAOD $\left(\mathrm{I}\right.$ de $\left.\mathrm{O}_{2}\right)$} & Maior & 9 & 3,91 \\
\hline & Menor & 4 & 2,11 \\
\hline
\end{tabular}


ANEXO IV - Resumo das análises estatísticas (continuação).

Teste de Normalidade de Shapiro-Wilk.

\begin{tabular}{|c|c|c|c|}
\hline Variável & Estatística & gl & Sig. \\
\hline Tempo (s) & ,924 & 9 & ,391 \\
\hline Intensidade (W) & ,827 & 9 & ,061 \\
\hline $\mathrm{VO}_{2}$ pico $(\mathrm{l} / \mathrm{min})$ & ,888 & 9 & , 160 \\
\hline $\mathrm{VO}_{2}$ pico $(\mathrm{ml} / \mathrm{kg} / \mathrm{min})$ & ,893 & 9 & , 182 \\
\hline FCpico (bpm) & ,956 & 9 & ,734 \\
\hline [La]pico (mmol/l) & ,914 & 9 & ,313 \\
\hline [La']repouso (mmol/l) & ,944 & 9 &, 593 \\
\hline Demanda de $\mathrm{O}_{2}\left(\mathrm{l}\right.$ de $\left.\mathrm{O}_{2}\right)$ & ,897 & 9 & ,205 \\
\hline Consumo de $\mathrm{O}_{2}$ acumulado (I de $\mathrm{O}_{2}$ ) & ,849 & 9 & ,066 \\
\hline $\operatorname{MAOD}_{\mathrm{CP}}\left(\mathrm{l}\right.$ de $\left.\mathrm{O}_{2}\right)$ & ,922 & 9 & ,377 \\
\hline 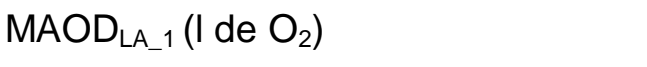 & ,933 & 9 & ,474 \\
\hline $\mathrm{MAOD}_{\mathrm{LA} \_2}\left(\mathrm{I}\right.$ de $\left.\mathrm{O}_{2}\right)$ & ,938 & 9 &, 526 \\
\hline $\operatorname{MAOD}_{\mathrm{MOD}}\left(\mathrm{I}\right.$ de $\left.\mathrm{O}_{2}\right)$ & ,917 & 9 & ,336 \\
\hline MAOD (I de $\left.\mathrm{O}_{2}\right)$ & ,937 & 9 &, 518 \\
\hline
\end{tabular}


ANEXO IV - Resumo das análises estatísticas (continuação).

Reposta cinética off do consumo de oxigênio no exercício realizado na intensidade acima da potência correspondente ao consumo máximo de oxigênio (110\%).

\begin{tabular}{lccc}
\multicolumn{3}{c}{ Valores Extremos } \\
\hline Variável & & Sujeito & Valor \\
\hline $\mathrm{A}_{1}(\mathrm{ml} / \mathrm{min})$ & Maior & 4 & 1941,54 \\
& Menor & 1 & 1020,44 \\
$\tau_{1}(\mathrm{~s})$ & Maior & 2 & 39 \\
& Menor & 8 & 18 \\
$\delta(\mathrm{s})$ & Maior & 4 & 19 \\
& Menor & 6 & 10 \\
$\mathrm{~A}_{2}(\mathrm{ml} / \mathrm{min})$ & Maior & 9 & 785,06 \\
& Menor & 8 & 369,26 \\
$\tau_{2}(\mathrm{~s})$ & Maior & 9 & 80 \\
& Menor & 7 & 30 \\
\hline
\end{tabular}

Teste de Normalidade de Shapiro-Wilk.

\begin{tabular}{lrrr}
\hline Variável & Estatística & gl & Sig. \\
\hline $\mathrm{A}_{1}(\mathrm{ml} / \mathrm{min})$ &, 792 & 9 &, 072 \\
$\tau_{1}(\mathrm{~s})$ &, 973 & 9 &, 914 \\
$\delta(\mathrm{s})$ &, 838 & 9 &, 061 \\
$\mathrm{~A}_{2}(\mathrm{ml} / \mathrm{min})$ &, 866 & 9 &, 090 \\
$\tau_{2}(\mathrm{~s})$ &, 865 & 9 &, 088 \\
\hline
\end{tabular}


ANEXO IV - Resumo das análises estatísticas (continuação).

Variáveis analisadas durante 0 exercício realizado nas intensidades percentuais abaixo da potência correspondente ao $\mathrm{VO}_{2} \max$.

Valores Extremos

\begin{tabular}{|c|c|c|c|c|c|c|c|}
\hline & & Sujeito & Valor & & & Sujeito & Valor \\
\hline \multirow[t]{2}{*}{$\mathrm{VO}_{2}$ pico $(40 \%)$} & Maior & 4 & 1,934 & FCpico (40\%) & Maior & 4 & 131 \\
\hline & Menor & 10 & 1,454 & & Menor & 9 & 108 \\
\hline \multirow[t]{2}{*}{$\mathrm{VO}_{2}$ pico $(50 \%)$} & Maior & 5 & 2,487 & FCpico (50\%) & Maior & 8 & 183 \\
\hline & Menor & 10 & 1,826 & & Menor & 5 & 123 \\
\hline \multirow[t]{2}{*}{$\mathrm{VO}_{2}$ pico $(60 \%)$} & Maior & 7 & 2,925 & FCpico (60\%) & Maior & 8 & 194 \\
\hline & Menor & 10 & 2,054 & & Menor & 10 & 127 \\
\hline \multirow[t]{2}{*}{$\mathrm{VO}_{2}$ pico $(70 \%)$} & Maior & 7 & 3,031 & FCpico $(70 \%)$ & Maior & 8 & 193 \\
\hline & Menor & 1 & 2,183 & & Menor & 1 & 157 \\
\hline \multirow[t]{2}{*}{$\mathrm{VO}_{2}$ pico $(80 \%)$} & Maior & 3 & 3,514 & FCpico (80\%) & Maior & 8 & 192 \\
\hline & Menor & 1 & 2,530 & & Menor & 1 & 165 \\
\hline \multirow[t]{2}{*}{$\mathrm{VO}_{2}$ pico $(90 \%)$} & Maior & 3 & 3,777 & FCpico (90\%) & Maior & 8 & 191 \\
\hline & Menor & 10 & 2,732 & & Menor & 3 & 163 \\
\hline
\end{tabular}

Valores Extremos

\begin{tabular}{|c|c|c|c|c|c|c|c|}
\hline \multirow{2}{*}{ [La]pico (40\%) } & \multirow[b]{2}{*}{ Maior } & \multirow{2}{*}{$\frac{\text { Sujeito }}{5}$} & \multicolumn{3}{|l|}{ Valor } & \multirow[t]{2}{*}{ Sujeito } & \multirow[t]{2}{*}{ Valor } \\
\hline & & & 5,82 & & & & \\
\hline & Menor & 4 & 1,18 & & & & \\
\hline \multirow[t]{2}{*}{ [La']pico (50\%) } & Maior & 8 & 8,60 & \multirow{2}{*}{\multicolumn{4}{|c|}{$\begin{array}{l}\text { Todos os sujeitos completaram } 600 \mathrm{~s} \text { de } \\
\text { exercício entre } 40-60 \% \text { da } \mathrm{WVO}_{2} \max \text {. }\end{array}$}} \\
\hline & Menor & 2 & 2,21 & & & & \\
\hline \multirow[t]{2}{*}{ [La']pico (60\%) } & Maior & 8 & 9,32 & & & & \\
\hline & Menor & 4 & 3,77 & & & & \\
\hline \multirow[t]{2}{*}{ [La]pico (70\%) } & Maior & 3 & 10,58 & Tempo (70\%) & Maior & 2 & 600 \\
\hline & Menor & 2 & 6,44 & & Menor & 1 & 371 \\
\hline \multirow[t]{2}{*}{ [La']pico (80\%) } & Maior & 2 & 12,29 & Tempo (80\%) & Maior & 2 & 600 \\
\hline & Menor & 10 & 7,55 & & Menor & 7 & 269 \\
\hline \multirow[t]{2}{*}{ [La']pico (90\%) } & Maior & 9 & 12,44 & Tempo (90\%) & Maior & 2 & 600 \\
\hline & Menor & 4 & 8,14 & & Menor & 6 & 160 \\
\hline
\end{tabular}


ANEXO IV - Resumo das análises estatísticas (continuação).

Teste de Normalidade de Shapiro-Wilk.

\begin{tabular}{|c|c|c|c|}
\hline Variável & Estatística & $\mathrm{gl}$ & Sig. \\
\hline $\mathrm{VO}_{2}$ pico $(40 \%)$ & 0,889 & 9 & 0,163 \\
\hline $\mathrm{VO}_{2}$ pico $(50 \%)$ & 0,926 & 9 & 0,409 \\
\hline $\mathrm{VO}_{2}$ pico $(60 \%)$ & 0,960 & 9 & 0,785 \\
\hline $\mathrm{VO}_{2}$ pico $(70 \%)$ & 0,941 & 9 & 0,566 \\
\hline $\mathrm{VO}_{2}$ pico $(80 \%)$ & 0,962 & 9 & 0,808 \\
\hline $\mathrm{VO}_{2}$ pico $(90 \%)$ & 0,951 & 9 & 0,678 \\
\hline FCpico (40\%) & 0,854 & 9 & 0,064 \\
\hline FCpico (50\%) & 0,910 & 9 & 0,282 \\
\hline FCpico (60\%) & 0,935 & 9 & 0,501 \\
\hline FCpico (70\%) & 0,994 & 9 & 1,000 \\
\hline FCpico (80\%) & 0,971 & 9 & 0,901 \\
\hline FCpico (90\%) & 0,945 & 9 & 0,614 \\
\hline [La“]pico (40\%) & 0,871 & 9 & 0,103 \\
\hline [La“]pico (50\%) & 0,961 & 9 & 0,797 \\
\hline [La“]pico (60\%) & 0,966 & 9 & 0,848 \\
\hline [La“]pico (70\%) & 0,955 & 9 & 0,733 \\
\hline [La“]pico (80\%) & 0,967 & 9 & 0,858 \\
\hline [La“]pico (90\%) & 0,942 & 9 & 0,581 \\
\hline Tempo (70\%) & 0,366 & 9 & $1 \mathrm{E}-07$ \\
\hline Tempo (80\%) & 0,800 & 9 & 0,015 \\
\hline Tempo (90\%) & 0,851 & 9 & 0,060 \\
\hline
\end{tabular}


ANEXO IV - Resumo das análises estatísticas (continuação).

Análise de variância a um fator (intensidade) com medidas repetidas do consumo de oxigênio de pico nas intensidades percentuais abaixo da potência correspondente ao $\mathrm{VO}_{2}$ max.

Teste de Esfericidade de Mauchly.

\begin{tabular}{lcccc}
\hline & Mauchly's W & Aprox. Qui-quadrado & gl & Sig. \\
\hline Fator 1 & 0,147 & 13,600 & 14 & 0,51 \\
\hline
\end{tabular}

Nível de significância ajustado pelo teste de Bonferroni para comparações múltiplas.

\begin{tabular}{|c|c|c|c|c|}
\hline & & \multirow[t]{2}{*}{ Sig. } & \multicolumn{2}{|c|}{$\begin{array}{l}\text { Intervalo de confiança de } \\
95 \% \text { para a diferença }\end{array}$} \\
\hline & & & Limite Inferior & Limite Superior \\
\hline \multirow[t]{5}{*}{$40 \%$} & $50 \%$ & $8,71988 \mathrm{E}-05$ & $-694,166$ & $-284,034$ \\
\hline & $60 \%$ & $9,70492 \mathrm{E}-06$ & $-1062,79$ & $-544,013$ \\
\hline & $70 \%$ & 7,49997E-07 & $-1242,96$ & $-761,64$ \\
\hline & $80 \%$ & $1,14201 \mathrm{E}-07$ & $-1507,42$ & $-1017,98$ \\
\hline & $90 \%$ & $9,23571 \mathrm{E}-08$ & $-1734,09$ & $-1182,31$ \\
\hline \multirow[t]{5}{*}{$50 \%$} & $40 \%$ & 8,71988E-05 & 284,0344 & 694,1656 \\
\hline & $60 \%$ & 0,007450235 & $-548,984$ & $-79,6163$ \\
\hline & $70 \%$ & 0,000642628 & $-788,943$ & $-237,457$ \\
\hline & $80 \%$ & $7,74111 \mathrm{E}-06$ & $-1016,85$ & $-530,354$ \\
\hline & $90 \%$ & $1,23372 \mathrm{E}-06$ & $-1215,45$ & $-722,747$ \\
\hline \multirow[t]{5}{*}{$60 \%$} & $40 \%$ & 9,70492E-06 & 544,0133 & 1062,787 \\
\hline & $50 \%$ & 0,007450235 & 79,61634 & 548,9837 \\
\hline & $70 \%$ & 0,005246522 & $-340,237$ & $-57,5629$ \\
\hline & $80 \%$ & 0,000925723 & $-717,931$ & $-200,669$ \\
\hline & $90 \%$ & 0,000108394 & $-936,695$ & $-372,905$ \\
\hline \multirow[t]{4}{*}{$70 \%$} & $40 \%$ & 7,49997E-07 & 761,6399 & 1242,96 \\
\hline & $50 \%$ & 0,000642628 & 237,4569 & 788,9431 \\
\hline & $60 \%$ & 0,005246522 & 57,56293 & 340,2371 \\
\hline & $80 \%$ & 0,028330987 & $-497,877$ & $-22,9228$ \\
\hline
\end{tabular}


ANEXO IV - Resumo das análises estatísticas (continuação).

Nível de significância ajustado pelo teste de Bonferroni para comparações múltiplas (continuação).

\begin{tabular}{lllll}
\hline & $90 \%$ & 0,001727957 & $-734,459$ & $-177,341$ \\
$80 \%$ & $40 \%$ & $1,14201 \mathrm{E}-07$ & 1017,984 & 1507,416 \\
& $50 \%$ & $7,74111 \mathrm{E}-06$ & 530,3541 & 1016,846 \\
& $60 \%$ & 0,000925723 & 200,6687 & 717,9313 \\
& $70 \%$ & 0,028330987 & 22,92275 & 497,8772 \\
& $90 \%$ & 0,005081946 & $-333,804$ & $-57,1962$ \\
& $40 \%$ & $9,23571 \mathrm{E}-08$ & 1182,308 & 1734,092 \\
& $50 \%$ & $1,23372 \mathrm{E}-06$ & 722,7469 & 1215,453 \\
& $60 \%$ & 0,000108394 & 372,905 & 936,695 \\
& $70 \%$ & 0,001727957 & 177,3407 & 734,4593 \\
& $80 \%$ & 0,005081946 & 57,1962 & 333,8038 \\
\hline
\end{tabular}


ANEXO IV - Resumo das análises estatísticas (continuação).

Análise de variância a um fator (intensidade) com medidas repetidas da freqüência cardíaca de pico nas intensidades percentuais abaixo da potência correspondente ao $\mathrm{VO}_{2} \mathrm{max}$.

Teste de Esfericidade de Mauchly.

\begin{tabular}{lcccc}
\hline & Mauchly's W & $\begin{array}{c}\text { Aprox. Qui- } \\
\text { quadrado }\end{array}$ & gl & Sig. \\
\hline Fator 1 & 0,021 & 27,579 & 14 & 0,061 \\
\hline
\end{tabular}

Nível de significância ajustado pelo teste de Bonferroni para comparações múltiplas.

\begin{tabular}{lcccc}
\hline & & Sig. & \multicolumn{2}{c}{$\begin{array}{c}\text { Intervalo de confiança de } \\
95 \% \text { para a diferença }\end{array}$} \\
\hline \multirow{3}{*}{$40 \%$} & & & Limite Inferior & Limite Superior \\
\cline { 5 - 5 } & $50 \%$ & 0,078 & $-45,733$ & 1,733 \\
& $60 \%$ & 0,002 & $-51,383$ & $-12,017$ \\
& $70 \%$ & 0,000 & $-62,750$ & $-40,250$ \\
$50 \%$ & $80 \%$ & 0,000 & $-67,249$ & $-43,751$ \\
& $90 \%$ & 0,000 & $-67,484$ & $-39,116$ \\
& $40 \%$ & 0,078 & $-1,733$ & 45,733 \\
& $60 \%$ & 1,000 & $-31,645$ & 12,245 \\
$60 \%$ & $70 \%$ & 0,002 & $-47,479$ & $-11,521$ \\
& $80 \%$ & 0,004 & $-56,461$ & $-10,539$ \\
& $90 \%$ & 0,002 & $-51,255$ & $-11,345$ \\
& $40 \%$ & 0,002 & 12,017 & 51,383 \\
& $50 \%$ & 1,000 & $-12,245$ & 31,645 \\
& $70 \%$ & 0,020 & $-36,933$ & $-2,667$ \\
& $80 \%$ & 0,017 & $-43,857$ & $-3,743$ \\
& $90 \%$ & 0,022 & $-40,520$ & $-2,680$ \\
& $40 \%$ & 0,000 & 40,250 & 62,750 \\
& $50 \%$ & 0,002 & 11,521 & 47,479 \\
\hline
\end{tabular}


ANEXO IV - $\underline{\text { Resumo das análises estatísticas (continuação). }}$

Nível de significância ajustado pelo teste de Bonferroni para comparações múltiplas (continuação).

\begin{tabular}{lcccc}
\hline & $60 \%$ & 0,020 & 2,667 & 36,933 \\
$80 \%$ & 1,000 & $-12,643$ & 4,643 \\
& $80 \%$ & 1,000 & $-10,006$ & 6,406 \\
& $40 \%$ & 0,000 & 43,751 & 67,249 \\
& $50 \%$ & 0,004 & 10,539 & 56,461 \\
& $60 \%$ & 0,017 & 3,743 & 43,857 \\
& $70 \%$ & 1,000 & $-4,643$ & 12,643 \\
& $90 \%$ & 1,000 & $-3,355$ & 7,755 \\
& $40 \%$ & 0,000 & 39,116 & 67,484 \\
& $50 \%$ & 0,002 & 11,345 & 51,255 \\
& $60 \%$ & 0,022 & 2,680 & 40,520 \\
& $70 \%$ & 1,000 & $-6,406$ & 10,006 \\
& $80 \%$ & 1,000 & $-7,755$ & 3,355 \\
\hline
\end{tabular}


ANEXO IV - Resumo das análises estatísticas (continuação).

Análise de variância a um fator (intensidade) com medidas repetidas das concentrações sangüíneas de lactato nas intensidades percentuais abaixo da potência correspondente ao $\mathrm{VO}_{2} \mathrm{max}$.

Teste de Esfericidade de Mauchly.

\begin{tabular}{ccccc}
\hline & Mauchly's W & Aprox. Qui-quadrado & gl & Sig. \\
\hline Fator 1 & 0,315 & 8,194 & 14,0 & 0,888 \\
\hline
\end{tabular}

Nível de significância ajustado pelo teste de Bonferroni para comparações múltiplas.

\begin{tabular}{lcccc}
\hline & & Sig. & \multicolumn{2}{c}{$\begin{array}{c}\text { Intervalo de confiança } \\
\text { de 95\% para a diferença }\end{array}$} \\
\hline \multirow{3}{*}{$40 \%$} & & & Limite Inferior & Limite Superior \\
\cline { 3 - 5 } & $50 \%$ & 0,049 & $-4,505$ & $-0,007$ \\
& $60 \%$ & 0,001 & $-6,956$ & $-1,814$ \\
& $70 \%$ & 0,000 & $-8,529$ & $-3,477$ \\
& $80 \%$ & 0,000 & $-10,403$ & $-4,869$ \\
& $90 \%$ & 0,000 & $-9,006$ & $-5,610$ \\
& $40 \%$ & 0,049 & 0,007 & 4,505 \\
& $60 \%$ & 0,024 & $-4,024$ & $-0,234$ \\
& $70 \%$ & 0,000 & $-5,596$ & $-1,898$ \\
& $80 \%$ & 0,000 & $-8,171$ & $-2,589$ \\
& $90 \%$ & 0,000 & $-7,495$ & $-2,609$ \\
& $40 \%$ & 0,001 & 1,814 & 6,956 \\
& $50 \%$ & 0,024 & 0,234 & 4,024 \\
& $70 \%$ & 0,242 & $-3,785$ & 0,549 \\
& $80 \%$ & 0,002 & $-5,281$ & $-1,221$ \\
& $90 \%$ & 0,006 & $-5,032$ & $-0,814$ \\
& $40 \%$ & 0,000 & 3,477 & 8,529 \\
& $50 \%$ & 0,000 & 1,898 & 5,596 \\
& $60 \%$ & 0,242 & $-0,549$ & 3,785 \\
& $80 \%$ & 0,323 & $-3,958$ & 0,692 \\
\hline \multirow{3}{*}{50} & & &
\end{tabular}


ANEXO IV - Resumo das análises estatísticas (continuação).

Nível de significância ajustado pelo teste de Bonferroni para comparações múltiplas (continuação).

\begin{tabular}{lcccc}
\hline & $90 \%$ & 0,838 & $-3,657$ & 1,047 \\
$80 \%$ & $40 \%$ & 0,000 & 4,869 & 10,403 \\
& $50 \%$ & 0,000 & 2,589 & 8,171 \\
& $60 \%$ & 0,002 & 1,221 & 5,281 \\
& $70 \%$ & 0,323 & $-0,692$ & 3,958 \\
& $90 \%$ & 1,000 & $-1,967$ & 2,623 \\
& $40 \%$ & 0,000 & 5,610 & 9,006 \\
& $50 \%$ & 0,000 & 2,609 & 7,495 \\
& $60 \%$ & 0,006 & 0,814 & 5,032 \\
& $70 \%$ & 0,838 & $-1,047$ & 3,657 \\
& $80 \%$ & 1,000 & $-2,623$ & 1,967 \\
\hline
\end{tabular}


ANEXO IV - $\underline{\text { Resumo das análises estatísticas (continuação). }}$

Resposta cinética do consumo de oxigênio durante o exercício realizado nas intensidades percentuais abaixo da potência correspondente ao $\mathrm{VO}_{2}$ max.

Valores Extremos

\begin{tabular}{llccllcc}
\hline & & Sujeito & \multicolumn{2}{c}{ Valor } & & Sujeito & Valor \\
\hline $\mathrm{A}_{1}(40 \%)$ & Maior & 4 & 1359,62 & $\tau_{1}(40 \%)$ & Maior & 1 & 48 \\
& Menor & 1 & 980,78 & & Menor & 2 & 22 \\
$\mathrm{~A}_{1}(50 \%)$ & Maior & 3 & 1482,29 & $\tau_{1}(50 \%)$ & Maior & 5 & 66 \\
& Menor & 9 & 965,37 & & Menor & 2 & 33 \\
$\mathrm{~A}_{1}(60 \%)$ & Maior & 4 & 1568,72 & $\tau_{1}(60 \%)$ & Maior & 7 & 77 \\
& Menor & 9 & 1021,81 & & Menor & 5 & 33 \\
$\mathrm{~A}_{1}(70 \%)$ & Maior & 10 & 1998,94 & $\tau_{1}(70 \%)$ & Maior & 3 & 96 \\
& Menor & 8 & 1488,31 & & Menor & 5 & 22 \\
$\mathrm{~A}_{1}(80 \%)$ & Maior & 7 & 2500,44 & $\tau_{1}(80 \%)$ & Maior & 9 & 79 \\
& Menor & 9 & 1131,99 & & Menor & 1 & 33 \\
$\mathrm{~A}_{1}(90 \%)$ & Maior & 4 & 2852,03 & $\tau_{1}(90 \%)$ & Maior & 9 & 55 \\
& Menor & 2 & 1564,37 & & Menor & 4 & 24 \\
\hline
\end{tabular}

\begin{tabular}{llrr}
\hline & & Sujeito & \multicolumn{2}{c}{ Valor } \\
\hline$\delta(40 \%)$ & Maior & 6 & 1 \\
& Menor & 3 & 0,1 \\
$\delta(50 \%)$ & Maior & 3 & 1,99 \\
& Menor & 1 & 0,1 \\
$\delta(60 \%)$ & Maior & 1 & 1,1 \\
& Menor & 8 & 0,86 \\
$\delta(70 \%)$ & Maior & 3 & 1 \\
& Menor & 10 & 0,84 \\
$\delta(80 \%)$ & Maior & 3 & 3 \\
& Menor & 7 & 0,62 \\
$\delta(90 \%)$ & Maior & 2 & 5 \\
& Menor & 4 & 0,3 \\
\hline
\end{tabular}


ANEXO IV - $\underline{\text { Resumo das análises estatísticas (continuação). }}$

Resposta cinética do consumo de oxigênio durante o exercício realizado nas intensidades percentuais abaixo da potência correspondente ao $\mathrm{VO}_{2} \max$.

Teste de Normalidade de Shapiro-Wilk.

\begin{tabular}{cccc|cccc}
\hline & Estatística & gl & \multicolumn{1}{c}{ Sig. } & Estatística & gl & Sig. \\
\hline $\mathrm{A}_{1}(40 \%)$ & 0,929 & 9 & 0,437 & $\tau_{1}(40 \%)$ & 0,887 & 9 & 0,157 \\
$\mathrm{~A}_{1}(50 \%)$ & 0,962 & 9 & 0,810 & $\tau_{1}(50 \%)$ & 0,934 & 9 & 0,486 \\
$\mathrm{~A}_{1}(60 \%)$ & 0,974 & 9 & 0,922 & $\tau_{1}(60 \%)$ & 0,942 & 9 & 0,571 \\
$\mathrm{~A}_{1}(70 \%)$ & 0,917 & 9 & 0,333 & $\tau_{1}(70 \%)$ & 0,931 & 9 & 0,456 \\
$\mathrm{~A}_{1}(80 \%)$ & 0,953 & 9 & 0,703 & $\tau_{1}(80 \%)$ & 0,934 & 9 & 0,493 \\
$\mathrm{~A}_{1}(90 \%)$ & 0,929 & 9 & 0,439 & $\tau_{1}(90 \%)$ & 0,928 & 9 & 0,429 \\
\hline
\end{tabular}

\begin{tabular}{lccc}
\hline & Estatística & gl & Sig. \\
\hline$\delta(40 \%)$ & 0,624 & 9 & 0,000 \\
$\delta(50 \%)$ & 0,827 & 9 & 0,031 \\
$\delta(60 \%)$ & 0,935 & 9 & 0,496 \\
$\delta(70 \%)$ & 0,769 & 9 & 0,006 \\
$\delta(80 \%)$ & 0,615 & 9 & 0,000 \\
$\delta(90 \%)$ & 0,910 & 9 & 0,284 \\
\hline
\end{tabular}


ANEXO IV - Resumo das análises estatísticas (continuação).

Análise de variância a um fator (intensidade) com medidas repetidas da amplitude da resposta cinética do consumo de oxigênio nas intensidades percentuais abaixo da potência correspondente ao $\mathrm{VO}_{2} \max$.

Teste de Esfericidade de Mauchly.

\begin{tabular}{lcccc}
\hline & Mauchly's W & Aprox. Qui-quadrado & gl & Sig. \\
\hline Fator 1 & 0,301 & 33,194 & 14,0 & 0,891 \\
\hline
\end{tabular}

Nível de significância ajustado pelo teste de Bonferroni para comparações múltiplas.

\begin{tabular}{|c|c|c|c|c|}
\hline & & \multirow[t]{2}{*}{ Sig. } & \multicolumn{2}{|c|}{$\begin{array}{l}\text { Intervalo de confiança de } \\
95 \% \text { para a diferença }\end{array}$} \\
\hline & & & Limite Inferior & Limite Superior \\
\hline \multirow[t]{5}{*}{$40 \%$} & $50 \%$ & 0,076 & $-253,746$ & 9,110 \\
\hline & $60 \%$ & 0,000 & $-297,104$ & $-98,686$ \\
\hline & $70 \%$ & 0,000 & $-930,119$ & $-385,817$ \\
\hline & $80 \%$ & 0,005 & $-1228,634$ & $-209,982$ \\
\hline & $90 \%$ & 0,000 & $-1527,540$ & $-558,478$ \\
\hline \multirow[t]{5}{*}{$50 \%$} & $40 \%$ & 0,076 & $-9,110$ & 253,746 \\
\hline & $60 \%$ & 1,000 & $-223,726$ & 72,572 \\
\hline & $70 \%$ & 0,001 & $-816,918$ & $-254,382$ \\
\hline & $80 \%$ & 0,007 & $-1037,341$ & $-156,639$ \\
\hline & $90 \%$ & 0,000 & $-1383,909$ & $-457,473$ \\
\hline \multirow[t]{5}{*}{$60 \%$} & $40 \%$ & 0,000 & 98,686 & 297,104 \\
\hline & $50 \%$ & 1,000 & $-72,572$ & 223,726 \\
\hline & $70 \%$ & 0,004 & $-770,427$ & $-149,719$ \\
\hline & $80 \%$ & 0,044 & $-1032,530$ & $-10,296$ \\
\hline & $90 \%$ & 0,002 & $-1352,107$ & $-338,121$ \\
\hline \multirow[t]{5}{*}{$70 \%$} & $40 \%$ & 0,000 & 385,817 & 930,119 \\
\hline & $50 \%$ & 0,001 & 254,382 & 816,918 \\
\hline & $60 \%$ & 0,004 & 149,719 & 770,427 \\
\hline & $80 \%$ & 1,000 & $-645,091$ & 522,411 \\
\hline & $90 \%$ & 0,229 & $-894,682$ & 124,600 \\
\hline \multirow[t]{2}{*}{$80 \%$} & $40 \%$ & 0,005 & 209,982 & 1228,634 \\
\hline & $50 \%$ & 0,007 & 156,639 & 1037,341 \\
\hline
\end{tabular}


ANEXO IV - Resumo das análises estatísticas (continuação).

Nível de significância ajustado pelo teste de Bonferroni para comparações múltiplas (continuação).

\begin{tabular}{lcccc}
\hline & $60 \%$ & 0,044 & 10,296 & 1032,530 \\
& $70 \%$ & 1,000 & $-522,411$ & 645,091 \\
$90 \%$ & $90 \%$ & 0,683 & $-875,585$ & 228,183 \\
& $40 \%$ & 0,000 & 558,478 & 1527,540 \\
& $50 \%$ & 0,000 & 457,473 & 1383,909 \\
& $60 \%$ & 0,002 & 338,121 & 1352,107 \\
& $70 \%$ & 0,229 & $-124,600$ & 894,682 \\
\hline
\end{tabular}


ANEXO IV - $\underline{\text { Resumo das análises estatísticas (continuação). }}$

Análise de variância a um fator (intensidade) com medidas repetidas da constante de tempo da resposta cinética do consumo de oxigênio nas intensidades percentuais abaixo da potência correspondente ao $\mathrm{VO}_{2} \max$.

Teste de Esfericidade de Mauchly.

\begin{tabular}{lcccc}
\hline & Mauchly's W & Aprox. Qui-quadrado & gl & Sig. \\
\hline Fator 1 & 0,086 & 17,420 & 14,0 & 0,260 \\
\hline
\end{tabular}

Nível de significância ajustado pelo teste de Bonferroni para comparações múltiplas.

\begin{tabular}{|c|c|c|c|c|}
\hline & & \multirow[t]{2}{*}{ Sig. } & \multicolumn{2}{|c|}{$\begin{array}{c}\text { Intervalo de confiança } \\
\text { de } 95 \% \text { para a diferença }\end{array}$} \\
\hline & & & Limite Inferior & Limite Superior \\
\hline \multirow[t]{5}{*}{$40 \%$} & $50 \%$ & 0,013 & $-22,616$ & $-2,378$ \\
\hline & $60 \%$ & 0,088 & $-38,038$ & 1,856 \\
\hline & $70 \%$ & 1,000 & $-39,241$ & 13,633 \\
\hline & $80 \%$ & 0,611 & $-35,480$ & 8,764 \\
\hline & $90 \%$ & 1,000 & $-17,801$ & 12,811 \\
\hline \multirow[t]{5}{*}{$50 \%$} & $40 \%$ & 0,013 & 2,378 & 22,616 \\
\hline & $60 \%$ & 1,000 & $-26,337$ & 15,149 \\
\hline & $70 \%$ & 1,000 & $-31,297$ & 30,683 \\
\hline & $80 \%$ & 1,000 & $-24,083$ & 22,361 \\
\hline & $90 \%$ & 0,915 & $-8,477$ & 28,481 \\
\hline \multirow[t]{5}{*}{$60 \%$} & $40 \%$ & 0,088 & $-1,856$ & 38,038 \\
\hline & $50 \%$ & 1,000 & $-15,149$ & 26,337 \\
\hline & $70 \%$ & 1,000 & $-20,574$ & 31,148 \\
\hline & $80 \%$ & 1,000 & $-6,577$ & 16,043 \\
\hline & $90 \%$ & 0,227 & $-5,005$ & 36,197 \\
\hline \multirow[t]{5}{*}{$70 \%$} & $40 \%$ & 1,000 & $-13,633$ & 39,241 \\
\hline & $50 \%$ & 1,000 & $-30,683$ & 31,297 \\
\hline & $60 \%$ & 1,000 & $-31,148$ & 20,574 \\
\hline & $80 \%$ & 1,000 & $-24,186$ & 23,078 \\
\hline & $90 \%$ & 1,000 & $-13,432$ & 34,050 \\
\hline \multirow[t]{2}{*}{$80 \%$} & $40 \%$ & 0,611 & $-8,764$ & 35,480 \\
\hline & $50 \%$ & 1,000 & $-22,361$ & 24,083 \\
\hline
\end{tabular}


ANEXO IV - Resumo das análises estatísticas (continuação).

Nível de significância ajustado pelo teste de Bonferroni para comparações múltiplas (continuação).

\begin{tabular}{lcccc}
\hline & $60 \%$ & 1,000 & $-16,043$ & 6,577 \\
& $70 \%$ & 1,000 & $-23,078$ & 24,186 \\
$90 \%$ & $90 \%$ & 1,000 & $-10,328$ & 32,054 \\
& $40 \%$ & 1,000 & $-12,811$ & 17,801 \\
& $50 \%$ & 0,915 & $-28,481$ & 8,477 \\
& $60 \%$ & 0,227 & $-36,197$ & 5,005 \\
& $70 \%$ & 1,000 & $-34,050$ & 13,432 \\
& $80 \%$ & 1,000 & $-32,054$ & 10,328 \\
\hline
\end{tabular}


ANEXO IV - $\underline{\text { Resumo das análises estatísticas (continuação). }}$

Análise de variância a um fator (intensidade) com medidas repetidas do tempo de atraso da resposta cinética do consumo de oxigênio nas intensidades percentuais abaixo da potência correspondente ao $\mathrm{VO}_{2} \max$.

Teste de Esfericidade de Mauchly.

\begin{tabular}{ccccc}
\hline & Mauchly's W & Aprox. Qui-quadrado & gl & Sig. \\
\hline Fator 1 & 0,000 & 75,649 & 14,0 & 0,010 \\
\hline
\end{tabular}

Nível de significância ajustado pelo teste de Bonferroni para comparações múltiplas.

\begin{tabular}{|c|c|c|c|c|}
\hline & & \multirow[t]{2}{*}{ Sig. } & \multicolumn{2}{|c|}{$\begin{array}{c}\text { Intervalo de confiança } \\
\text { de } 95 \% \text { para a diferença }\end{array}$} \\
\hline \multirow{3}{*}{$40 \%$} & & & Limite Inferior & Limite Superior \\
\hline & $50 \%$ & 1,000 & $-0,919$ & 0,637 \\
\hline & $60 \%$ & 1,000 & $-0,812$ & 0,340 \\
\hline \multirow{7}{*}{$50 \%$} & $70 \%$ & 1,000 & $-0,773$ & 0,315 \\
\hline & $80 \%$ & 1,000 & $-1,914$ & 0,700 \\
\hline & $90 \%$ & 0,322 & $-4,256$ & 0,744 \\
\hline & $40 \%$ & 1,000 & $-0,637$ & 0,919 \\
\hline & $60 \%$ & 1,000 & $-0,768$ & 0,578 \\
\hline & $70 \%$ & 1,000 & $-0,731$ & 0,555 \\
\hline & $80 \%$ & 0,869 & $-1,314$ & 0,382 \\
\hline \multirow{3}{*}{$60 \%$} & $90 \%$ & 0,419 & $-4,055$ & 0,825 \\
\hline & $40 \%$ & 1,000 & $-0,340$ & 0,812 \\
\hline & $50 \%$ & 1,000 & $-0,578$ & 0,768 \\
\hline \multirow{7}{*}{$70 \%$} & $70 \%$ & 1,000 & $-0,059$ & 0,073 \\
\hline & $80 \%$ & 1,000 & $-1,450$ & 0,708 \\
\hline & $90 \%$ & 0,302 & $-3,653$ & 0,613 \\
\hline & $40 \%$ & 1,000 & $-0,315$ & 0,773 \\
\hline & $50 \%$ & 1,000 & $-0,555$ & 0,731 \\
\hline & $60 \%$ & 1,000 & $-0,073$ & 0,059 \\
\hline & $80 \%$ & 1,000 & $-1,467$ & 0,711 \\
\hline \multirow{3}{*}{$80 \%$} & $90 \%$ & 0,299 & $-3,665$ & 0,611 \\
\hline & $40 \%$ & 1,000 & $-0,700$ & 1,914 \\
\hline & $50 \%$ & 0,869 & $-0,382$ & 1,314 \\
\hline
\end{tabular}


ANEXO IV - Resumo das análises estatísticas (continuação).

Nível de significância ajustado pelo teste de Bonferroni para comparações múltiplas (continuação).

\begin{tabular}{lllll}
\hline & $60 \%$ & 1,000 & $-0,708$ & 1,450 \\
& $70 \%$ & 1,000 & $-0,711$ & 1,467 \\
$90 \%$ & $90 \%$ & 1,000 & $-3,608$ & 1,310 \\
& $40 \%$ & 0,322 & $-0,744$ & 4,256 \\
& $50 \%$ & 0,419 & $-0,825$ & 4,055 \\
& $60 \%$ & 0,302 & $-0,613$ & 3,653 \\
& $70 \%$ & 0,299 & $-0,611$ & 3,665 \\
& $80 \%$ & 1,000 & $-1,310$ & 3,608 \\
\hline
\end{tabular}


ANEXO IV - $\underline{\text { Resumo das análises estatísticas (continuação). }}$

Contribuições absolutas do metabolismo anaeróbio lático e alático durante o exercício realizado nas intensidades percentuais abaixo da potência correspondente ao $\mathrm{VO}_{2} \max$.

Valores Extremos.

\begin{tabular}{|c|c|c|c|c|c|c|c|}
\hline & & Sujeito & Valor & & & Sujeito & Valor \\
\hline \multirow[t]{2}{*}{ MAL (40\%) } & Maior & 5 & 1,14 & MAA (40\%) & Maior & 3 & 0,86 \\
\hline & Menor & 4 & 0,06 & & Menor & 2 & 0,41 \\
\hline \multirow[t]{2}{*}{ MAL (50\%) } & Maior & 8 & 1,60 & MAA (50\%) & Maior & 7 & 1,60 \\
\hline & Menor & 2 & 0,26 & & Menor & 2 & 0,68 \\
\hline \multirow[t]{2}{*}{ MAL (60\%) } & Maior & 7 & 1,41 & MAA $(60 \%)$ & Maior & 7 & 1,87 \\
\hline & Menor & 4 & 0,67 & & Menor & 5 & 0,78 \\
\hline \multirow[t]{2}{*}{ MAL (70\%) } & Maior & 3 & 2,10 & MAA (70\%) & Maior & 3 & 3,19 \\
\hline & Menor & 2 & 0,84 & & Menor & 5 & 0,58 \\
\hline \multirow[t]{2}{*}{ MAL (80\%) } & Maior & 3 & 2,62 & MAA (80\%) & Maior & 7 & 2,73 \\
\hline & Menor & 10 & 1,44 & & Menor & 2 & 0,75 \\
\hline \multirow[t]{2}{*}{ MAL (90\%) } & Maior & 5 & 2,32 & MAA (90\%) & Maior & 3 & 2,33 \\
\hline & Menor & 2 & 1,58 & & Menor & 8 & 0,79 \\
\hline
\end{tabular}

Teste de Normalidade de Shapiro-Wilk.

\begin{tabular}{lccc|lccc}
\hline & Estatística & gl & Sig. & & Estatística & gl & Sig. \\
\hline MAL (40\%) & 0,861 & 9 & 0,079 & MAA (40\%) & 0,877 & 9 & 0,122 \\
MAL (50\%) & 0,971 & 9 & 0,903 & MAA (50\%) & 0,944 & 9 & 0,596 \\
MAL (60\%) & 0,900 & 9 & 0,220 & MAA (60\%) & 0,921 & 9 & 0,363 \\
MAL (70\%) & 0,851 & 9 & 0,060 & MAA (70\%) & 0,893 & 9 & 0,184 \\
MAL (80\%) & 0,972 & 9 & 0,908 & MAA (80\%) & 0,932 & 9 & 0,470 \\
MAL (90\%) & 0,953 & 9 & 0,703 & MAA (90\%) & 0,957 & 9 & 0,748 \\
\hline
\end{tabular}


ANEXO IV - Resumo das análises estatísticas (continuação).

Análise de variância a um fator (intensidade) com medidas repetidas da contribuição absoluta do metabolismo anaeróbio lático nas intensidades percentuais abaixo da potência correspondente ao $\mathrm{VO}_{2} \max$.

Teste de Esfericidade de Mauchly.

\begin{tabular}{lcccc}
\hline & Mauchly's W & Aprox. Qui-quadrado & gl & Sig. \\
\hline Fator 1 & 0,228 & 10,503 & 14,0 & 0,743 \\
\hline
\end{tabular}

Nível de significância ajustado pelo teste de Bonferroni para comparações múltiplas

\begin{tabular}{|c|c|c|c|c|}
\hline & & \multirow[t]{2}{*}{ Sig. } & \multicolumn{2}{|c|}{$\begin{array}{l}\text { Intervalo de confiança } \\
\text { de } 95 \% \text { para a diferença }\end{array}$} \\
\hline & & & Limite Inferior & Limite Superior \\
\hline \multirow[t]{5}{*}{$40 \%$} & $50 \%$ & 0,063 & $-1,001$ & 0,019 \\
\hline & $60 \%$ & 0,001 & $-1,224$ & $-0,368$ \\
\hline & $70 \%$ & 0,000 & $-1,712$ & $-0,548$ \\
\hline & $80 \%$ & 0,000 & $-2,252$ & $-0,948$ \\
\hline & $90 \%$ & 0,000 & $-1,991$ & $-1,247$ \\
\hline \multirow[t]{5}{*}{$50 \%$} & $40 \%$ & 0,063 & $-0,019$ & 1,001 \\
\hline & $60 \%$ & 0,085 & $-0,639$ & 0,029 \\
\hline & $70 \%$ & 0,016 & $-1,171$ & $-0,107$ \\
\hline & $80 \%$ & 0,000 & $-1,656$ & $-0,562$ \\
\hline & $90 \%$ & 0,000 & $-1,614$ & $-0,642$ \\
\hline \multirow[t]{5}{*}{$60 \%$} & $40 \%$ & 0,001 & 0,368 & 1,224 \\
\hline & $50 \%$ & 0,085 & $-0,029$ & 0,639 \\
\hline & $70 \%$ & 0,302 & $-0,803$ & 0,135 \\
\hline & $80 \%$ & 0,002 & $-1,291$ & $-0,317$ \\
\hline & $90 \%$ & 0,000 & $-1,178$ & $-0,468$ \\
\hline \multirow[t]{5}{*}{$70 \%$} & $40 \%$ & 0,000 & 0,548 & 1,712 \\
\hline & $50 \%$ & 0,016 & 0,107 & 1,171 \\
\hline & $60 \%$ & 0,302 & $-0,135$ & 0,803 \\
\hline & $80 \%$ & 0,066 & $-0,962$ & 0,022 \\
\hline & $90 \%$ & 0,006 & $-0,843$ & $-0,135$ \\
\hline \multirow[t]{2}{*}{$80 \%$} & $40 \%$ & 0,000 & 0,948 & 2,252 \\
\hline & $50 \%$ & 0,000 & 0,562 & 1,656 \\
\hline
\end{tabular}


ANEXO IV - Resumo das análises estatísticas (continuação).

Nível de significância ajustado pelo teste de Bonferroni para comparações múltiplas (continuação).

\begin{tabular}{lllll}
\hline & $60 \%$ & 0,002 & 0,317 & 1,291 \\
& $70 \%$ & 0,066 & $-0,022$ & 0,962 \\
$90 \%$ & $90 \%$ & 1,000 & $-0,475$ & 0,437 \\
& $40 \%$ & 0,000 & 1,247 & 1,991 \\
& $50 \%$ & 0,000 & 0,642 & 1,614 \\
& $60 \%$ & 0,000 & 0,468 & 1,178 \\
& $70 \%$ & 0,006 & 0,135 & 0,843 \\
\hline
\end{tabular}


ANEXO IV - Resumo das análises estatísticas (continuação).

Análise de variância a um fator (intensidade) com medidas repetidas da contribuição absoluta do metabolismo anaeróbio alático nas intensidades percentuais abaixo da potência correspondente ao $\mathrm{VO}_{2} \max$.

Teste de Esfericidade de Mauchly.

\begin{tabular}{lcccc}
\hline & Mauchly's W & Aprox. Qui-quadrado & gl & Sig. \\
\hline Fator 1 & 0,128 & 17,503 & 14,0 & 0,063 \\
\hline
\end{tabular}

Nível de significância ajustado pelo teste de Bonferroni para comparações múltiplas

\begin{tabular}{|c|c|c|c|c|}
\hline & & \multirow[t]{2}{*}{ Sig. } & \multicolumn{2}{|c|}{$\begin{array}{c}\text { Intervalo de confiança } \\
\text { de } 95 \% \text { para a diferença }\end{array}$} \\
\hline \multirow{3}{*}{$40 \%$} & & & Limite Inferior & Limite Superior \\
\hline & $50 \%$ & 0,007 & $-0,600$ & $-0,090$ \\
\hline & $60 \%$ & 0,011 & $-0,951$ & $-0,111$ \\
\hline \multirow{7}{*}{$50 \%$} & $70 \%$ & 0,064 & $-1,686$ & 0,036 \\
\hline & $80 \%$ & 0,017 & $-1,653$ & $-0,145$ \\
\hline & $90 \%$ & 0,007 & $-1,326$ & $-0,198$ \\
\hline & $40 \%$ & 0,007 & 0,090 & 0,600 \\
\hline & $60 \%$ & 1,000 & $-0,642$ & 0,270 \\
\hline & $70 \%$ & 1,000 & $-1,432$ & 0,472 \\
\hline & $80 \%$ & 0,150 & $-1,228$ & 0,120 \\
\hline \multirow{3}{*}{$60 \%$} & $90 \%$ & 0,304 & $-1,003$ & 0,169 \\
\hline & $40 \%$ & 0,011 & 0,111 & 0,951 \\
\hline & $50 \%$ & 1,000 & $-0,270$ & 0,642 \\
\hline \multirow{7}{*}{$70 \%$} & $70 \%$ & 1,000 & $-1,198$ & 0,610 \\
\hline & $80 \%$ & 0,303 & $-0,885$ & 0,149 \\
\hline & $90 \%$ & 1,000 & $-0,954$ & 0,492 \\
\hline & $40 \%$ & 0,064 & $-0,036$ & 1,686 \\
\hline & $50 \%$ & 1,000 & $-0,472$ & 1,432 \\
\hline & $60 \%$ & 1,000 & $-0,610$ & 1,198 \\
\hline & $80 \%$ & 1,000 & $-0,949$ & 0,801 \\
\hline \multirow{3}{*}{$80 \%$} & $90 \%$ & 1,000 & $-0,667$ & 0,793 \\
\hline & $40 \%$ & 0,017 & 0,145 & 1,653 \\
\hline & $50 \%$ & 0,150 & $-0,120$ & 1,228 \\
\hline
\end{tabular}


ANEXO IV - Resumo das análises estatísticas (continuação).

Nível de significância ajustado pelo teste de Bonferroni para comparações múltiplas (continuação).

\begin{tabular}{lllll}
\hline & $60 \%$ & 0,303 & $-0,149$ & 0,885 \\
& $70 \%$ & 1,000 & $-0,801$ & 0,949 \\
$90 \%$ & $90 \%$ & 1,000 & $-0,649$ & 0,923 \\
& $40 \%$ & 0,007 & 0,198 & 1,326 \\
& $50 \%$ & 0,304 & $-0,169$ & 1,003 \\
& $60 \%$ & 1,000 & $-0,492$ & 0,954 \\
& $70 \%$ & 1,000 & $-0,793$ & 0,667 \\
& $80 \%$ & 1,000 & $-0,923$ & 0,649 \\
\hline
\end{tabular}


ANEXO IV - $\underline{\text { Resumo das análises estatísticas (continuação). }}$

Contribuições absolutas do metabolismo anaeróbio (somatória do lático com o alático) durante o exercício realizado nas intensidades percentuais abaixo da potência correspondente ao $\mathrm{VO}_{2} \max$.

Valores Extremos.

\begin{tabular}{llcc}
\hline & & Sujeito & Valor \\
\hline Anaeróbio (40\%) & Maior & 5 & 1,99 \\
& Menor & 2 & 0,54 \\
Anaeróbio (50\%) & Maior & 8 & 2,63 \\
& Menor & 2 & 0,95 \\
Anaeróbio (60\%) & Maior & 7 & 3,28 \\
& Menor & 2 & 1,90 \\
Anaeróbio (70\%) & Maior & 3 & 5,29 \\
& Menor & 2 & 2,02 \\
Anaeróbio (80\%) & Maior & 3 & 5,24 \\
& Menor & 2 & 2,64 \\
Anaeróbio (90\%) & Maior & 3 & 4,56 \\
& Menor & 8 & 2,71 \\
\hline
\end{tabular}

Teste de Normalidade de Shapiro-Wilk.

\begin{tabular}{lrrr}
\hline Variável & Estatística & gl & Sig. \\
\hline Anaeróbio (40\%) & 0,921 & 9 & 0,368 \\
Anaeróbio (50\%) & 0,939 & 9 & 0,543 \\
Anaeróbio (60\%) & 0,923 & 9 & 0,379 \\
Anaeróbio (70\%) & 0,856 & 9 & 0,068 \\
Anaeróbio (80\%) & 0,931 & 9 & 0,457 \\
Anaeróbio (90\%) & 0,927 & 9 & 0,415 \\
\hline
\end{tabular}


ANEXO IV - Resumo das análises estatísticas (continuação).

Análise de variância a um fator (intensidade) com medidas repetidas da contribuição absoluta do metabolismo anaeróbio (somatória do lático com o alático) nas intensidades percentuais abaixo da potência correspondente ao $\mathrm{VO}_{2} \max$.

Teste de Esfericidade de Mauchly.

\begin{tabular}{lcccc}
\hline & Mauchly's W & Aprox. Qui-quadrado & gl & Sig. \\
\hline Fator 1 & 0,063 & 19,679 & 14 & 0,161 \\
\hline
\end{tabular}

Nível de significância ajustado pelo teste de Bonferroni para comparações múltiplas.

\begin{tabular}{lllcc}
\hline & & Sig. & \multicolumn{2}{c}{$\begin{array}{c}\text { Intervalo de confiança } \\
\text { de } 95 \% \text { para a diferença }\end{array}$} \\
\hline \multirow{3}{*}{$40 \%$} & $50 \%$ & 0,004 & $-1,401$ & $-0,273$ \\
& $60 \%$ & 0,001 & $-2,081$ & $-0,569$ \\
& $70 \%$ & 0,003 & $-3,252$ & $-0,664$ \\
& $80 \%$ & 0,000 & $-3,706$ & $-1,296$ \\
& $90 \%$ & 0,000 & $-3,169$ & $-1,599$ \\
$50 \%$ & $40 \%$ & 0,004 & 0,273 & 1,401 \\
& $60 \%$ & 0,124 & $-1,061$ & 0,085 \\
& $70 \%$ & 0,062 & $-2,284$ & 0,042 \\
& $80 \%$ & 0,001 & $-2,636$ & $-0,692$ \\
& $90 \%$ & 0,002 & $-2,496$ & $-0,598$ \\
& $40 \%$ & 0,001 & 0,569 & 2,081 \\
& $50 \%$ & 0,124 & $-0,085$ & 1,061 \\
& $70 \%$ & 0,575 & $-1,665$ & 0,399 \\
& $80 \%$ & 0,002 & $-1,895$ & $-0,457$ \\
& $90 \%$ & 0,017 & $-1,953$ & $-0,165$ \\
& $40 \%$ & 0,003 & 0,664 & 3,252 \\
& $50 \%$ & 0,062 & $-0,042$ & 2,284 \\
& $60 \%$ & 0,575 & $-0,399$ & 1,665 \\
& $80 \%$ & 0,483 & $-1,391$ & 0,305 \\
& $90 \%$ & 1,000 & $-1,290$ & 0,438 \\
& $40 \%$ & 0,000 & 1,296 & 3,706 \\
& $50 \%$ & 0,001 & 0,692 & 2,636 \\
\hline & & & &
\end{tabular}


ANEXO IV - Resumo das análises estatísticas (continuação).

Nível de significância ajustado pelo teste de Bonferroni para comparações múltiplas (continuação).

\begin{tabular}{lllll}
\hline & $60 \%$ & 0,002 & 0,457 & 1,895 \\
& $70 \%$ & 0,483 & $-0,305$ & 1,391 \\
$90 \%$ & $90 \%$ & 1,000 & $-0,935$ & 1,169 \\
& $40 \%$ & 0,000 & 1,599 & 3,169 \\
& $50 \%$ & 0,002 & 0,598 & 2,496 \\
& $60 \%$ & 0,017 & 0,165 & 1,953 \\
& $70 \%$ & 1,000 & $-0,438$ & 1,290 \\
& $80 \%$ & 1,000 & $-1,169$ & 0,935 \\
\hline
\end{tabular}

